\title{
Do the populists have a say? Estimating their effect on topic prevalence and polarization in German state legislature
}

by

\author{
Felix Idelberger \\ Submitted to the Department of Economics and Business Administration \\ on 7 October 2019, in partial fulfillment of the \\ requirements for the degree of \\ Master of Science in Economics
}

\begin{abstract}
Between 2008 and 2014, German politics experienced a shake-up by AfD's move into the state parliaments. While many studies examine the party's success factor in elections, only a few studies study the effect of the new party on parliamentary work. This thesis tests two hypotheses in this regard: First if the AfD set its primary focus on different policy areas than the other parties in the minor appellations and second if the entrance of the AfD leads to a higher polarization in a state parliament. We use the structural topic model to obtain topics for each appellation. To measure polarization, we rely on the expression of agreement and disagreement during a speech and a text classifier's ability to distinguish between non-AfD and AfD speeches. As headline findings, we note that the AfD emphasizes policy areas in their appellations that provide the potential for populist statements such as extremism, migration, or law \& order. Secondly, polarization generally increases with the party's entrance into a state parliament, but the influence varies with the measurement chosen. More broadly, the results suggest that the STM and text classifiers' metrics can be a reliable tool to draw inferences on significant research questions in social science.
\end{abstract}

Thesis Supervisor: Stefan Lessmann

Title: Prof. Dr. 


\section{Acknowledgments}

I would like to thank Prof. Dr. Stefan Lessmann for the freedom to pursue my topic of choice and his permanent willigness to give feedback if needed. Branden Stewart, assistant professor for Computational Social Sciences at Princeton University, has my gratitude for answering my questions regarding the structural topic model and the posterior estimation of effects. Arthur Spilling, professor of Politics and Data Science at New York University, showed no less sympathy with me by commenting on my research design. My last professional acknowledgment aims at Hanno Hilbig, PhD

candidate in Government at Harvard University. Our continous exchange helped to sharpen this thesis.

Lastly, I would like to express greatest gratitude to my family and friends who always supported me during my exciting journey at university. 


\section{Contents}

1 Motivation $\quad 15$

2 Hypotheses and related work $\quad 19$

2.1 Parliamentary documents as data . . . . . . . . . . . . . 19

2.2 STM and the text-as-data approach . . . . . . . . . . . . 22

3 Data 23

3.1 Appellations . . . . . . . . . . . . . . . . . . . . . 24

3.2 Parliamentary Speeches . . . . . . . . . . . . . . 26

4 Methodology $\quad 31$

4.1 Structural Topic Model . . . . . . . . . . . . . . . . . . . . . 31

4.1.1 Basic Concept . . . . . . . . . . . . . . 32

4.1.2 Estimation and initialization . . . . . . . . . . . . 35

4.1.3 FREX and Semantic Coherence . . . . . . . . . . . 37

4.1.4 Uncertainty . . . . . . . . . . . . . . . . . . 38

5 Research Design $\quad 39$

5.1 Appellations and topic prevalence . . . . . . . . . . . . . . . . 39

5.2 Parliamentary speeches and polarization . . . . . . . . . . 43

$\begin{array}{llr}6 & \text { Results } & 47\end{array}$

6.1 Appellations and topic prevalence . . . . . . . . . . . . 47

6.1.1 Effect of party on topical prevalence . . . . . . . . . . 50 
6.2 Parliamentary speeches and polarization . . . . . . . . . . . . 57

6.2.1 Who claps for whom ............... 57

6.2 .2 Who provokes the most . . . . . . . . . . . . 60

6.2.3 The parties' sentiment ............... 61

6.2.4 AfD's distinctiveness . . . . . . . . . . . . . . 62

$\begin{array}{lll}7 & \text { Discussion } & 65\end{array}$

7.1 Appellations and topic prevalence . . . . . . . . . . 65

7.2 Parliamentary speeches and polarization . . . . . . . . . 66

$\begin{array}{llr}8 & \text { Conclusion } & 69\end{array}$

$\begin{array}{ll}\text { A Tables } & 73\end{array}$

$\begin{array}{lr}\text { B Figures } & 85\end{array}$ 


\section{List of Figures}

3-1 Legislature periods covered by state. AfD holds seats in each, exceptions are BY and HE. See list of acronyms for the corresponding long names of the states. . . . . . . . . . . . . . . . .

3-2 Parliamentary groups' share of appellations in each state. Numbers at the right side, next to each row of bars, indicate the total amount of appellations and average amount per year in the state. Ratio of appellation share to vote share is given by the number on the bar. . .

3-3 Box plots for each state representing the page length of the appellations. 26

3-4 Bars grouped by state indicate number of speeches for one legislative period. The grey of the bars ranks the legislative periods chronologically. Except for Bavaria (BY), Hesse (HE) and Saarland (SL) the second one includes member of parliaments (MPs) of the AfD. . . . . . . . . 27

3-5 Box plots show the distribution of speech length by state. . . . . . . 28

3-6 Bars show the average no. of interjections in one legislative period by state. The grey of the bars ranks the legislative periods chronologically. Except for BY, HE and SL the second one includes MPs of the AfD. .

4-1 A graphical representation of the STM. . . . . . . . . . . . . .

5-1 A graphical representation of the pipeline. Repeats for each state. . .

6-1 The expected policy area proportions by state. A column approximately sums up to one and 0.1 equals to an expected share of ten percent in the corpus. . . . . . . . . . . . . . . . . 
6-2 Estimate for each party's expected proportion for the policy area education. The values are not anchored in the intercept. . . . . . . . 50

6-3 Estimate for each party's expected proportion for the policy area environment \& energy. The values are not anchored in the intercept. . . . 51

6-4 Estimate for each party's expected proportion for the policy area extremism. The values are not anchored in the intercept. . . . . . . . 52

6-5 Estimate for each party's expected proportion for the policy area environment \& energy. The values are not anchored in the intercept. . . . 53

6-6 Estimate for each party's expected proportion for the policy area law $\&$ order. The values are not anchored in the intercept. . . . . . . 54

6-7 Estimate for each party's expected proportion for the policy area migration. The values are not anchored in the intercept. . . . . . . . 55

6-8 Estimate for each party's expected proportion for the policy area social welfare. The values are not anchored in the intercept. . . . . . . 56 56

6-9 One heatmap per state with the average number of applause a party receives from the other parties. . . . . . . . . . 58

6-10 Polarization scores average over states by party pairs. Low values indicate low polarization. . . . . . . . . . . . . . . . . 59

6-11 Parties' negative language share in each legislative period. . . . . . . 62

6-12 Classifer's accuracy, precision and recall per state. . . . . . . . . 63

6-13 Feature importance of the classifier for Baden-Württemberg. . . . . . 64

6-14 Feature importance of the classifier for Saxony. . . . . . . . . . . 64

B-1 Held-out likelihood, lower bound, residuals and semantic coherence for a span of number of topics . . . . . . . . . . . . 86

B-2 Correlation graph for the appellation topics in the state parliament of Brandenburg. Vertex size is proportional to topic proportion. . . . . 87 


\section{List of Tables}

2.1 Summary of literature which uses text documents provided by parliaments. 20

2.2 Publications which apply a topic model. . . . . . . . . . . . . 22

6.1 polarization score per state calculated as stated in equation (5.4). The lack of interjections for the first legislative period of Lower Saxony (NI) makes the score incomputable. Aside from BY and HE, the second score is for a legislative period in which the AfD forms a parliamentary group. . . . . . . . . . . . . . . . . . . 6 60

6.2 First three politicians per state who receive on average the most interjections that are not applause. . . . . . . . . . . . . . . . . 61

A.2 Most representative words for each topic in the state parliament of

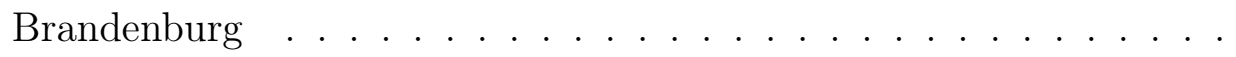




\section{Acronyms}

BB Brandenburg

BE Berlin

BW Baden-Württemberg

BY Bavaria

CTM Correlated Topic Model

dfm document-feature matrix

DMR dirichlet-multinomial Regression

EM nonconjugate variational expectation-maximization algorithm

HB Bremen

HE Hesse

HH Hamburg

LDA Latent dirichlet allocation

MP member of parliament

MV Mecklenburg-Western Pomerania

NI Lower Saxony

NW North Rhine-Westphalia

PAP policy area proportion

pLSI probabilistic Latent Semantic Indexing

RP Rhineland-Palatinate 
SAGE Sparse Additive Generative

SH Schleswig-Holstein

SL Saarland

SN Saxony

ST Saxony-Anhalt

STM structural topic model

TH Thuringia 


\section{Motivation}

Populism has been on the rise in Western Europe since the early nineties, when at that time (right-wing) populist parties in France, Switzerland and Denmark achieved their best results after the second world war (Albertazzi and McDonnell 2008). In the same period, populist parties in Italy, Austria and the Netherlands became part of the national government for the first time. This first surge of populist parties had not reached the German parliaments, both on the federal and national level, until the economic and financial crisis in Europe around 2007 which provoked a second wave. With the foundation of the Alternative für Deutschland (AfD) in 2013, Germany's political system obtained a party which not only is successful in elections but fulfills the academic definition of populism as well. Mudde (2004) defines populism as "an ideology that considers society to be ultimately separated into two homogeneous and antagonistic groups, 'the pure people' versus 'the corrupt elite', and which argues that politics should be an expression of the volonté générale (general will) of the people". He further calls populism a 'thin-centred ideology' whose agents focus more on moralistic rather than programmatic aspects. Markus Frohnmaier, AfD, then a candidate for the state parliament of Baden-Württemberg and today a member of the Bundestag, provides a statement with an illustrative example for the populist attitude of the party. I tell these left terrorists of political correctness, this party-sleaze quite clear: if we come, then we tidy up, throw out, then politics is being made for the people again and only made for the people - because we are the people, dear friends (Markus Frohnmaier 2015). ${ }^{1}$

\footnotetext{
${ }^{1}$ the original statement was paraphrased from German to English: "Ich sage diesen linken Gesinnungsterroristen, diesem Parteienfilz ganz klar: Wenn wir kommen, dann wird aufgeräumt,
} 
The first success of a right-wing populist party throughout Germany after the second world war is the motivation for this paper to pursue the research question of how the politicians and parliamentary groups of the AfD, effect the sixteen state parliaments in Germany? Regarding this research question, this thesis narrows its focus on political issues that MPs stress in their parliamentary activity and on the extent of polarization in the state parliaments. To this end, the (minor) appellations submitted and the plenum speeches given by the MPs serve as text-as-data.

The first part of the analysis is dedicated to estimate the effect of party affiliation on the topic prevalence within an appellation. To achieve this, this thesis relies on the structural topic model structural topic model (STM), a recent methodological advance in the field of Computational Social Science. The STM enables the creation of topic models, including arbitrary metadata and the estimation of effects on the resulting topic prevalence proportions. The second part examines if the polarization in the state parliaments changes due to the entrance of the AfD. Polarization can mean differences in language use or differences in the amount of approval and disapproval towards other parties. Thus, a set of methods with varying complexity is used: from the categorization of words as positive or negative to the use of text classifiers' accuracy as proxy for polarization.

The paper aims to verify existing findings about the AfD's activity in German state parliaments. For instance, the finding that its parliamentary groups pay the same level of attention to policy areas than the other parties, unless the policy area is migration (Schroeder, Weßels, Neusser, et al. 2017). Another finding is that the AfD follows a bipolar strategy in the state parliaments: either fundamental opposition or generally open to participate in the regular parliamentary work.

A second aim is to produce new knowledge about the party's impact. In this regard, The comparison across state parliaments represents a particularly promising and novel approach. It results in the analysis of more observations, and any finding might be more robust and generalizable as opposed to if we would only analyze one or only a dann wird ausgemistet, dann wird wieder Politik für das Volk und nur für das Volk gemacht - denn wir sind das Volk, liebe Freunde." 
few (state) parliaments. Besides, the state parliaments in Germany often indicate a transformation in the political landscape of Germany faster than the analysis of the German Bundestag. The probability of having at least one state election per year is considerable higher.

Quite substantial differences between the political systems of Europe exist. For example, France's political system is parliamentarian-presidential and as a result very different to Germany's polity. Despite these differences, the findings of this paper can extend beyond Germany by contributing to the general findings on populist parties' effect on parliaments. Moreover, they can stimulate similar research in other countries or on a pan-European level. As the thesis shows, the AfD's parliamentary groups do indeed have preferential policy areas for their appellations in the German state parliaments, and the party's speeches are received differently and quite distinct from those of the other parties.

The remainder is as follows: the following chapter 2 relates this paper to the existing literature and derives the hypothesis. Chapter 3 continues and introduces the data. Chapter 4 gives a brief introduction to the STM. The research design is explained in chapter 5 , before chapter 6 and chapter 7 present the results and the discussion respectively. Chapter 8 completes the paper with concluding remarks. 


\section{$2 \quad$ Hypotheses and related work}

This section is divided into two parts: the first summarizes the academic literature that uses data from a parliament in its analysis and derives the hypothesis of this work from this literature. The second part relates this thesis to academic research that successfully applied the STM and to academic work which provides instructions for the successful application of text-as-data methods in general.

\subsection{Parliamentary documents as data}

Table 2.1 shows that this paper is not the first to examine either parliamentary speeches, bills (Linder et al. 2018; Wilkerson, Smith, and Stramp 2015), or other written documents that are produced by parliaments. It splits the publications into groups according to what their research examines: policy positions and ideological placement, polarization, sentiment, or topic prevalence. Within these groups, each row summarizes the publications that share the same research method, and ranks them in order of their publication date. Researchers are interested in working with

parliamentary data as it is supposedly the heart of any democracy (Proksch and Slapin 2012). They use parliamentary speeches, for instance, to determine which aspects influence policy positions of MPs (Proksch and Slapin 2010; Schwarz, Traber, and Benoit 2017; Willis 2017; Tzelgov and Olander 2018) or the parliament's agenda (Greene and Cross 2017; Senninger and Bischof 2018; Høyland and Søyland 2019).

At the beginning of this century, scientists started to use scaling algorithms such as wordfish and wordscore to place party manifestos on an ideological scale (Laver, Benoit, and Garry 2003; Laver and Garry 2000). Today, the research which uses 
Table 2.1: Summary of literature which uses text documents provided by parliaments.

\begin{tabular}{lll}
\hline target & publications & method \\
\hline \multirow{3}{*}{ policy position } & O'Grady (2019), Tzelgov and Olander (2018), and Benoit and Herzog (2017); & scaling algorithms \\
& Schwarz, Traber, and Benoit (2017), Lauderdale and Herzog (2016), and Debus and Bäck (2014); & SVM \\
& Proksch and Slapin (2012), Proksch and Slapin (2010), and Slapin and Proksch (2008) & custom model \\
& Diermeier et al. (2012) & wordfish \\
& Gentzkow, Shapiro, and Taddy (2016) & text classifier \\
& Curini, Hino, and Osaka (2018) & bayesian \\
polarization & Goet (2019), Abercrombie and Batista-Navarro (2018), and Peterson and Spirling (2018) & word embeddings \\
& Spirling, Huang, and Patrick (2018) & GloVe \\
& Rheault and Cochrane (2019) & Multilingual dictionary \\
\hline sentiment & Rheault, Beelen, et al. (2016) & regression \\
\hline floor time & Proksch, Lowe, et al. (2018) & topic models \\
\hline topical prevalence & Blumenau (2019) and Bäck, Debus, and Müller (2014) &
\end{tabular}

scaling algorithms still constitutes a large part of the literature on legislative speeches as they are well-established and easy to apply. However, with advances in the fields of computer science, i.e. natural language processing, and linguistics, political scientists have started to explore classification algorithms (Peterson and Spirling 2018; Goet 2019; Abercrombie and Batista-Navarro 2018), topic models (Høyland and Søyland 2019; Greene and Cross 2017) and word embeddings for their research (Rheault and Cochrane 2019; Rheault, Beelen, et al. 2016).

Independent of the applied method, many papers concern the UK parliament, the US congress or the Canadian parliament, due to the more straightforward collection process for these institutions' data compared to other parliaments such as Bundestag ${ }^{1}$. Additionally, table 2.1 reveals that many papers concern the policy position or the ideology of a party and the polarization of the parliament, but seldom tackle the sentiment or topic prevalence in speeches. This paper is the first to regard topic prevalence in multiple parliaments at the same time and the first to use a text-as-data approach on the German state parliaments.

While a few studies on the Bundestag exist (Debus and Bäck 2014; Baumann, Debus, and Müller 2013), no study analyzes and compares all state parliaments altogether. Schroeder, Weßels, Neusser, et al. (2017) provide an overview over the personal characteristics of AfD's MPs: male, age distribution compared to other parties, the party of self-employed people and social climbers and so forth, but their content

\footnotetext{
${ }^{1}$ Bundestag is the proper noun for the German parliament on the federal level.
} 
analysis of the appellations is rather descriptive and does not systematically test the effect of party authorship on topic prevalence. The remaining papers (Schroeder, Weßels, and Berzel 2018; Rütters 2017) discuss the party's capability to participate in the procedures of the parliaments. One significant finding is that the AfD's parliamentary groups either establish a fundamental opposition (movement-oriented) or try to get some of the other parties to cooperate with them. With these few studies, the literature on the AfD in the state parliaments is close to exhausted. The highest share of literature considers the AfD's success factors in elections (Pappi, Kurella, and Bräuninger 2019; Schmitt-Beck, Deth, and Staudt 2017; Lengfeld 2017; Niedermayer 2015), its stance on various policy areas (Jankowski, Schneider, and Tepe 2017) or how far right the party is (Bebnowski 2015). Partly drawing on this previous research and partly exploring new paths, this thesis postulates the following two hypotheses:

Hypothesis 1 (H1): The MPs of the AfD put their primary focus on different policy areas in the appellations than their fellow MPs from the other parties.

The assumption here is that populist MPs and parties have to maintain the antagonistic image of 'we the pure people' and 'they the corrupt elites' to remain credible for their electorate. This "duty" is reflected well in the shares of policy areas that the AfD's MPs consider in their appellations. AfD's entrance as new party might be a result of missing representation and lack of confidence in established parties perceived by a substantial amount of the electorate (Meguid 2005). By definition, this shall lead to less uniformity in parliament, because a part of the political spectrum of society is better represented again. Less uniformity equals an increase in polarization, which following this line of thought should be observable in those state parliaments where the AfD is present. Hence, the second hypothesis of this paper is as follows:

Hypothesis 2 (H2): The entrance of the AfD into a state parliament leads to a higher polarization. 


\subsection{STM and the text-as-data approach}

Apart from the field of legislative studies, this paper relates to other work as well, which uses the STM. Table 2.2 lists selected publications that have successfully applied the STM to their research question. Wilkerson and Casas (2017) rightly point out that topic instability can be a severe problem of topic models, but the STM's new spectral initialization makes it quite robust against this issue. Topics remain very stable across different model specifications compared to the Latent dirichlet allocation (LDA) topic model. The STM's robustness and advantages are motivation for this paper to bring forward not only additional evidence for proof of concept but sincerely attempt to draw inferences with the text-as-data approach. Inference, however, is a challenging task as results sometimes change significantly, if only one parameter of the model is changed slightly. Laver and Garry (2000) argue that automated-labeling of text data must not be inferior to manual labeling. In their opinion, it can even yield better results.

Table 2.2: Publications which apply a topic model.

\begin{tabular}{lll}
\hline publication & issue & data \\
\hline Grajzl and Murrell (2019) & extraction of francois's economic ideas & francois's texts \\
Kim (2018) & bias against foreign automakers exists in state-controlled media & newspaper \\
Zafari and Ekin (2018) & the reach of abuse for medical prescription fraud & billings \\
Gilardi and Wüest (2017) & coverage of female candidates during election campaign & newspaper \\
Larsen (2017) & topic model as identification strategy for the type of uncertainty & newspaper \\
Roberts, Stewart, and Airoldi (2016) & coverage of SARS epidemic in China & newspaper \\
Roberts, Stewart, Tingley, et al. (2014) & identification of most important political problems in the US & ANES \\
Taylor Young (2013) & measurement of constitutional change & newspaper \\
\hline Source: own compilation & &
\end{tabular}

To counteract meaningless research, a few scientists of the field have published guidelines for text preprocessing and modeling (Spirling and Rodriguez 2019; Gilardi and Wasserfallen 2019; Egami et al. 2018; Wilkerson and Casas 2017; Jungherr and Theocharis 2017; Pietsch and Lessmann 2019). The recommendations of these papers have assisted the research design of this paper in chapter 5 to a great extent and the decisions made for this research ideally contribute back to the researchers who use text-as-data methods. Grounding the thesis on this theoretical framework, the next chapter describes the data used to examine the hypotheses. 


\section{Data}

The data used in this thesis is comprised of two data sets: one contains 62,511 appellations submitted to any of the sixteen German state parliaments. It is made available by the project kleineanfragen.de. The other holds 200,287 speeches (accompanied by 1,024,432 interjections) given in the state parliaments, collected through custom scripts. Both data sets cover the legislative periods shown in figure $3-1 .{ }^{1}$ The data set with the parliaments' speeches additionally includes the previous legislative period of each state as well, in which the AfD was not part of any parliament yet. They only include appellations for speeches from AfD, CDU, Die Grünen, Die Linke, FDP and SPD. ${ }^{2}$ Only these parties are relevant throughout the whole of Germany. It follows a brief explanation and a summary of the two data sets.

\footnotetext{
${ }^{1}$ see the list of acronyms for the corresponding full name.

${ }^{2}$ The term Die Grünen includes every regional association of Bündnis 90/Die Grünen, regardless of the exact name.
} 


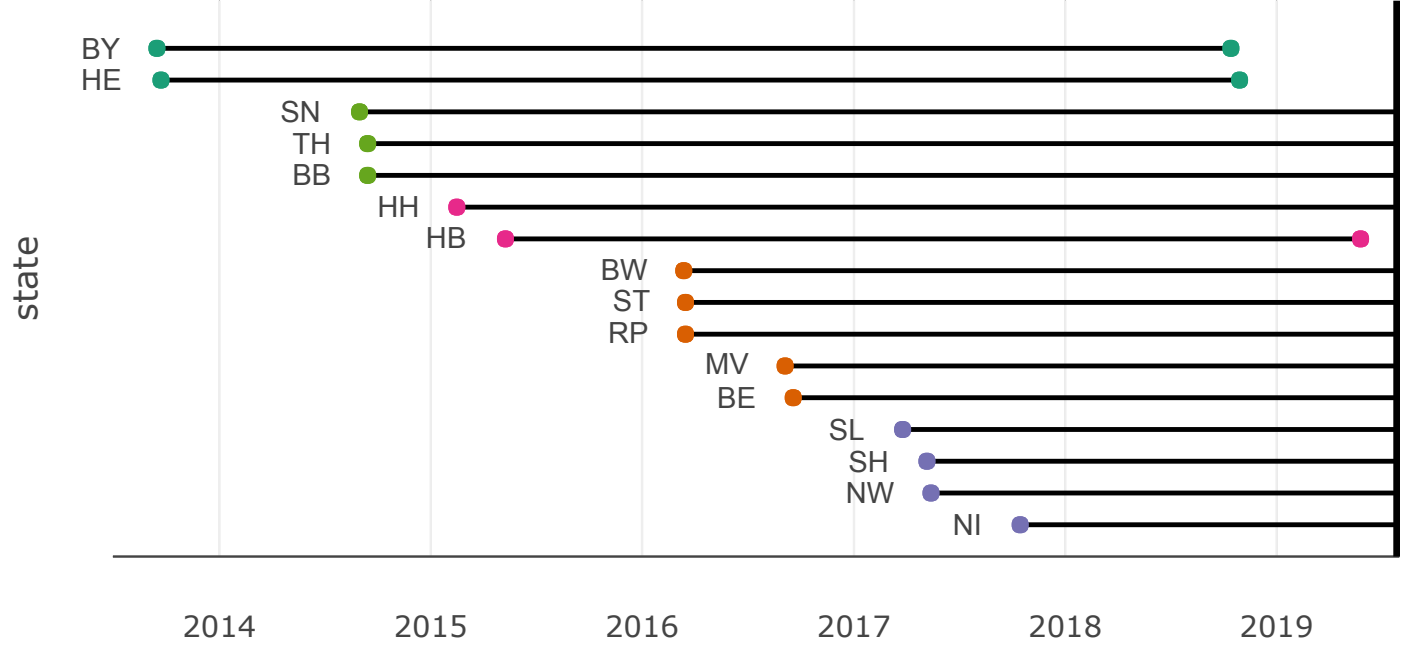

Figure 3-1: Legislature periods covered by state. AfD holds seats in each, exceptions are BY and HE. See list of acronyms for the corresponding long names of the states.

\subsection{Appellations}

In German state parliaments, an MP has the possibility to ask the government about any issue of interest. For example, such questions can regard the state of the police's equipment or the government's investment strategy into local infrastructure. The stacked bars in figure 3-2 illustrate the parties' shares in the total appellations submitted in each state for the legislative period drawn in the timeline above.

The parties' variance between the states is enormous. One reason for this fact is that appellations are mostly used by the opposition to control the state government (Schroeder, Weßels, Neusser, et al. 2017). Except for the city states of Berlin and Bremen, the parties in government typically use this instrument considerably less. The numbers on the right side of the figure indicate the total amount of submitted appellations in each state. They vary greatly, from a few hundred to more than ten thousand. These circumstances are not only due to different time duration covered but as well due to a different tradition in usage (Mielke and Reutter 2004, p. 45) as the average amount of appellations shows. ${ }^{3}$ The numbers directly on the bars give

\footnotetext{
${ }^{3}$ Unless the legislative period of a state has ended before, the cut off date is the 7 August 2018. Due to changes in the access to Baden-Württemberg's documentation, the data set only includes
} 


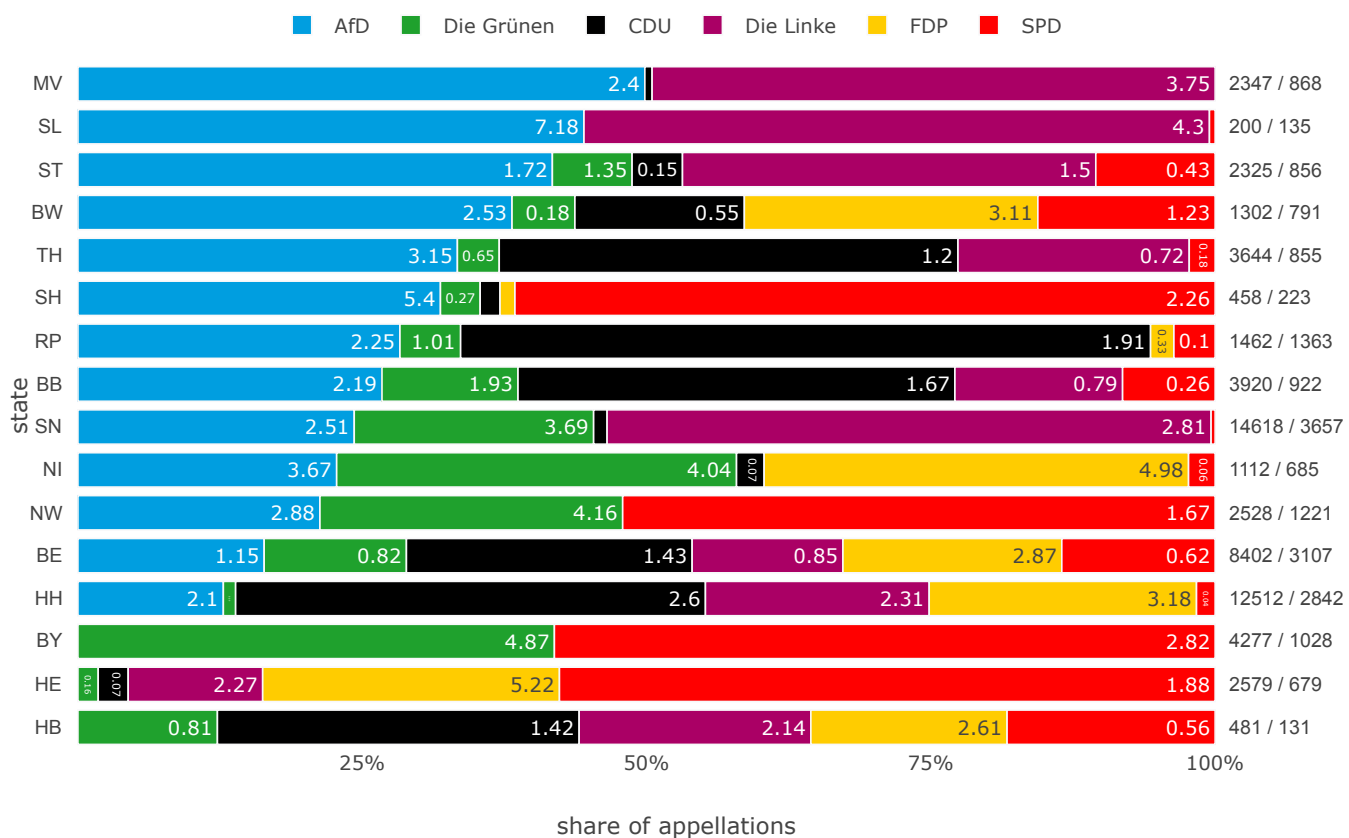

Figure 3-2: Parliamentary groups' share of appellations in each state. Numbers at the right side, next to each row of bars, indicate the total amount of appellations and average amount per year in the state. Ratio of appellation share to vote share is given by the number on the bar.

the ratio of a parliamentary group to its vote share. AfD's parliamentary groups in Saarland and Schleswig-Holstein possess a very high ratio, whereas the ratio of the other AfD's parliamentary groups are located in the same range as most of the ratios of Die Linke and FDP.

The states of Bavaria and Berlin only know written appellations, while the other states distinguish between minor and major appellations. Bremen often demands a parliamentary group as the author to fulfill the formal requirements. Only in the city state of Bremen, this requirement applies to minor appellations as well. This circumstance explains the lack of appellations from AfD's MPs in this state. Four AfD seats in total is one less than needed to form a parliamentary group. This paper focuses on minor appellations, because the numbers of motions or initiatives are too low to be suitable for an analysis of parliamentary work. One last descriptive appellations from the state prior March 2018. 


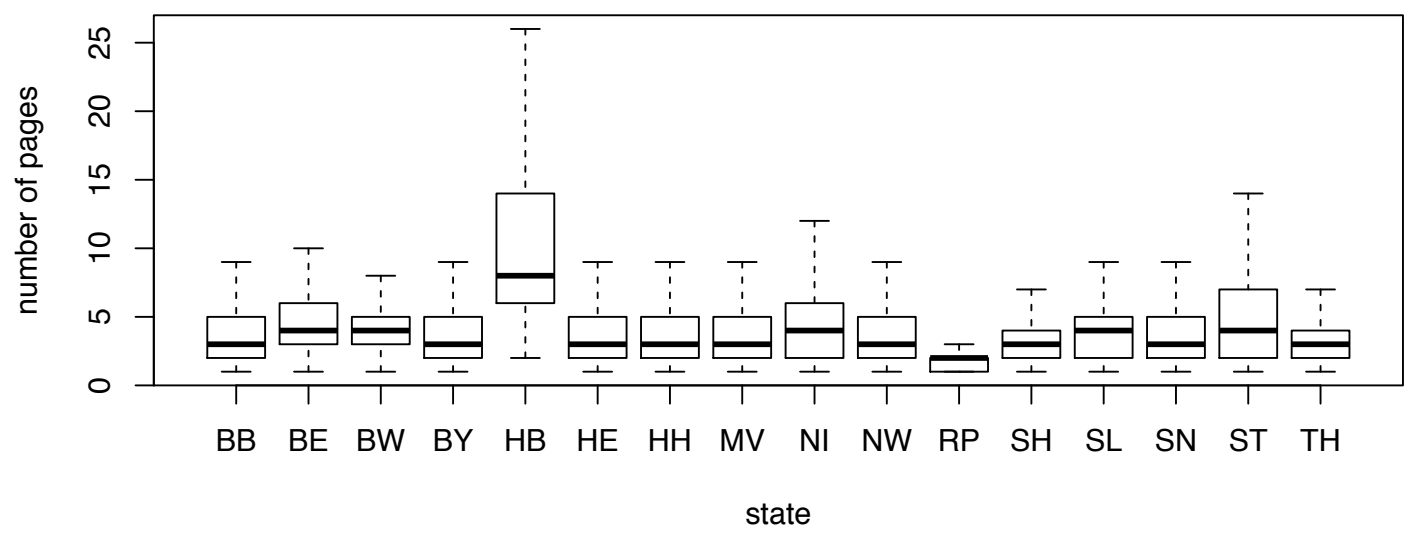

Figure 3-3: Box plots for each state representing the page length of the appellations.

characteristic of the appellations is worth looking at: the length. The box plots in figure 3-3 show that the vast majority of appellations are between three and six pages long, an exception are those of Bremen and Rhineland-Palatinate which fall above and below respectively.

\subsection{Parliamentary Speeches}

As mentioned above, the data set of parliament speeches covers the latest and previous legislative period of each state that span from February 2008 until October 2018. It includes every speech given in these two legislative periods, tied together with metadata such as the speaker's name, party, gender, and age or the date of the parliamentary debate. The text units obtained do not only cover the speeches themselves but the responses of other MPs during a speech too. If the stenographer hears such responses like applause from a party or an interjection by an MP, she inserts them in her protocol of the parliamentary session. Due to the alternating election years between the federal states, the periods covered vary with the longest, (Bavaria and Hesse) being from 2008 to 2018. The data set deliberately ends with the last entrance of the AfD into the state parliaments of Bavaria and Hesse in October 2018. As a consequence, Bavaria 
and Hesse's legislative periods - in which the AfD is not part of the parliament yet serve as control group in the subsequent analysis, in particular for a potential time effect.

In order to obtain this data set, a great deal of work had to be carried out. Unlike other parliaments such as the ones in the UK, US or Canada, the German state parliaments do not offer a ready to use application programming interface. The contrary is the case; most of them offer their plenary records only in proprietary file formats, mainly as PDF. This meant that three preprocessing steps were necessary to convert the data into a machine-readable format: 1. Conversion to extensible markup language (XML), 2. Layout analysis (font size, boldness, etc.) to ease splitting a plenary record into speeches and to keep the text order right ${ }^{4}$ and 3. Splitting up the plenary records and writing the resulting text units (speeches and interjections) into a database. Out-of-the-box solutions or one custom scraper for all state parliaments were not feasible. No standard format for plenary records, that is used by all administration, exists. Thus, sixteen custom scrapers were programmed in such a way that they are even robust against errors like misspellings of a speaker's name or against the non-compliance of the usual speaker representation. These efforts led to the creation of a unique data set with respect to the German state parliaments that has not been part of a text analysis to this extent before.

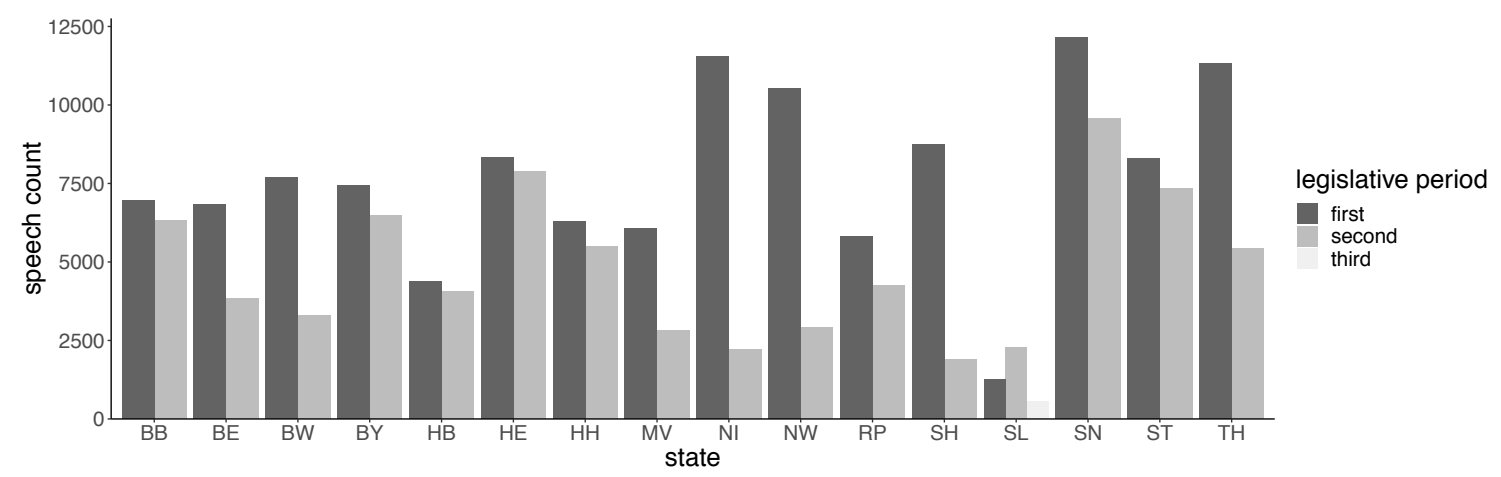

Figure 3-4: Bars grouped by state indicate number of speeches for one legislative period. The grey of the bars ranks the legislative periods chronologically. Except for BY, HE and SL the second one includes MPs of the AfD.

\footnotetext{
${ }^{4}$ The administrations publish their plenary records with a two column layout. This makes it very difficult to keep the text order correct.
} 
Figure 3-4 presents the number of speeches per state that resulted from these scrapers. Parliaments with a higher number of MPs naturally tend also to have more speeches during a legislative period. However, the amount of MPs is not the only relevant aspect; it very much depends on the parliamentary rules of procedure. For this paper, it is important to note that the speech shares of the parties are not proportional to their seat shares. Albeit the fact that more seats of a parliamentary group commonly do translate to more floor time, every parliamentary group has the right to some floor time as well. Subsequently, the speech shares are relatively balanced and do not limit the subsequent analysis.

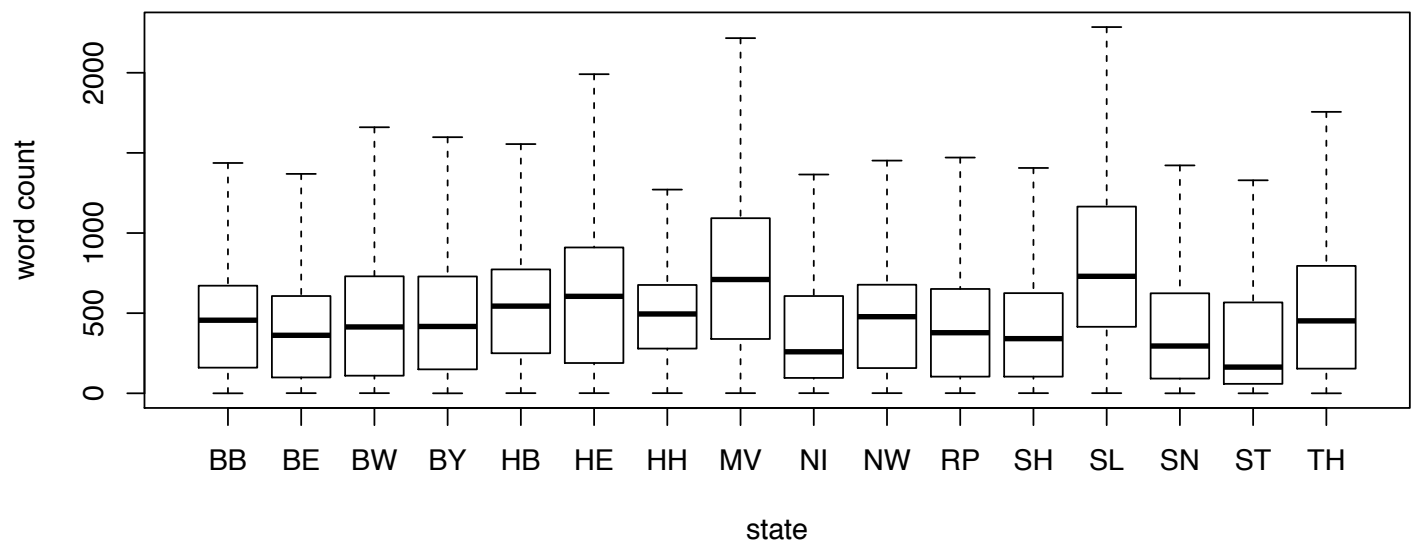

Figure 3-5: Box plots show the distribution of speech length by state.

Two last notes on the speech length and the average number of interjections per speech: figure 3-5 shows that in most states a common speech is between 100 and 700 words long. ${ }^{5}$ Only Mecklenburg-Western Pomerania and Saarland are an exception to this rule where a common speech tends to be a bit longer. In contrast, figure 3-6 does not suggest a common average number of interjections per speech across all states. The MPs of Baden-Württemberg, Hesse, and especially Mecklenburg-Western Pomerania are engaging a lot more during a speech, while the MPs of Rhineland-Palatinate, Saxony, and Thuringia are well-behaved in comparison. The bars for Berlin, Baden-

\footnotetext{
${ }^{5}$ Counted without punctuation and numbers. Outliers are not drawn.
} 


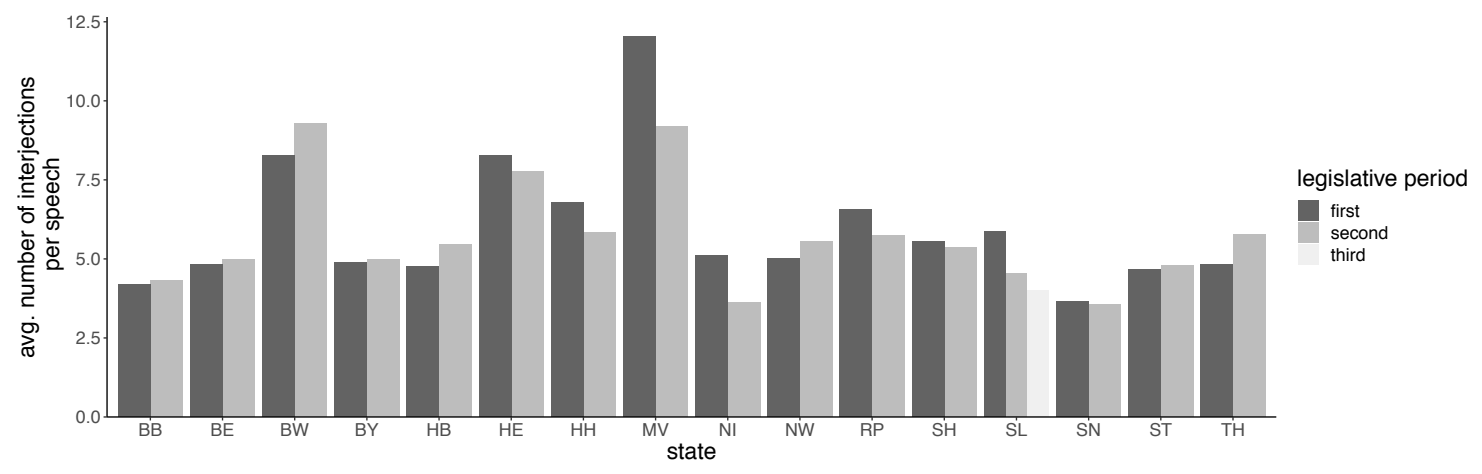

Figure 3-6: Bars show the average no. of interjections in one legislative period by state. The grey of the bars ranks the legislative periods chronologically. Except for BY, HE and SL the second one includes MPs of the AfD.

Württemberg, Bremen, North Rhine-Westphalia, and Thuringia show an uptick for the period in which the AfD is present, but the bars of other states remain stable or even decrease. The renunciation from the "Schweriner Weg" probably caused the large decline in Mecklenburg-Western Pomerania. It was a political strategy by all other parliamentary groups against the NPD in the sixth legislative period. In the successive seventh legislative period, they dismissed this strategy as improper for their fight against the AfD. This last note marks the end of the chapter and the following chapter briefly explains the STM as it only fully developed in 2016 (Roberts, Stewart, and Airoldi 2016). 


\section{Methodology}

This section first highlights the advantages of the STM compared to other topic models. Following this, it briefly explains the core statistical concepts behind the STM and describes methods to interpret the topics' plausibility.

\subsection{Structural Topic Model}

LDA topic models are well-established and recognized in academia these days, but scholars in the social sciences remained skeptical about the use for their discipline. Their primary interest is not high predictive power; instead, it is what influences the prevalence of topics or how groups differ in their language use while discussing the same topic. Chang et al. (2009) show that practitioners often judge the quality of classical topic models like LDA, Correlated Topic Model (CTM) and probabilistic Latent Semantic Indexing (pLSI) only on measures like held-out likelihood, but not on measures such as semantic coherence which are more important to social scientists. A model with the highest likelihood is useless if the resulting topics are of poor quality. Semantic coherence captures to what extent topics are coherent in themselves or expressed differently, to what extent the model can separate topics that are not related.

This lack of fit for classical topic models towards the end in social science research motivated Roberts, Stewart, and Airoldi (2016) to develop the new structural topic model that combines the advantages of the CTM, dirichlet-multinomial Regression (DMR), and Sparse Additive Generative (SAGE) topic models in one model. It already by design accounts more for the research goals of social scientists and focuses on more 
useful quality measures like semantic coherence within topics and exclusivity across topics. The aim was to create a model that facilitates analyzing the relationship between the topics recognized by the model and arbitrary covariates. While several other topic models were developed to analyze the effect of geographical location, time or authorship, the STM is a general-purpose topic model that allows to incorporate arbitrary meta-data.

The classical LDA topic model draws the topic assignment for each word in a document from a corpus-wide shared topic prevalence vector. In contrast to this, the STM does not use a global topic prevalence prior; instead, it introduces documentspecific topic prevalence priors which allow to capture variance caused by covariates. In this thesis, such covariates could be the author's party affiliation, gender, or age. The second significant difference is that once the model assigned a topic to a word, the STM provides the opportunity to incorporate topic-word distributions for each level of a content covariate. The last significant advantage is that it allows for potential correlations between the topics. Taking these three aspects of the STM into consideration, the model is an excellent evolution of existing models and is more suited for researchers who would like to make inferences from text-as-data ${ }^{1}$. In order to improve the understanding of the results, the next section gives a brief introduction to the STM's core concepts, to equip or refresh the reader's knowledge.

\subsubsection{Basic Concept}

Similar to other topic models, the STM has the overall aim to model the data generating process of documents in such a way that the determined topic distributions for each document $d \epsilon\{1 \ldots D\}$ and word distributions for each topic $k \epsilon\{1 \ldots K\}$ approximate the "true" distribution of these latent variables reasonably well. In the case of this thesis, the documents are the appellations submitted by MPs of the state parliaments. The words within each appellation are the primary observations $w_{d, n}$ where $n \epsilon\left\{1 \ldots N_{d}\right\}$ indexes the position of the word in the document. The words from

\footnotetext{
${ }^{1}$ The win of the Political Methodology Society's award in 2018 for the $\mathrm{r}$ package of the same name is a testimonial for the methodological innovation of the STM.
} 
all documents form a vocabulary where $v \epsilon\{1 \ldots V\}$ represents one unique word.

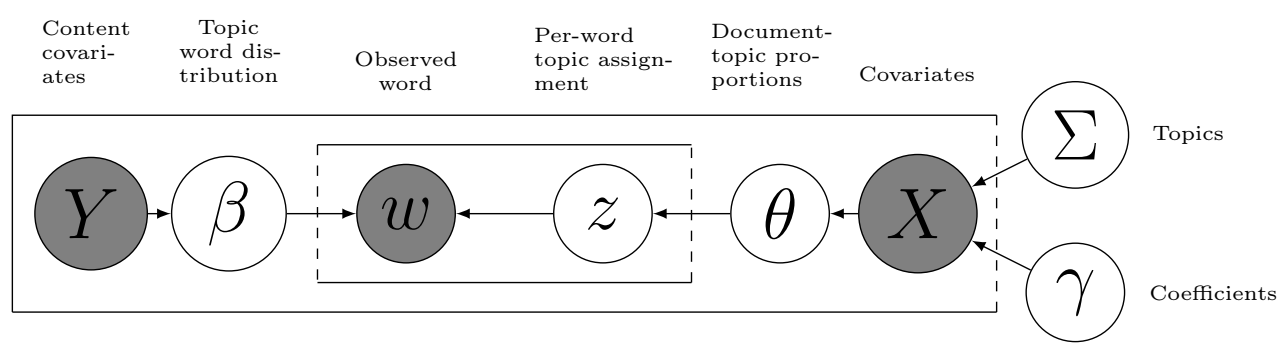

Figure 4-1: A graphical representation of the STM.

As already mentioned, the STM allows to include covariates, either to estimate their influence on topic prevalence, topical content or both. The $X$ matrix with the dimensions $D \times P$ contains the values for each covariate that we suspect to influence the topic prevalence and the $Y$ matrix with the dimensions $D \times A$ contains the values of the covariates between which we expect to observe different language use. For example, the model in this thesis uses data like which party created the appellation, and at which date as covariates for topic prevalence. The following steps define the data generating process of the STM , and figure 4-1 illustrates them graphically:

1. In the beginning, document $d$ has $N_{d}$ empty positions for which the model needs to find distributions of words (topics) that could have generated this document. To fill every empty position, the model first draws a topic prevalence vector from the logistic normal distribution denoted in equation (4.1). The equation shows that topic prevalence vector depends on the covariates $x_{d}$ and the estimated coefficients $\Gamma=\left[\gamma_{1}|\ldots| \gamma_{K}\right] . \Sigma$ is a variance-covariance matrix whose off-diagonal elements represent the correlation between the topics. We further note that the properties of the logistic normal distribution are responsible for the possibility of correlations between topics.

$$
\boldsymbol{\theta}_{d} \sim \text { LogisticNormal }_{k-1}\left(\Gamma^{\prime} x_{d}^{\prime}, \Sigma\right)
$$

The data generating process replaces equation (4.1) by drawing from the following distribution $\boldsymbol{\eta}_{d} \sim \operatorname{Normal}_{K-1}\left(\mu_{d}, \Sigma\right)$ and calculating every value of $\theta_{d}$ by $\theta_{d, k}=$ 
$\exp \left(\theta_{d, k} /\left(\sum_{i=1}^{K} \exp \left(\theta_{d, i}\right)\right)\right.$. It further uses a zero mean Gaussian distribution $\gamma_{p, k} \sim \operatorname{Normal}\left(0, \sigma_{\mathrm{k}}^{2}\right)$ as prior to draw the coefficient values for one topic and where they share the same variance. All coefficient values together constitute the resulting multivariate normal distribution for one topic depicted in equation (4.2). $\sigma_{k}^{2}$ is an inverse gamma distribution with the fixed hyperparameters a and $\mathrm{b}:{ }^{2}$

$$
\gamma_{k} \sim \operatorname{Normal}_{\mathrm{P}}\left(0, \sigma_{k}^{2} I_{P}\right)
$$

2. After the data generating process has drawn a topic prevalence vector, it samples a topic for each word in document $d$ and holds the results in the one-hot encoded vector $z_{d, n}$.

$$
\mathbf{z}_{d, n} \sim \operatorname{Multinomial}_{K}\left(\boldsymbol{\theta}_{d}\right), \quad \text { for } n=1 \ldots N_{d}
$$

3. The equations (4.1) and (4.2) measure the impact of covariates on the documentspecific topic prevalence, but not the impact on the topical content. However, equation (4.4) includes this effect. It captures the impact of topics, covariates and the interactions between both on the word:

$$
\beta_{d, k, v}=\frac{\exp \left(m_{v}+\kappa_{k, v}^{(t)}+\kappa_{y_{d}, v}^{(c)}+\kappa_{y_{d}, k, v}^{(i)}\right)}{\sum_{v} \exp \left(m_{v}+\kappa_{k, v}^{(t)}+\kappa_{y_{d}, v}^{(c)}+\kappa_{y_{d}, k, v}^{(i)}\right)}
$$

In a nutshell, the equation expresses the log-transformed rate deviation for term $v$ of the three parameters topics, covariates and their interactions from a corpus-wide marginal log-transformed rate $m_{v}$ for the same term. The matrices $\kappa^{(t)}, \kappa^{(c)}$ and $\kappa^{(i)}$ contain the deviations for each term and topic $\mathrm{t}$, for each term and level of the covariate $Y_{d}$ or for each term for and interaction between the topics and covariates respectively. It is often practice to estimate $m_{v}$ as the marginal log-transformed rate of occurrence in the corpus of interest, however any other distribution is also applicable to determine the rate for term $v$. Ultimately, the data generating process obtains a multinomial logistic

\footnotetext{
${ }^{2}$ The method paper Roberts, Stewart, and Airoldi 2016 explains the hyperparameters exact specification.
} 
expression which is a function of word-topic latent variable $z_{d, n}$, the provided covariates like the author's party affiliation and their interactions. The function provides the opportunity to compute the probability of occurrence for any word in our vocabulary given topic $k$, the level $y_{d}$ of the content covariate and their interactions.

Theoretically, the basic idea to use the multinomial distribution of word occurrences to attain different marginal log-transformed rates for different set of parameters allows to include more than one topical content variable. In practice however, the matrices $\kappa^{(c)}$ and $\kappa^{(i)}$ would massively increase in size. Roberts, Stewart, and Airoldi 2016 advise to restrict a STM to one topical content variable for the time being with regard to computational considerations.

4. Lastly, the data generating process takes the topic in equation (4.3) as input to sample a word from the multinomial distribution over the created vocabulary denoted in (4.5). The equation presents another innovative part of the STM: not only does the assigned topic to a word change the topic word distribution in equation (4.4) but also the level of a specified content covariate and their interactions.

$$
\mathbf{w}_{d, n} \sim \operatorname{Multinomial}_{V}\left(\beta_{d, k, v}\right), \quad \text { for } n=1 \ldots N_{d}
$$

\subsubsection{Estimation and initialization}

As with most statistical topic models, the most complex part is the estimation. This is not different in the case of the STM for which we would like to estimate the unknown parameters in the full posterior $p(\eta, z, \kappa, \gamma, \Sigma \mid w, X, Y)$ that is proportional to:

$$
\begin{aligned}
& \left(\prod _ { d = 1 } ^ { D } \operatorname { N o r m a l } ( \eta _ { d } | X _ { d } \gamma , \Sigma ) \left(\prod_{n=1}^{N} \operatorname{Multinomial}\left(z_{n, d} \mid \theta_{d}\right)\right.\right. \\
& \left.\left.\times \operatorname{Multinomial}\left(w_{n} \mid \beta_{d, k=z_{d, n}}\right)\right)\right) \times \prod p(\kappa) \prod p(\Gamma)
\end{aligned}
$$


The full posterior of the model is not solvable and is in this respect not different from posteriors of other topic models. To enable a solution, Roberts, Stewart, and Airoldi (2016) rely on methods of approximate inference that are are very suitable for iterative model fitting. They have implemented a nonconjugate variational expectationmaximization algorithm (EM) to approximate the posterior distribution in equation (4.6). The implemented algorithm matches a standard EM, besides calculating the expectations with regard to the variational distributions $q(\eta)$ and $q(z)$. We note that these distributions represent the document-topic-proportions and the topic assignment for each word. They are the latent variables of interest in the STM. Ultimately, inference splits into an E-step and M-step. Taking turns, the E-step optimizes the variational posterior for each document's topic proportions and the M-step estimates the topical prevalence and content coefficients. The following steps give an intuitive summary of the STM's iterative procedure until it has reached convergence: ${ }^{3}$
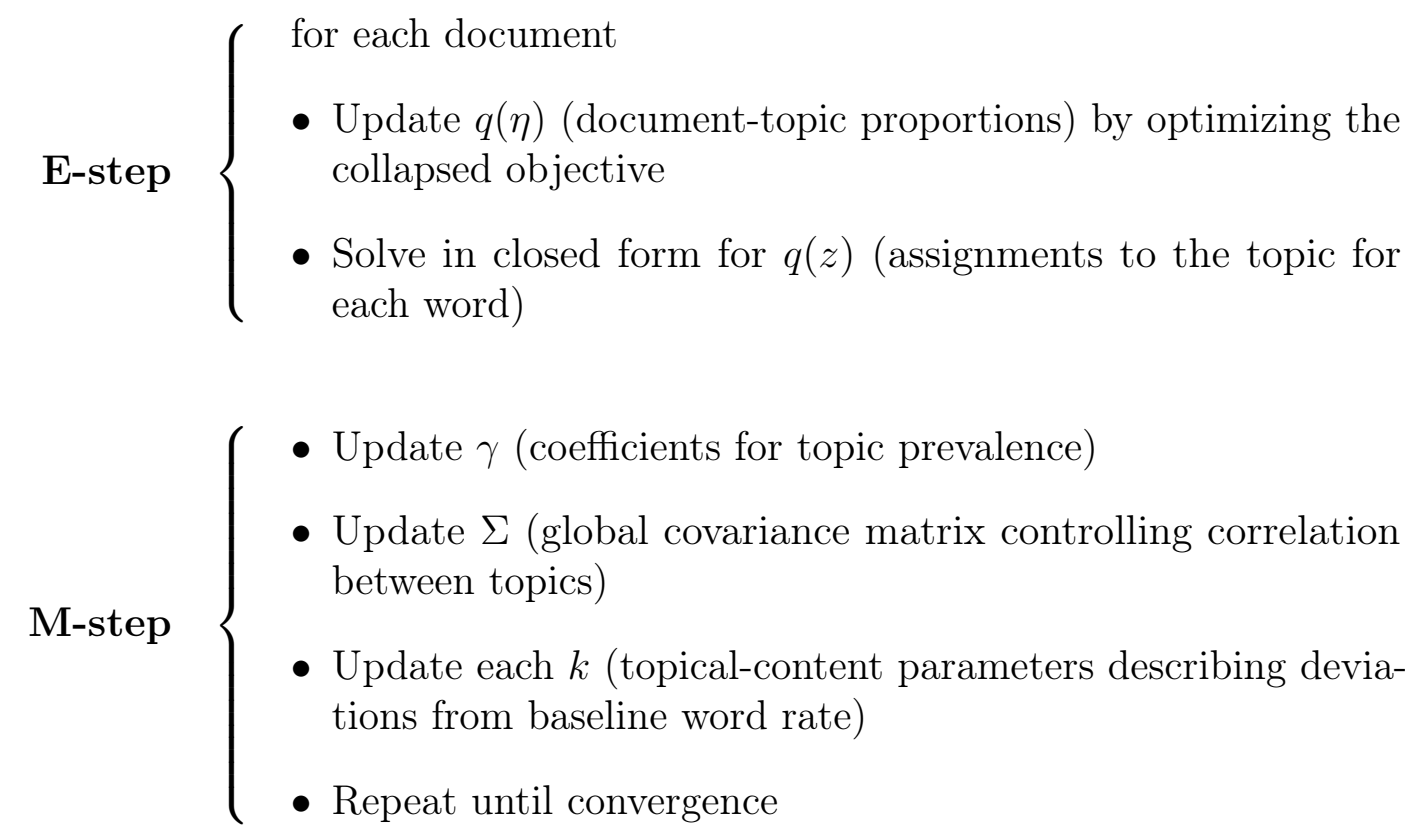

The STM reaches convergence when the proportional change in the approximated bound on the marginal likelihood at the global level falls below a threshold specified beforehand. In other words, when the change to the likelihood of choosing the observed words with the estimated parameters $\eta, z, \kappa, \gamma$ and $\Sigma$ in our speeches is less than the

\footnotetext{
${ }^{3}$ The steps are taken from the appendix of Roberts, Stewart, Tingley, et al. (2014).
} 
threshold. It is important to emphasize that the computed marginal likelihood is only an approximation, i.e. it does not correspond to the actual bound for the marginal likelihood which is not tractable.

Like other topic models the STM outputs posterior distributions that may contain many local optima. Whether the model finishes in one optimum or the other strongly depends upon the initialization values drawn at the beginning of estimation. To reduce topic instability between different runs, the creators of the STM embrace the spectral method of moments algorithm of Arora as initialization strategy. According to Wilkerson and Casas (2017) the STM outperforms other topic models on various test settings mainly due to the different initialization approach.

\subsubsection{FREX and Semantic Coherence}

To diagnose the model's fit after estimation, a mere consideration of word frequency per topic does not suffice. In the case of politics, specific terms always come up because they are part of the politicians' vocabulary independent of the topic at hand. Roberts, Stewart, and Airoldi (2016) propose FREX, a combination of frequency and exclusivity, to find representative words for topics. The FREX score of every word can support to check the plausibility of the estimated topics. It is defined as follows:

$$
\operatorname{FREX}_{k, v}=\left(\frac{w}{\operatorname{ECDF}\left(\beta_{\mathrm{k}, \mathrm{v}} / \sum_{j=1}^{K} \beta_{j, v}\right)}+\frac{1-w}{\operatorname{ECDF}\left(\beta_{k, v}\right)}\right)^{-1}
$$

where ECDF is the empirical CDF function, $w$ represents the weight given to exclusivity $i$ indexes the topics and $j$ indexes the vocabulary words.

Ideally, topics are semantically coherent in themselves. This means that words frequently co-occur in documents that have the same topic assigned. We can measure this co-occurence as proposed by Roberts, Stewart, and Airoldi (2016) through

$$
\sum_{n=2}^{N} \sum_{m=1}^{n-1} \log \left(\frac{D\left(v_{n}, v_{m}\right)+1}{D\left(v_{m}\right)}\right.
$$

where $D()$ is a function of a word index $v_{i}$. It returns the number of documents 
holding its arguments.

\subsubsection{Uncertainty}

It would be optimal to incorporate the estimation uncertainty into the subsequent analysis of the topic proportions. The STM enables this using the method of composition. In practice, the method repeatedly samples topic proportions from each document's approximate posterior $\tilde{n_{d}} \sim N\left(\lambda_{d}, v_{d}\right)$, maps the draw to the simplex $\tilde{\theta_{d}}=\frac{\exp \left(\tilde{\eta_{d}}\right)}{\sum_{k} \exp \left(\tilde{\left.n_{d}\right)}\right.}$ and regresses the topic proportions on document characteristics such as party affiliation. To obtain for instance a standard regression output we then still have to simulate within each group of coefficients and average the results. By acquainting the reader with the essential concepts to apply a STM, the thesis has established a solid basis for the subsequent chapter about the research design. It elaborates on how the thesis intents to operationalize the two hypotheses. 


\section{$5 \quad$ Research Design}

This section explicitly states the statistical analyses that produce the results in chapter 6. It contains two parts, one considering hypothesis 1 about topical prevalence and the other regarding hypothesis 2 about polarization.

\subsection{Appellations and topic prevalence}

Considering the first hypothesis, the aim is to analyze whether the AfD significantly differs from the other parties in the choice of topics they make the subject of discussions in their appellations. The approach of this thesis is to run one STM for each state, as illustrated in figure 5-1, to gather expected proportions for policy areas in an appellation. Another possible design was to run a single STM on the appellations from all 16 states. However, this would have induced hierarchy into the data generating process of the corpus which the model itself is not capable to include at this point. A second possible obstacle would have been the tremendous difference in the number of appellations between the states. Under these circumstances, the one-state-one-model approach seems less error-prone while allowing more straight-forward interpretation of the results.

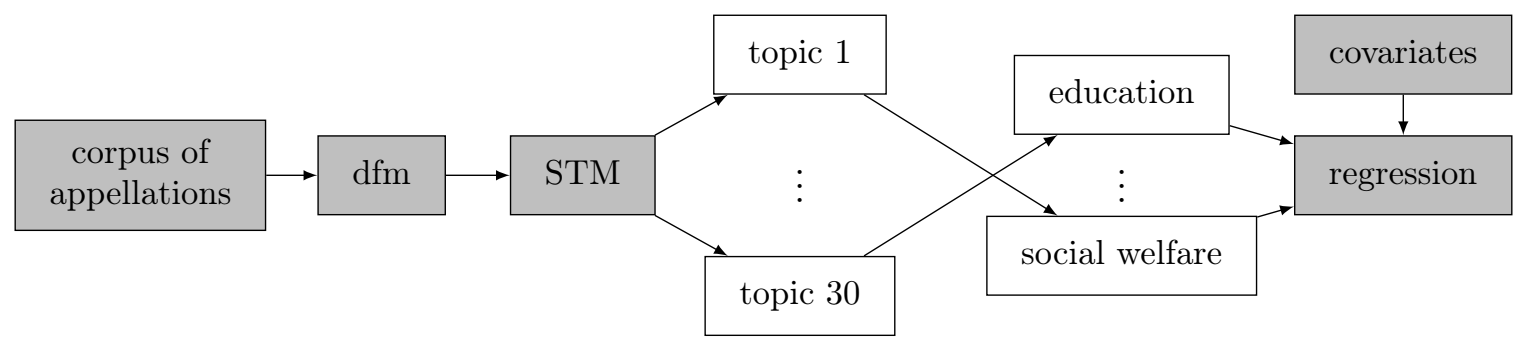

Figure 5-1: A graphical representation of the pipeline. Repeats for each state. 


\section{Preprocessing the appellations}

Before the machine learning pipeline is able to run the STM for each state, the preprocessing part as drawn in figure 5-1 is necessary. It applies standard filters on the documents (appellations) in the corpus and transforms them into the correct format, a document-feature matrix $(\mathrm{dfm})$ where each unique word is a feature: One filter is the removal of documents that contain less than 100 words and words with or less than two characters. The comparison of different model specifications has shown that the inclusion of words with less characters leads to worse models. One reason for this result is that the answers of the state government to the appellations often include tables. The conversion tools of kleineanfragen.de did not always convert them into recognizable words; instead, they created unknown words with two or less characters.

We further apply other standard preprocessing tasks such as the removal of punctuation, stopwords, numbers and infrequent words from the $\mathrm{dfm}$ for two reasons (Denny and Spirling 2018): First, in theory these sets of words do not convey any meaning if the researchers are interested in the term usage inside a corpus. Second, the removal of words with very low frequency decreases the vocabulary size greatly, while it typically increases speed during computation significantly. For this reason, the $\mathrm{dfm}$ only keeps the 10,000 words that occur the most across documents (document frequency). These criteria approximately reproduce the common rule of thumb to remove terms that do not appear in at least one percent of the documents (Denny and Spirling 2018). Following recent research the preprocessing part explicitly does not stem the words, as this transformation does not improve heldout-likelihood and semantic coherence but can impair topic stability (Schofield and Mimno 2016).

Sometimes several MPs or parliamentary groups submit an appellation together. In this case, the dfm only keeps the first MP's name or party as metadata. However, the STM does not only rely on the authorship or the associated party affiliation of an appellation to discover topics. It includes the appellation type, the responsible ministry, the date of creation, and other personal characteristics' like gender and age too. Certainly a thoughtful reader might notice that this is the same data we regress 
the expected topic proportions on, but the testing of the STM shows that the joint estimation of topic proportions and covariates does not induce spurious correlations between these (Roberts, Stewart, Tingley, et al. (2014), appendix).

\section{Fitting the STMs}

After the preprocessing is completed, we move on to the STM in the pipeline portrayed in figure $5-1$ by specifying the model parameters and fitting the topic models. The STM has many parameters, but the most important parameter is the number of topics that the corpus should supposedly contain. Diagnostic tests of semantic coherence, exclusivity, held-out likelihood and residuals for models with a range of topics from 5 to 120 indicate that a topic number of 25 for smaller corpora and 30 for larger corpora delivers the best results. ${ }^{1}$ In addition to these calculable model fit measures, the selection and evaluation process involved carefully examining a set of words, that according to their word score ranking describe the topics most representatively.

\section{Summarizing topics by policy area}

A common approach is to specify a higher number of topics rather than having the topic model separating topics fuzzy. This procedure also allows choosing the aggregation level retrospectively. More precisely, for an STM words that frequently co-occur together constitute a topic. It depends upon the specific research, if this base level of topics suffices or if the analysis demands an aggregation of topics. As the pipeline in figure 5-1 shows, policy areas summarize the topics in this thesis, preventing having an inadequate level of detail and the analysis of becoming too fragmented. Policy areas typically have complementary sub-issues. For instance, the organization of police forces, prisons, and courts belong to the policy area law and order. The words to describe these political issues may differ significantly. Nonetheless, the regression model treats them as belonging to the same policy area, i.e. the following analysis only estimates an effect of party affiliation on policy areas not on sub-issues. The

\footnotetext{
${ }^{1}$ see B-1 for an example graph of tests for Brandenburg.
} 
policy areas mostly follow the codebook of the Comparative Agendas Project and the policy areas used in Schroeder, Weßels, Neusser, et al. (2017). ${ }^{2}$

To know to which policy area a specific topic belongs, the STM lets the user examine the top words of a topic according to frequency, FREX and other word scores (see A.2 for such a word list). They usually give the first hint, and often the correct policy area can be directly derived from the top thirty words. Another useful source of information to assign a topic to a policy area are the correlations between the topics (see B-2 for a graphical illustration). In a few cases where the policy areas are less precise, the STM provides the option to look at the most representative appellations for the topic. Both measures assure to a very high degree that no policy area contains an unsuitable topic and consequently that the appellations in a policy area are coherent.

\section{Estimating the effect}

In the end, the machine learning pipeline in figure 5-1 completes with the regression part. We take 100 draws from the theta posterior to receive policy area proportions (PAPs) that include uncertainty (as explained in section 4.1.4). The PAPs serve as a dependent variable in a regression where authorship, party affiliation, date of creation, appellation type and personal characteristics are the independent variables. ${ }^{3}$ Significant coefficients for the characteristic values of party affiliation, deviating sufficiently, would suggest a difference in interest of the parties for the specific policy area. The other variables control for a possible effect of time, appellation type and personal characteristics.

\footnotetext{
${ }^{2}$ Comparative Agendas Project's codebook: https://www.comparativeagendas.net/pages/mastercodebook.

${ }^{3}$ The states of BE or BY only know one type of appellation - written appellations - and do not differentiate between minor and major appellations.
} 


\subsection{Parliamentary speeches and polarization}

After explaining how we test hypothesis 1, we now structure the second part of the analysis about polarization. We recall hypothesis 2: it claims that the AfD's entrance leads to a higher polarization in the state parliaments. Peterson and Spirling (2018) argue, the better we can distinguish between parliamentary groups' speeches, the higher is the parliament's polarization and vice versa. This thesis borrows this definition and extends it by also considering MP's reactions during the speech of another MP's as a suitable indicator for polarization. The assumption is that the more polarized a parliament is, the more MPs avoid to clap (agreement) for a speech or the contrary comment (mainly disagreement) on a speech. MPs who have very opposing political views shall feel a strong urge to react with an interjection to one another. Beyond interjections in the speeches, polarization may additionally surface through a different use of language. Usually, the opposition uses the floor time to attack the government, and logically the MPs of the opposition might opt more for negative wording. Another non-exclusionary possibility is that the wording is not more negative but only different.

\section{Deriving a polarization score}

In order to examine these three dimensions of polarization by state, this thesis first determines with what frequency the parties clap for each other. Through clapping MPs reliably signal agreement with the content of a speech. This thesis suggests that the average frequency of applause one party gives to another party in proportion to the average frequency of applause it gives to itself indicates how polarizing the party perceives speeches of the other party. For this measurement, it is necessary assuming the amount of applause a party receives from itself represents the maximum degree of agreement this party can express. On parliament level, such an assumption then enables to compute a polarization score for the parliamentary debate as a whole. First, we calculate to what extent a party gives applause relative to the maximum degree of 
agreement through,

$$
p_{\substack{t, f, s \\ t \neq f}}=1-\frac{b_{t, f, s} t \neq f}{b_{t, f, s}} \quad \text { for } t=f \in\{\mathrm{AfD}, \ldots, \mathrm{SPD}\}
$$

where $b$ is the average amount of applause party $t$ receives from party $f$ in state $s$ and $p$ indicates how polarizing party $f$ perceives speeches form party $t$. Subsequently, we can compute from the resulting values an average score of perceived polarization for each party by,

$$
\mu_{f, s}=\bar{P}_{f, s}
$$

where $P_{f, s}$ is a vector containing every possible pair of $t$ and $f$ in state $s$. The last step is to average over states by party pairs $p_{\substack{t, f, s \\ t \neq f}}$ and over the existing $\mu_{f, s}$ as followed,

$$
\begin{gathered}
\substack{t, f \\
t \neq f}_{\substack{t \neq f \\
t \neq f}} \quad \text { for } s \in\{B B, \ldots, T H\} \\
\phi_{s}=\bar{M}_{s}
\end{gathered}
$$

where $\theta_{t, f}$ expresses to what extent party $f$ perceives speeches from party $t$ as polarizing, averaged across states. $\mathrm{M}$ is a vector holding every available $\mu_{f, s}$ and $\phi$ is the polarization score for state $s$ between zero and one.

\section{Detecting provocations and sentiment}

The opposite, disagreement, is less readily determinable as interjections that do not explicitly contain clapping may express support or dissent with the speech. Nonetheless, a TOP 3 ranking of speakers per state who evoke the most interjections on average, which are not clapping, may yield informative results. In the second part of the analysis, we apply the sentiment dictionary of Rauh (2018) for political language on the speeches. This exercise returns the average proportion of positive and negative wording per party and legislative period in each state. 


\section{Measuring AfD's distinctiveness}

The last part uses a linear SVM classifier to distinguish between the AfD and all other parties (binary). Other classifiers, including a non-linear SVM or based on word embeddings, do sometimes yield higher accuracy but their interpretation is not as simple. For interpretation purposes, potential contribution to political theory or empirical confirmation of political theory, it is indispensable to know what enables the algorithm to differentiate between the AfD and all other parties. Another term for this is feature importance which the linear SVM model provides out-of-the-box. In comparison to other non-linear classifiers that have many dimensions, the one dimension of the linear SVM makes the features directly interpretable. Taking this into consideration, the SVM classifier with the linear kernel is the best choice despite its granularity, but to integrate other classifiers remains an aim for future work.

The model pipeline only includes speeches that contain at least 100 words; excluding speeches that concern formal procedures and other short speeches that do not deliver

a political statement. Four $(80 \%)$ to one $(20 \%)$ is the ratio between the train and test set. A random oversampling - only of the training set - ensures that imbalanced classes do not distort the classifiers' accuracy. The next chapter presents the results of the two part analysis described in this chapter. 


\section{$6 \quad$ Results}

This chapter presents the results of the analysis. The first section describes the general policy area proportions (PAPs) within a single state parliament estimated by the STM and subsequently examines the party impact on the expected policy area of an appellation. It is followed by a second part that explains the findings of AfD's effect on polarization in German state parliaments.

\subsection{Appellations and topic prevalence}

At first, it is necessary to look at how the policy areas are distributed over the corpus of appellations by state. The main jurisdiction of the German states reflects well in the expected policy area proportions of the appellations from each state given in figure $6-1$.

Education and law \& order ${ }^{1}$ are the most visible policy areas over which the German state governments have full law-making power. The STM discovers both policy areas in all 16 federal states. Although in general, the law gives the law-making power to the states, the federal government has the law-making power over most policy areas such as citizenship, economy, or infrastructure. In these areas of the legislation, the state governments only have the role of implementing and executing laws that the Bundestag passes on the federal level, but sometimes federal states can deviate from the federal law.

After all, state governments and parliamentarians have not only an interest in policy areas that they can immediately influence through their law-making power,

\footnotetext{
${ }^{1}$ specifically the organization of police forces and the penal system.
} 


\begin{tabular}{|c|c|c|c|c|c|c|c|c|c|c|c|c|c|c|c|c|}
\hline agriculture \& forestry & 0.01 & & 0.05 & 0.05 & & 0.06 & & 0.03 & & 0.02 & & & & & & \\
\hline economy and labor - & 0.11 & & 0.05 & 0.04 & 0.14 & 0.04 & 0.07 & 0.05 & 0.09 & 0.23 & 0.04 & & & & 0.01 & 0.07 \\
\hline education - & 0.03 & 0.05 & 0.07 & 0.11 & 0.12 & 0.14 & 0.06 & 0.13 & 0.08 & 0.11 & 0.17 & 0.15 & 0.08 & 0.05 & 0.11 & 0.1 \\
\hline environment \& energy & 0.11 & & 0.07 & 0.06 & 0 & 0.04 & & 0.19 & 0.13 & 0.11 & 0.08 & 0.14 & 0.07 & 0 & 0.13 & 0.05 \\
\hline extremism - & 0.05 & 0.01 & 0.05 & 0.08 & 0.11 & 0.05 & 0.03 & & 0.06 & 0.13 & & 0.11 & & 0.11 & 0.08 & 0.05 \\
\hline finances and funding & 0.02 & & 0.03 & & 0.09 & 0.04 & 0.17 & 0.06 & & 0.08 & 0.01 & 0.07 & 0.04 & 0.27 & 0.07 & 0.12 \\
\hline government operations & 0.04 & 0.11 & 0.11 & 0.38 & 0.08 & 0.25 & 0.03 & 0.1 & 0.09 & 0.06 & 0.19 & 0.02 & 0.23 & 0.32 & 0.27 & 0.27 \\
\hline cture and transportation & 0.17 & 0.2 & 0.21 & 0.08 & & 0.1 & 0.12 & & 0.07 & 0.04 & 0.12 & 0.09 & 0.03 & & 0.09 & 0.01 \\
\hline law \& order - & 0.34 & 0.14 & 0.08 & 0.01 & 0.06 & 0.05 & 0.33 & 0.09 & 0.23 & 0.04 & 0.12 & 0.11 & 0.03 & 0.15 & 0.11 & 0.22 \\
\hline migration - & 0.01 & 0.04 & 0.1 & 0.01 & 0.06 & 0.12 & 0.06 & 0.09 & 0.03 & 0.01 & 0.08 & 0.06 & 0.11 & & 0.03 & 0.01 \\
\hline social welfare- & 0.1 & 0.09 & 0.03 & 0.07 & 0.13 & 0.01 & 0.04 & 0.2 & 0.12 & 0.14 & 0.02 & 0.1 & 0.08 & 0.03 & 0.03 & 0.08 \\
\hline unassigned & 0 & 0.24 & 0.06 & 0.03 & 0.04 & 0.03 & 0.06 & 0.01 & 0.09 & 0 & 0.07 & 0.05 & 0.23 & 0.03 & 0.02 & \\
\hline health - & & 0.02 & 0.05 & & 0.11 & 0.09 & 0.01 & 0.03 & & & 0.02 & 0.04 & 0.03 & & 0.06 & \\
\hline housing & & 0.05 & 0.03 & 0.07 & & & 0.02 & & & 0.02 & & 0.02 & & & & \\
\hline \multirow[t]{2}{*}{ political } & & 0.03 & & & 0.06 & & & & & & 0.08 & 0.03 & 0.07 & 0.05 & & 0.03 \\
\hline & BB & $B E$ & BW & BY & $\mathrm{HB}$ & $\mathrm{HE}$ & $\mathrm{HH}$ & $\begin{array}{l}\mathrm{MV} \\
\text { sta }\end{array}$ & $e^{\mathrm{Nl}}$ & NW & $\mathrm{RP}$ & $\mathrm{SH}$ & SL & SN & ST & $\mathrm{TH}$ \\
\hline
\end{tabular}

Figure 6-1: The expected policy area proportions by state. A column approximately sums up to one and 0.1 equals to an expected share of ten percent in the corpus. 
as figure 6-1 shows but in other policy areas which matter for their constituents too. Road or railway construction is such a policy area where cooperation between state and federal level is necessary to plan and implement projects. Many times parliamentarians are interested in how funding either from the state, federal, or EU level distributes itself across districts or projects. The policy area finances \& funding summarizes these kinds of appellations.

The missing policy areas agriculture \& forestry and environment \& energy in the city state's of Berlin, Bremen and Hamburg are very plausible as they neither have considerable agriculture nor wind turbines. Furthermore, the topic models discovered that affordable housing became a very huge topic in the city states and the southern states Baden-Württemberg and Bavaria.

In many states, parliamentarians submit appellations that concern extremism. They either worry about the spread and violence from the left or right side of the political spectrum. To a similar extent, the MPs are interested in the policy area migration, although the federal level mostly possesses the law-making power over this policy area and oversees the authorities that grant residence permits or recognize asylum. However, the state governments are responsible for the accommodation of refugees and the allowance of social services where they can establish deviating implementations to a certain extent. A prime example is, whether refugees receive money or only vouchers for matters that are their lawful right or not.

Classifying all topics from the STM in one of the fourteen policy areas in figure 6-1 was not possible. The answers from the state government recurrently include very long lists, listing street names or cities. Through these lists, speeches share words without actually sharing the same topic. One way to avoid such topics in the final topic model would be to cut off such lists, but the answer from the state government does not follow one style guide. Thus, one can not apply a regular expression pattern to reliably remove long lists or similar parts of the printed matters. 


\subsubsection{Effect of party on topical prevalence}

To answer the first hypothesis 1 that the expected policy area proportion for an appellation varies with the party from which the appellation originates, the regression results for seven selected policy areas in table A.1 (appendix) provide insights. This table only presents the seven most informative policy areas to keep the results tightly structured. The six are the most informative policy areas, because they fulfill at least one of the following criteria: every STM finds them, the state possesses the full law-making power over them or it is very likely a policy area of central interest for the AfD, like migration. Every combination of policy area and state, which in total can include up to 12 values (six coefficients and standard errors respectively), is the output of regressing the party affiliation on the expected policy area proportion. The table A.1 omits the control variables such as appellation type or personal characteristics since the comparison of models has shown that they do not change the strength nor the direction of the party impact.

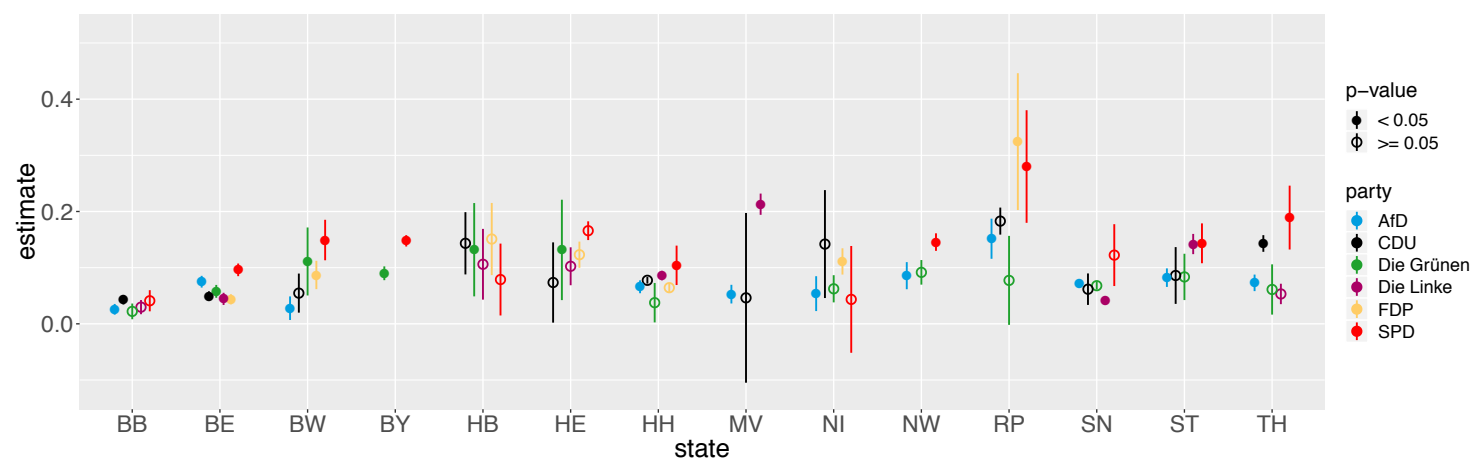

Figure 6-2: Estimate for each party's expected proportion for the policy area education. The values are not anchored in the intercept.

A large table does not convey the essential results very intuitively. Therefore, a graph like figure 6-2 visualizes the results for each policy area further. In contrast to the table output, the graph displays the expected policy area without relation to the intercept, i.e., the value is given in absolute terms. The graphs do not include the parties' coefficients for Schleswig-Holstein and Saarland as their in comparison strongly scattering standard errors would distort the scale. The loss through the 
removal is marginal, considering that these coefficients are often insignificant due to the states' small sample size.

\section{Education}

The regression results plotted in figure 6-2 suggest that education is an important policy area for the parliamentary groups of the AfD, but the importance varies with very low expected proportions for Brandenburg and Baden-Württemberg and higher numbers for Berlin, Saxony-Anhalt and North Rhine-Westphalia. The MPs of RhinelandPalatinate mark a particular case, where not only those from the AfD draw up many appellations about education but the other parties as well. It is noticeable that the parliamentary groups of the SPD consistently have a higher expected proportion from 0.058 for Bavaria to 0.121 for Baden-Württemberg (see A.1 in the states where they are not part of the government. Interestingly, the expected proportion for the CDU only increases for Thuringia, but not for Berlin and Brandenburg where they possibly disagree with the education policy of the SPD-led government.

\section{Environment \& energy}

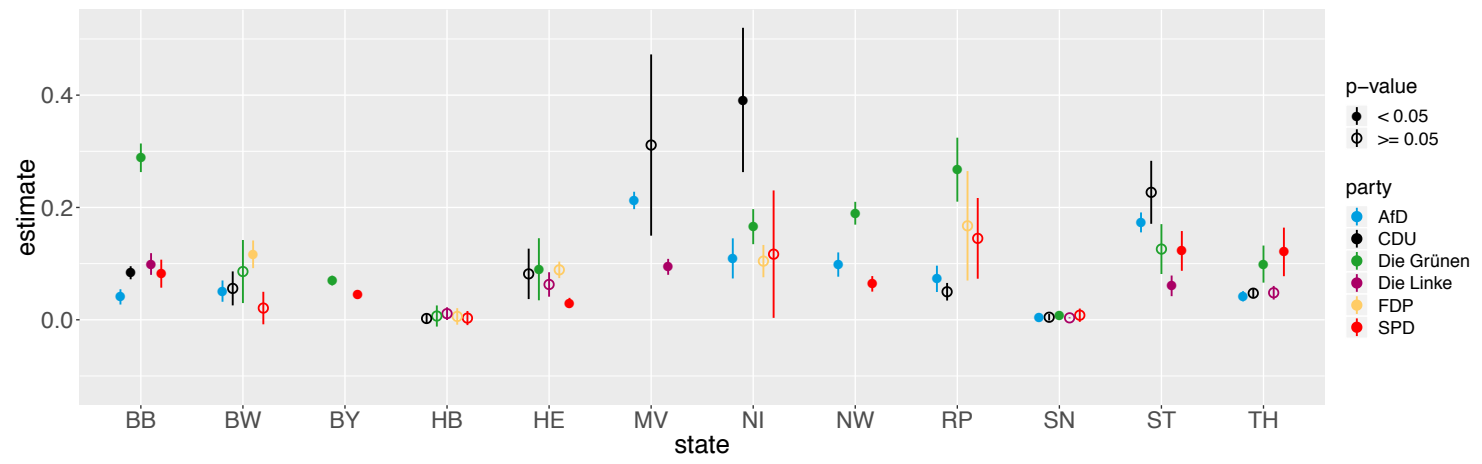

Figure 6-3: Estimate for each party's expected proportion for the policy area environment \& energy. The values are not anchored in the intercept.

Table A.1 and figure 6-3 reveal that the policy area environment and energy is of mixed importance for the parliamentary groups of the AfD. While the expected topic proportion is below 10 percent for most states, it rises above for Lower Saxony, Schleswig-Holstein and Saxony-Anhalt. In those states, many companies already 
run wind parks and more areas in these states are suitable for wind energy (Lewicki 2013; Jung, Schindler, and Grau 2018). The foundation of such parks often faces resistance by local citizens who fear the blots on the landscape, the noise and the danger for birds. Politicians who want to establish and keep an anti-establishment image of themselves may use such conflicts between locals and the government for this purpose (Gölz and Wedderhoff 2018; Hess and Renner 2019). While the greens mainly support the construction plans of wind turbines, they nevertheless pay attention to the compensation for construction projects that interfere with the ecosystem. The importance which they put on sustainability shows in the high expected policy area proportion in states such as Brandenburg, Rhineland-Palatinate and Lower Saxony.

\section{Extremism}

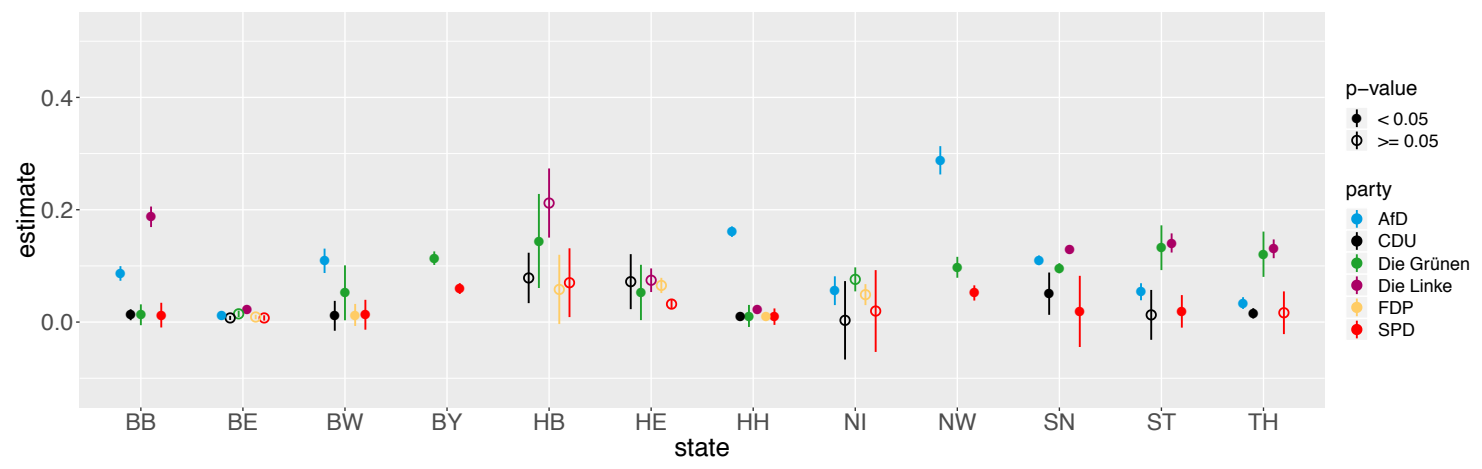

Figure 6-4: Estimate for each party's expected proportion for the policy area extremism. The values are not anchored in the intercept.

Political groups, movements or parties such as Interventionistische Linke (left), Identitäre Bewegung or III. Weg (both right) have aims that the parliamentary groups consider unconstitutional or they resort to questionable methods that the parliamentary parties disapprove of as too radial or violent. The AfD takes on this issue in their appellations quite strongly like the coefficients for its parliamentary groups prove. The expected policy area proportion ranges from a very low 0.011 in Berlin to a very high 0.288 in North Rhine-Westphalia. An illustrative example of such an appellation is the printed matter 21/14042 from Dr. Alexander Wolf (AfD) which he submitted to the state parliament of Hamburg. In this appellation, he asks the 
state government which projects and training programs for teachers it currently funds to reduce the risk of pupils to become either left- or right-wing extremists or to help them to exit their extremist life. We can further conclude from table A.1 that neither the CDU nor the SPD acts as the major counterpart against the AfD in this policy area. Instead, Die Grünen and Die Linke fill this role as their coefficients for Saxony, Saxony-Anhalt and Thuringia indicate. Especially their MPs in the new federal states submit appellations regarding concerts organized by right-wing extremists or the use of unconstitutional signs on demonstrations.

\section{Infrastructure \& transport}

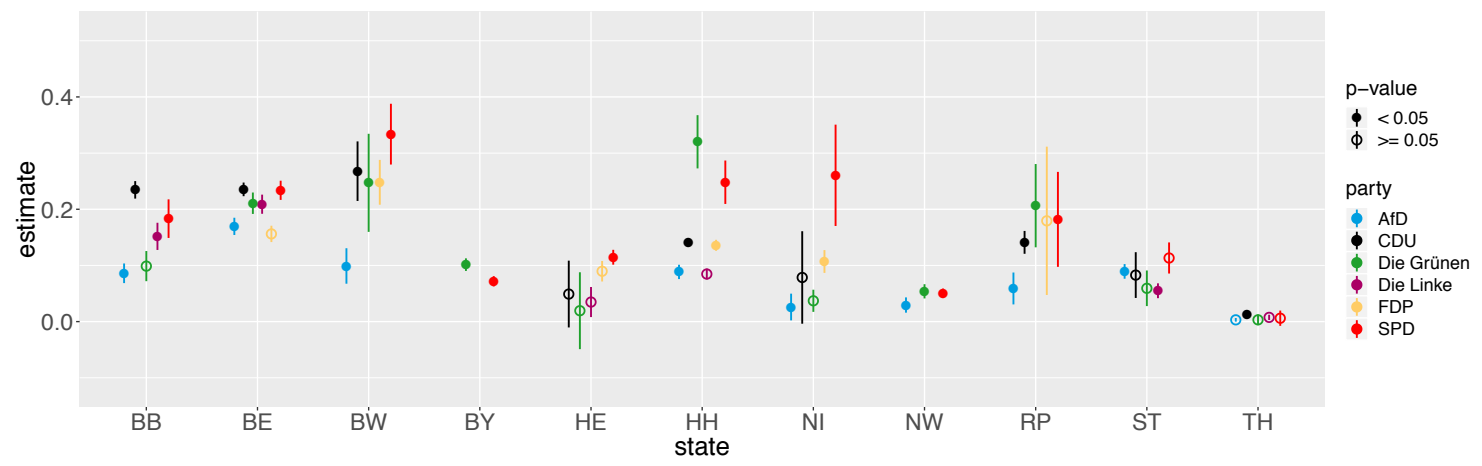

Figure 6-5: Estimate for each party's expected proportion for the policy area environment \& energy. The values are not anchored in the intercept.

Based on the regression outputs illustrated in figure 6-5, it is noticeable that infrastructure \& transport is an important policy area for the parliamentary groups of the AfD, but not the most important one. Their expected policy area proportions range from a very low 0.026 in Lower Saxony to a rather high 0.17 in Berlin. The policy area includes the possible ban on cars with high CO2-emissions from entering individual areas or the whole city. A political issue which the protagonists from cyclists and drivers to media and politicians debate quite intensely, making the issue in particular suitable for politicians to fuel it in a populist fashion. Another insight is that the expected policy area proportion for both city states Berlin and Hamburg is significantly higher than for the other states. One explanation for this observation might be that the public space in these states is very dense, which is why the protagonists fight over 
this policy area with an intensiveness proportional to the density. Another possible reason is that the available public transportation system does not have to compete with other cities, unlike in area states. Nonetheless, the policy area infrastructure \& transport seems to be an essential policy area for the opposition parties in some area states to interrogate the current government. For instance, the expected policy area proportion for an appellation from the CDU Brandenburg is well beyond 20 percent and even above 30 percent for the SPD in Baden-Württemberg.

\section{Law \& order}

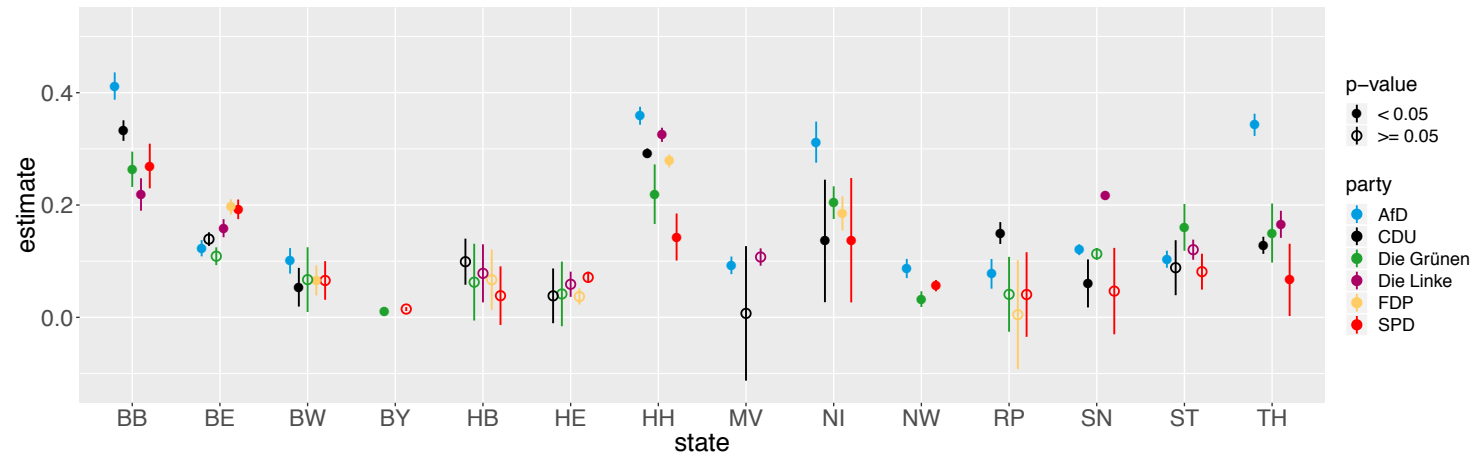

Figure 6-6: Estimate for each party's expected proportion for the policy area law \& order. The values are not anchored in the intercept.

According to the regression estimates in figure 6-6 law \& order is the primary policy area of AfD's MPs to make a mark as a politician. Besides North Rhine-Westphalia and Rhineland-Palatinate, the expected policy area proportion is above 10 percent and even rises to 0.412 in Brandenburg or 0.359 in Hamburg. It aligns with the party's program and claims that the public order is in danger or already vanished. As a consequence, the MPs question the state governments in their appellations to show that the current state governments fail on this matter and are incapable of reestablishing public order. Examples for such appellations are the printed matters 6/2727 (Brandenburg) and 17/7080 (North Rhine-Westphalia) in which the respective MP of the AfD accuses the state government of leaving the citizens alone with the violence of the arrived refugees and of not tackling the defacement of buildings and infrastructure insistently enough. Although the AfD's MPs deal the most with the 
policy area law \& order across all states, the other parties' MPs dedicate a considerable share of their appellations to this policy area as well. However, the expected value rarely surpass the AfD's value, as is the case for Die Grünen in Rhineland-Palatinate. The general importance of the policy area across parties and states also mirrors the fact that law \& order includes many political issues such as the structure of the penal system and courts and the rights of police forces. Traditionally, parties like Die Linke and Die Grünen critically question excessive use of force, while in particular CDU and AfD see an increase of violence against police forces.

\section{Migration}

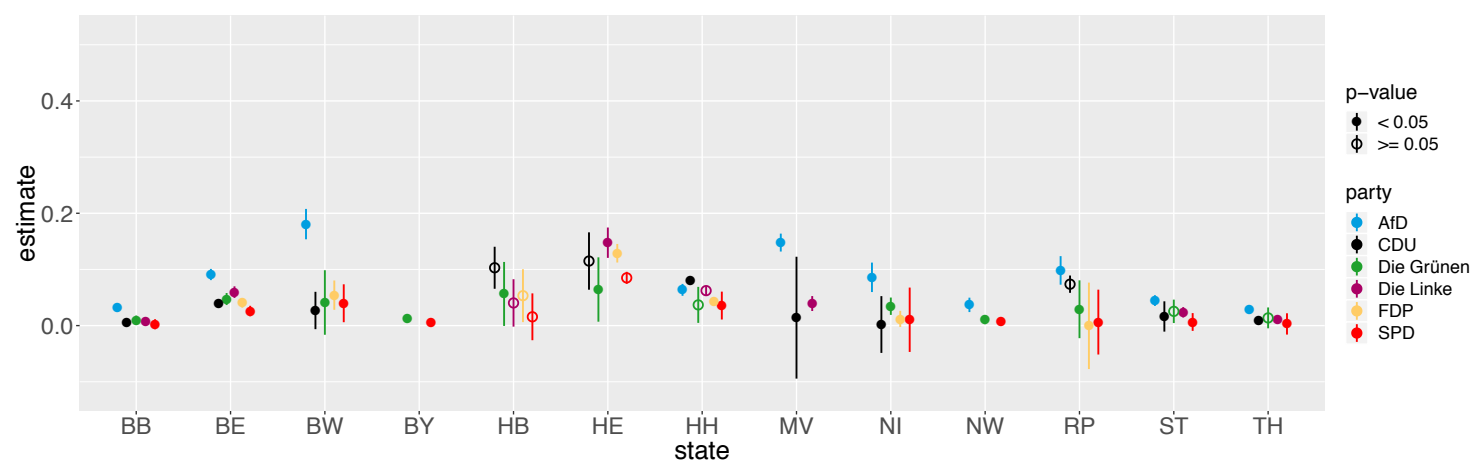

Figure 6-7: Estimate for each party's expected proportion for the policy area migration. The values are not anchored in the intercept.

Since the large increase of refugees in the years of 2015 and 2016, migration became a widely and controversially discussed policy area in Germany. Lees (2018) argues that the migration issue quickly became the main mobilizing impetus of AfD and put aside the prior Anti-EURO topic as the main issue. This thesis takes up this claim; the expected policy area proportions of extremism also support this claim. Figure 6-7 presents quite a variance from 0.028 in Thuringia to 0.181 in Baden-Württemberg and 0.147 too. A topic was only subsumed under migration if it has a very evident link to migration like right of residency or deportation procedures. For example, appellations concerning the criminal activities of refugees are subsumed under law \& order. Consequently, the coefficients do not indicate if a party has a welcoming or rejecting attitude towards immigrants. Parties' may take the stance of reducing 
migration or criticizing deportations which they aim to strengthen through their appellations. While the expected policy area proportion of all other parties takes on a value near zero, the parliamentary group of Die Linke in Hesse is more likely to write an appellation about migration. An example of such an appellation is the printed matter 19/3169 in which the MP Barbara Cárdenas (Die Linke) raises doubts about the claimed voluntary nature of leaving the country towards Afghanistan by rejected asylum seekers.

\section{Social welfare}

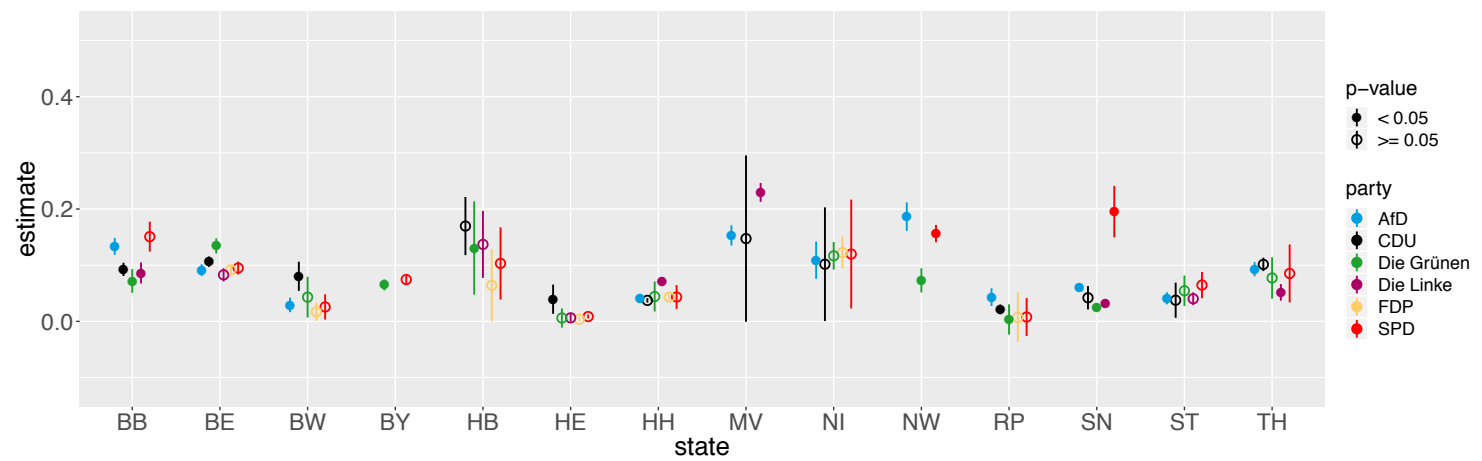

Figure 6-8: Estimate for each party's expected proportion for the policy area social welfare. The values are not anchored in the intercept.

The results for the policy area social welfare in table A.1 and figure 6-8 indicate that the AfD does not solely draw up appellations about the policy areas law \& order and migration. Instead, the MPs of the party on average show more interest in social welfare than their colleagues from other parties. The other parties only contend with certainty against this circumstance in Berlin, Hamburg, and Saxony. Social welfare regards many issues such as low-income assistance, elderly assistance, or childcare; thus, many reasons for the high proportion of the AfD's parliamentary groups are possible. The party's representatives might push forward the debate about how much regular citizens have benefited from the economic upturn in recent years or if these social benefits should be more restricted to a group of people. Showing the effect of party affiliation finishes the part on topic prevalence, the chapter continues with the second part of the analysis on parliamentary speeches and polarization. 


\subsection{Parliamentary speeches and polarization}

This section presents the results with regard to polarization in the state parliaments. First, to what extent MPs's express agreement or disagreement with speeches of their own party and other parties. A second part is dedicated to classifiers' accuracy to determine the degree of polarization and to its feature importance in identifying distinctive terms.

\subsubsection{Who claps for whom}

Looking at the clapping patterns of parliamentary groups is a suitable first opportunity to approach the hypothesis 2 that the AfD's presence leads to higher polarization in a state parliament.

Figure 6-9 illustrates to what extent one party on average honours the speeches given by the MPs of the other parties. It allows to draw a few general conclusions: First, according to the expectations the diagonal of each heatmap reveals that every parliamentary party spends the most applause on its own members. In line with the findings of other work, the state parliaments appear to have a varying culture of applause or more generally a different debate culture (Mielke and Reutter 2004). According to the figure 6-9, the MPs of Baden-Württemberg, Hesse and Hamburg are most keen to clap for their fellow MPs speeches. Second, parliamentary parties who form a coalition government together also partner up during the parliament debate. On the opposition's side we can recognize similar behaviour but far less pronounced. The AfD is a special case, the other parties seemingly try to avoid spending applause for the newcomers in parliament. There is no significant difference observable between parliamentary parties that are part of the state government and those that form the opposition with the AfD. On the contrary, the AfD visibly spends the most applause if an MP of CDU/CSU or FDP speaks and the fewest on MPs of Die Grünen and Die Linke. Third, this observation generalizes to the other parties: political closeness triggers MPs to more likely spend applause. But the coalition-government divide 


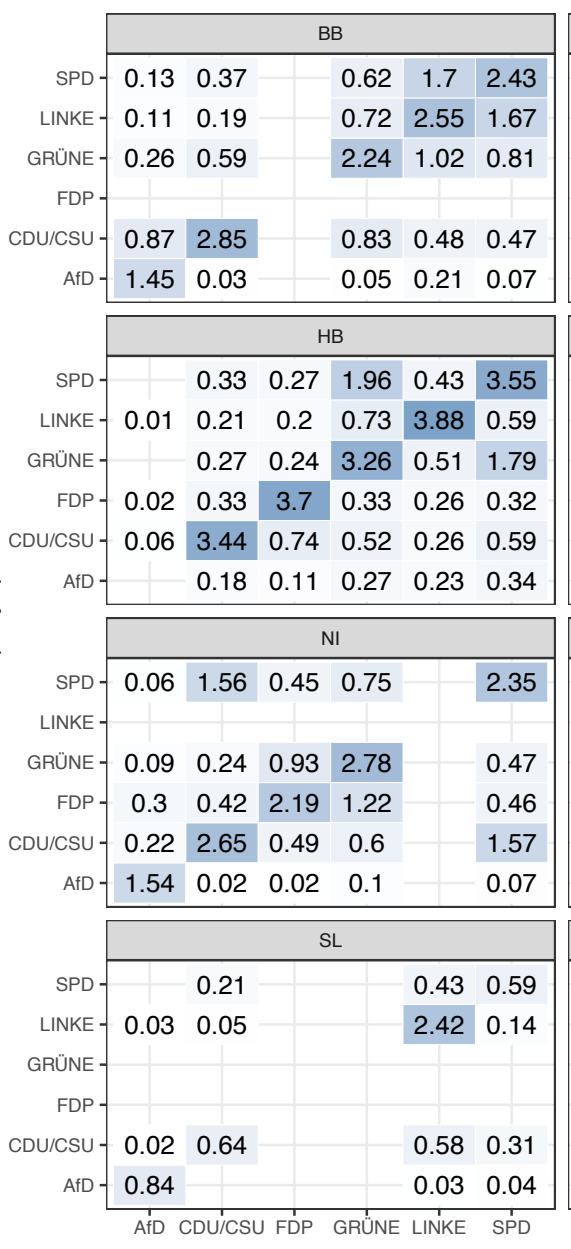

\begin{tabular}{|c|c|c|c|c|c|}
\hline \multicolumn{6}{|c|}{$\mathrm{BE}$} \\
\hline 0.26 & 0.26 & 0.28 & 2.34 & 2.34 & 2.38 \\
\hline 0.22 & 0.14 & 0.16 & 2.35 & 2.74 & 1.79 \\
\hline 0.28 & 0.21 & 0.27 & 2.84 & 2.58 & 2.06 \\
\hline 0.81 & 0.82 & 3.22 & 0.56 & 0.63 & 0.38 \\
\hline 0.68 & 2.07 & 1.1 & 0.38 & 0.36 & 0.28 \\
\hline 2.63 & 0.04 & 0.11 & 0.24 & 0.35 & 0.12 \\
\hline \multicolumn{6}{|c|}{ HE } \\
\hline & 0.5 & 0.6 & 0.55 & 1.57 & 5.08 \\
\hline & 0.21 & 0.09 & 0.21 & 4.55 & 0.91 \\
\hline & 4.2 & 0.22 & 5.29 & 0.52 & 0.66 \\
\hline & 0.66 & 4.62 & 0.5 & 0.51 & 1.03 \\
\hline & 3.4 & 0.2 & 2.83 & 0.28 & 0.35 \\
\hline \multicolumn{6}{|c|}{ NRW } \\
\hline 0.08 & 0.27 & 0.18 & 1.26 & & 2.83 \\
\hline 0.05 & 0.19 & 0.14 & 3.28 & & 1.23 \\
\hline 0.1 & 2.36 & 2.95 & 0.3 & & 0.29 \\
\hline 0.18 & 2.93 & 2.16 & 0.32 & & 0.32 \\
\hline 2.85 & 0.02 & 0.02 & 0.09 & & 0.05 \\
\hline \multicolumn{6}{|c|}{ SN } \\
\hline 0.06 & 0.64 & & 0.28 & 0.33 & 1.05 \\
\hline 0.04 & 0.1 & & 0.23 & 0.94 & 0.06 \\
\hline 0.07 & 0.13 & & 1.47 & 0.51 & 0.19 \\
\hline 0.18 & 1.17 & & 0.16 & 0.27 & 0.57 \\
\hline 0.51 & 0.04 & & 0.04 & 0.08 & 0.01 \\
\hline
\end{tabular}

\begin{tabular}{|c|c|c|c|c|c|}
\hline \multicolumn{6}{|c|}{ BW } \\
\hline 0.89 & 0.92 & 1.19 & 1.32 & & 3.49 \\
\hline 0.41 & 2.85 & 0.34 & 4.15 & & 0.78 \\
\hline 1.8 & 0.68 & 3.21 & 0.75 & & 0.86 \\
\hline 0.84 & 3.69 & 0.71 & 3.35 & & 0.81 \\
\hline 4.73 & 0.19 & 0.08 & 0.59 & & 0.22 \\
\hline \multicolumn{6}{|c|}{$\mathrm{HH}$} \\
\hline 0.13 & 0.47 & 0.34 & 3.97 & 0.31 & 4.53 \\
\hline 0.06 & 0.23 & 0.2 & 0.48 & 3.61 & 0.5 \\
\hline 0.07 & 0.31 & 0.19 & 3.77 & 0.27 & 3.51 \\
\hline 0.51 & 1.29 & 3.14 & 0.35 & 0.2 & 0.61 \\
\hline 0.57 & 3.59 & 1.21 & 0.4 & 0.2 & 0.66 \\
\hline 1.45 & 0.04 & 0.03 & 0.03 & 0.04 & 0.05 \\
\hline \multicolumn{6}{|c|}{$\mathrm{RP}$} \\
\hline 0.09 & 0.26 & 1.33 & 1.54 & & 1.5 \\
\hline 0.09 & 0.14 & 1.24 & 1.6 & & 1.29 \\
\hline 0.09 & 0.26 & 1.46 & 1.42 & & 1.3 \\
\hline 1.01 & 4.31 & 0.36 & 0.56 & & 0.43 \\
\hline 2.22 & 0.02 & 0.02 & 0.09 & & 0.1 \\
\hline \multicolumn{6}{|c|}{ ST } \\
\hline 0.29 & 0.64 & & 1.02 & 0.62 & 1.92 \\
\hline 0.22 & 0.15 & & 0.48 & 3.47 & 0.27 \\
\hline 0.13 & 0.32 & & 1.99 & 0.58 & 0.41 \\
\hline 0.6 & 1.94 & & 0.44 & 0.23 & 0.45 \\
\hline 2.4 & 0.08 & & 0.16 & 0.16 & 0.06 \\
\hline
\end{tabular}

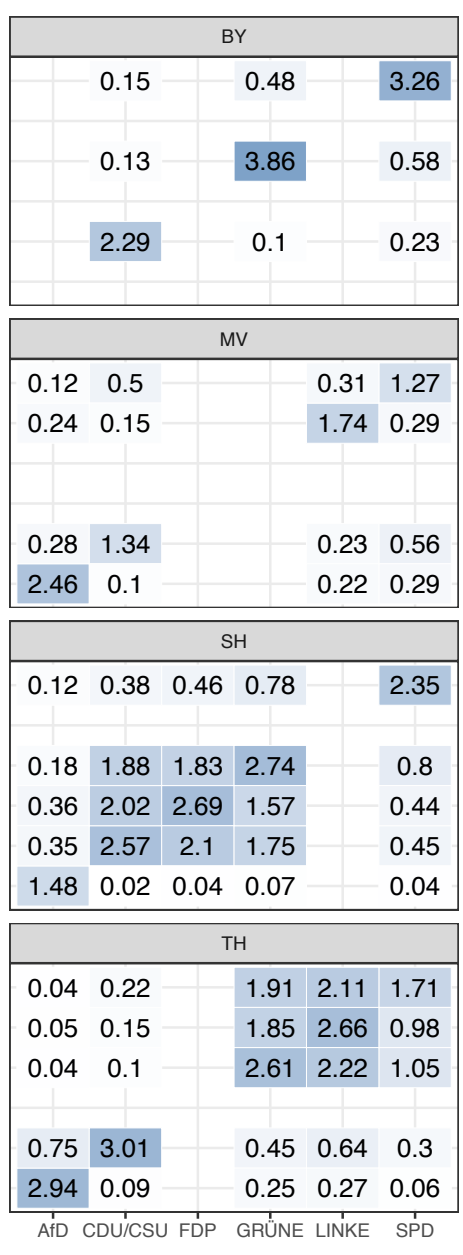

AfD CDUICSU FDP GRÜNE LINKE SPD

$\begin{array}{lllllll}\text {...with this frequency } & 1 & 2 & 3 & 4 & 5\end{array}$

Figure 6-9: One heatmap per state with the average number of applause a party receives from the other parties. 
supersedes in general.

\section{Polarization score}

The level of self-affirmation, by clapping for party colleagues MPs can represent the maximum degree of agreement parliamentary groups are willing to express. By the same logic, clapping given to other parties expresses to what extent their speeches polarize. Few claps suggest that the party perceives the content of the speech giving party as polarizing, and vice versa.

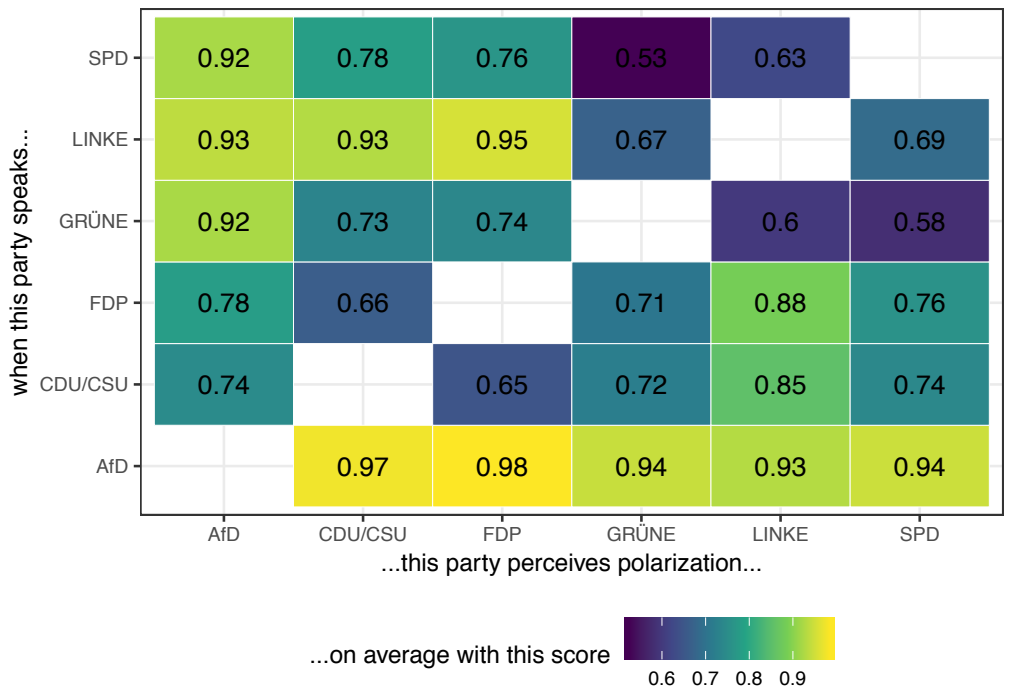

Figure 6-10: Polarization scores average over states by party pairs. Low values indicate low polarization.

Figure 6-10 displays the computed polarization values per party pair as derived in the research design chapter. The first row from below indicates to what extent the other parties receive speeches from the AfD as polarizing, which is what the polarization score reflects for all pairs of parties per state. According to the perceived polarization by party, AfD's speeches are strongly polarizing. Interestingly, as the first column from the left shows, this does not apply in this absoluteness to the other direction. The AfD receives speeches from CDU and FDP as significantly less polarizing as those from Die Grünen, Die Linke and SPD. In general, it is striking to see that the closer parties are along the traditional left-right political spectrum (see 
CDU/FDP and Die Grünen, Die Linke and SPD) the more the score decreases.

\begin{tabular}{lcccccccccccccccc}
\hline state & $\mathrm{BB}$ & $\mathrm{BE}$ & $\mathrm{BW}$ & $\mathrm{BY}$ & $\mathrm{HB}$ & $\mathrm{HE}$ & $\mathrm{HH}$ & $\mathrm{MV}$ & $\mathrm{NI}$ & $\mathrm{NW}$ & $\mathrm{RP}$ & $\mathrm{SH}$ & $\mathrm{SL}$ & $\mathrm{SN}$ & $\mathrm{ST}$ & $\mathrm{TH}$ \\
\hline \#1 score & 0.78 & 0.73 & 0.64 & 0.87 & 0.81 & 0.77 & 0.86 & 0.73 & & 0.78 & 0.63 & 0.67 & 0.86 & 0.73 & 0.84 & 0.85 \\
\#2 score & 0.75 & 0.72 & 0.75 & 0.91 & 0.86 & 0.81 & 0.83 & 0.82 & 0.79 & 0.84 & 0.65 & 0.69 & 0.84 & 0.80 & 0.84 & 0.72 \\
\hline
\end{tabular}

Table 6.1: polarization score per state calculated as stated in equation (5.4). The lack of interjections for the first legislative period of NI makes the score incomputable. Aside from BY and $\mathrm{HE}$, the second score is for a legislative period in which the AfD forms a parliamentary group.

The polarization scores for each state is given in table 6.1 where the first score represents the first legislative period and the second one the successive legislative period. From the first to the second legislative period, the numbers reveal a general increase in polarization in the German state legislature. It is ambiguous, whether this uptick is due to the AfD's move into the parliaments or not. Baden-Württemberg, Mecklenburg-Western Pomerania and North Rhine-Westphalia's polarization scores suggest this, but the control states of Bavaria and Hesse reach a higher score as well.

\subsubsection{Who provokes the most}

Table 6.2 lists the top three politicians ranked after the average amount of interjections they receive during a speech. The level of differences between the states are once again an indicator for a different debate culture in the state parliaments. In the case of Mecklenburg-Western Pomerania, the high level of interjections might be an expression of practice that the MPs have gathered during the dispute with the NPD in the previous legislative period.

It is striking that many politicians from the AfD rank among the top three in comparison to the party's vote share in a single state parliament and in the state parliaments overall. Considering the fact that the party is not present in the parliament of Bavaria and Hesse and that it does not form a parliamentary group in Bremen, the party's politicians occupy around $33 \%$ of the remaining top three positions. This number is clearly above the party's vote share in the state parliaments.

The regional associations of the AfD in Brandenburg, Saxony-Anhalt and Thuringia who lean towards the movement-wing of the party seem to realize the strategy of 


\begin{tabular}{llll}
\hline state & No. 1 & No. 2 & No. 3 \\
\hline BB & Senftleben, CDU (4.5) & Gauland, AfD (3.8) & Ness, SPD (3.7) \\
BE & Kapek, GRÜNE (4.8) & Pazderski, AfD (4.5) & Kerker, AfD (2.5) \\
BW & Meuthen, AfD (5.3) & Schwarz, GRÜNE (5.2) & Gögel, AfD (5) \\
BY & Kreuzer, CSU (3) & Baumgärtner, CSU (2.5) & Huber, CSU (2.5) \\
HB & Özdal, CSU (2.1) & Röwekamp, CSU (1.6) & Strohman, CSU (1.3) \\
HE & Alex, SPD (4.9) & Weiß, SPD (3.5) & Pentz, CDU (3.4) \\
HH & Dressel, SPD (1.5) & Trepol, CDU (1.4) & Münster, SPD (1.3) \\
NI & Toepffer, CDU (1.7) & Piel, GRÜNE (0.8) & Guth, AfD (0.8) \\
NW & Löttgen, CDU (9.1) & Kerkhoff, CDU (4.2) & Stinka, SPD (3.5) \\
MV & Holm, AfD (8.4) & Fernandes, AfD (5.8) & Oldenburg, LINKE (5.8) \\
RP & Schweitzer, SPD (3.9) & Klöckner, CDU (3.4) & Dr. Braun, GRÜNE (3) \\
SH & Hölck, SPD (2.9) & Koch, CDU (2.9) & Kubicki, FDP (2.5) \\
SL & Lafontaine, LINKE (1.8) & Dörr, AfD (1.5) & Hans, CDU (0.9) \\
SN & Gebhardt, LINKE (4.4) & Kupfer, CDU (3.4) & Spangenberg, AfD (2.5) \\
ST & Backhaus, AfD (4) & Farle, Afd (2.2) & Scheurell, CDU (2.1) \\
TH & Mohring, CDU (8) & Hennig-Wellsow, LINKE (6.9) & Höcke, AfD (4.8) \\
\hline
\end{tabular}

Table 6.2: First three politicians per state who receive on average the most interjections that are not applause.

fundamental opposition, if we take their high ranking positions as measurement. For the regional associations that supposedly lean towards the parliamentary-oriented wing of the party a general strategy is not evident. While the party's MPs in RhinelandPalatinate and North Rhine-Westphalia do not rank among the top three, their fellow MP's in Berlin have even two high-ranking representatives.

\subsubsection{The parties' sentiment}

In this thesis, the third perspective to look at polarization in parliament is the parties' use of negative language. Figure 6-11 portrays the parties' share of negative language use in each legislative periods and reveals new findings: First, government parties evidently use less negative language than the opposition in their speeches. Most parliamentary parties in government have a share below 40\%. This finding aligns with the fact that MPs of the government parties usually support the government's political aims and have to vote in favour of their legislation. It also fits with the second finding that parliamentary parties' share of negative language increases or decreases respectively, when they change from government to opposition or vice versa. Examples 


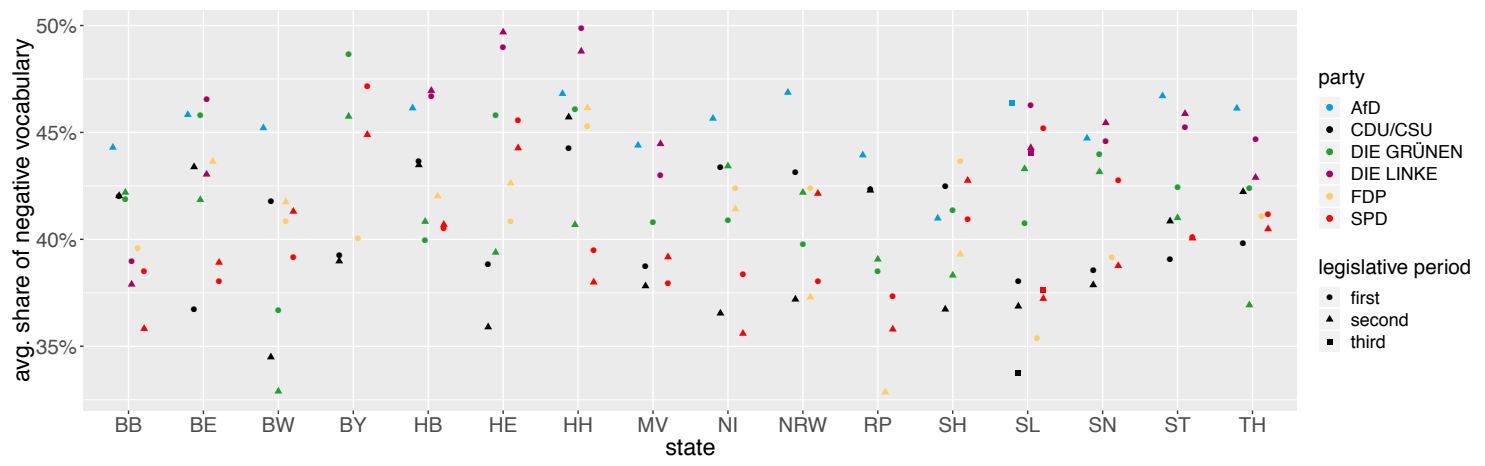

Figure 6-11: Parties' negative language share in each legislative period.

for this change are the CDU and SPD in Baden-Württemberg or the CDU in Lower Saxony. Consistent with this change is that the parliamentary parties' share remains remarkably stable, when the role of the group does not change between legislative periods. To exemplify, CDU and Die Grünen in Brandenburg and most parties in Bremen have almost the same share of negative language in both legislative periods. The last finding is that, except for the city state Bremen, the AfD possess the highest share of negative language of all opposition parties. A mere time effect is also unlikely as the parties' share in the control states Bavaria and Hesse do not change much or only decrease.

\subsubsection{AfD's distinctiveness}

This last section of the results presents the findings of the classifiers that were trained to distinguish between non-AfD and AfD speeches. Figure 6-12 displays the metrics of the classifier accuracy, precision and recall for each state. We can draw the insight that the accuracy scores are consistently higher than a random guess. All three scores of Bremen are not usable, because the AfD's parliamentary group quickly disbanded itself after the start of the legislative period. The sample size is too small for valid metrics. In most states the precision score is higher than the recall score. This means in plain English, that the classifier is better at not mistaking non-AfD speeches as speeches from the AfD than correctly recognizing AfD's speeches as such. Considering the fact that the non-AfD speeches are coming from up to five other parties it is remarkable 


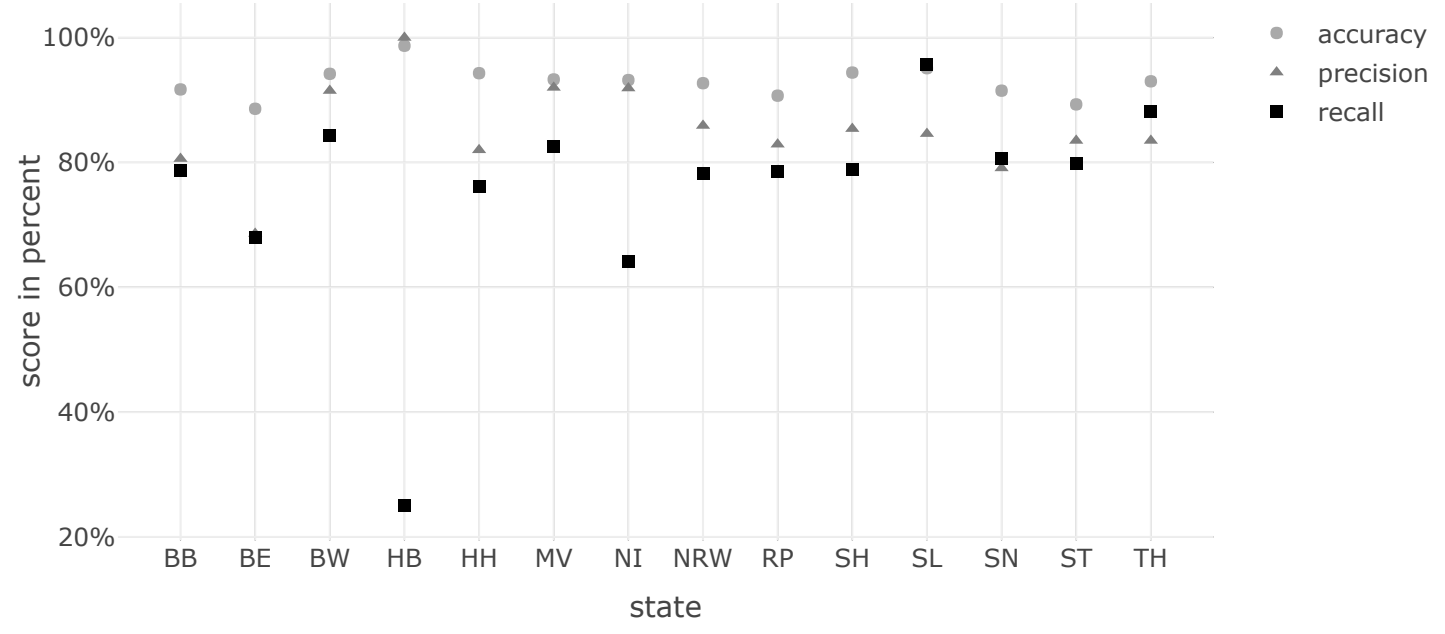

Figure 6-12: Classifer's accuracy, precision and recall per state.

that the classifier manages to find such a strong distinctiveness for non-AfD speches. With these scores it is justified to assume that the classifier found distinct terms to discriminate between both groups.

Which words the classifiers find most decisive to identify AfD (positive label) or non-AfD speeches, the figures 6-13 and 6-14 show them for Baden-Württemberg and Saxony. The word rankings reveal that the most distinctive feature between the AfD and non-AfD groups is the form of address: Without exception MP's of the AfD usually start their speech with "Sehr geehrte Damen und Herren" (Dear Sir or Madam) while the MPs of the other parties more likely begin with "Liebe Kolleginnen und Kollegen" (Dear colleagues [female gendered] or colleagues [male gendered]). This pattern of a diverging form of address goes beyond the beginning of an ordinary speech of the AfD. The AfD's MPs generally use the generic masculinum of German to address the citizens (in German: Bürger) or the students (Studenten).

There is a second group of words across the state parliaments that distinguish the AfD and non-AfD speeches. For instance, the AfD's MPs rely on the terms EU (European Union), Steuerzahler (tax payer) and Werte (values) in their speeches. Another popular word is Deutschland (Germany) and Sogenannten (so-called) in North Rhine-Westphalia. Interestingly, according to the classifier's results for the feature importance, the term Altparteien (parties of the establishment) is only distinct 
for the AfD's parliamentary group in Thuringia. Limitations and a general discussion of the results presented in this chapter are parts of the following chapter.

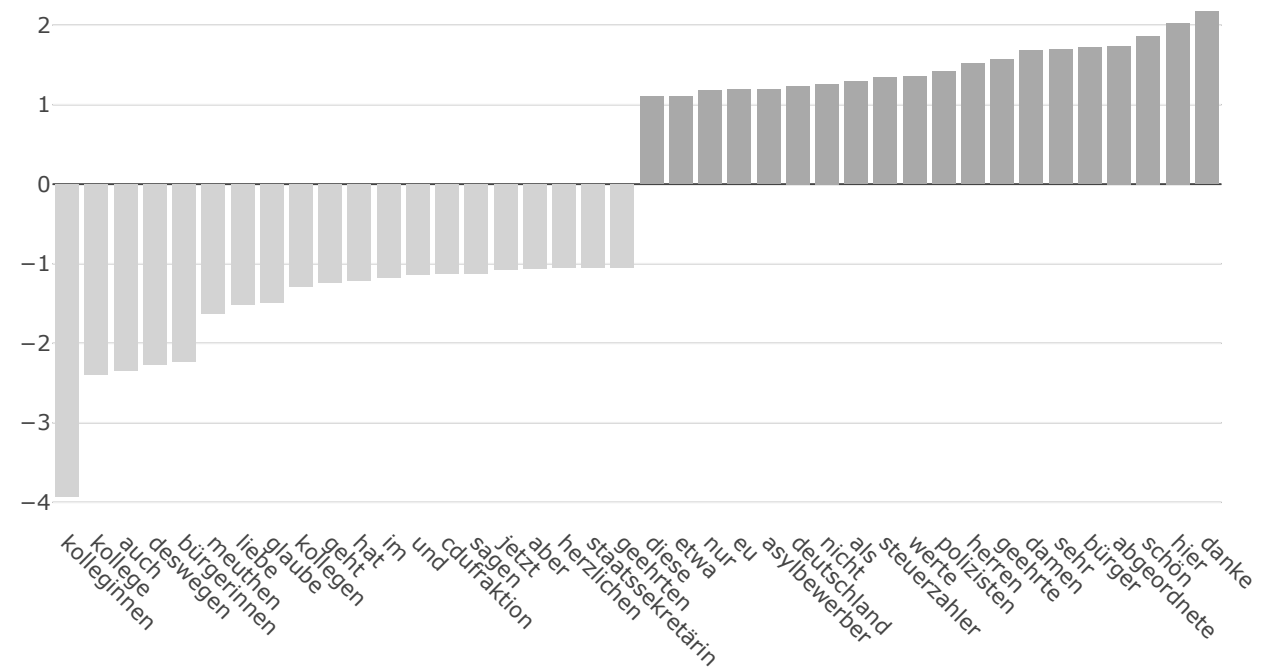

Figure 6-13: Feature importance of the classifier for Baden-Württemberg.

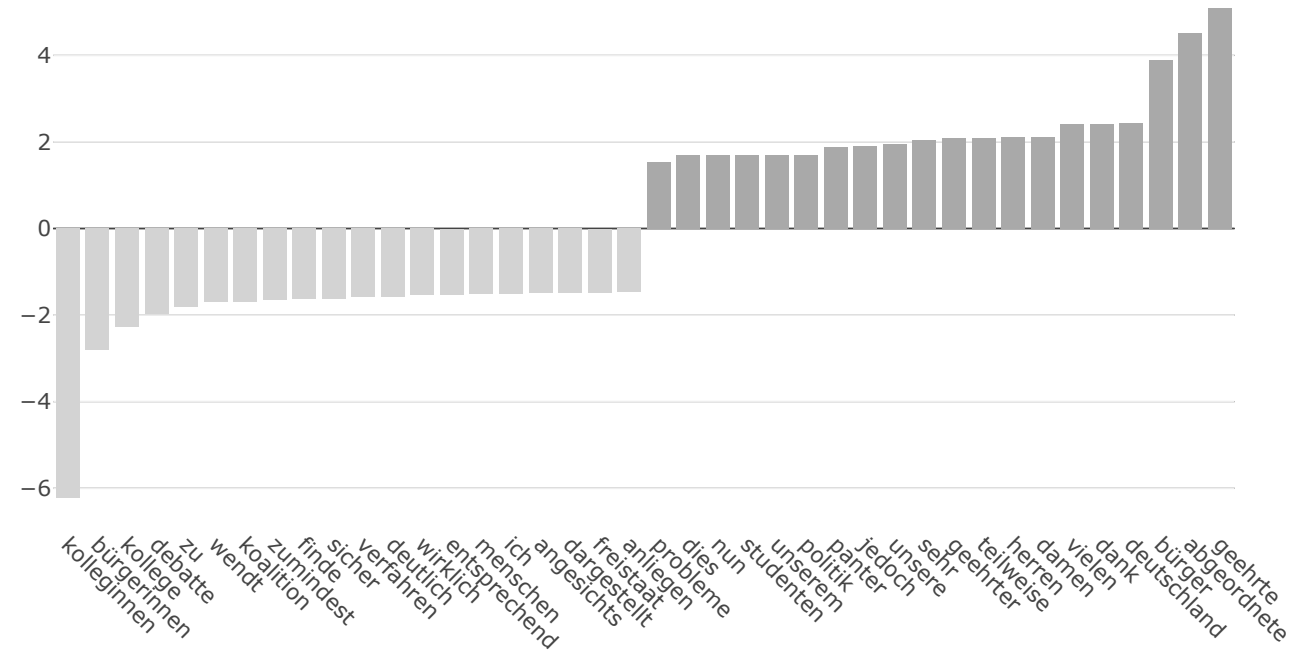

Figure 6-14: Feature importance of the classifier for Saxony. 


\section{$7 \quad$ Discussion}

Adapting to the two-fold structure of this thesis, the following discussion also consists of one part on appellations and topic prevalence, and of a second part on parliamentary speeches and polarization.

\subsection{Appellations and topic prevalence}

The findings of this thesis indicate that the parties do focus on different policy areas in their appellations. As one might expect, AfD's MPs are more likely to draw appellations about the policy areas law \& order and migration than the other parties. Generally, the MPs of the AfD try to preserve their images as anti-establishment through their parliamentary practice. They seem to choose policy areas in their appellations that are suitable to portray themselves as the actual representative of the people. Which policy area is suited best for this purpose depends up on the state. Opportunities are the installation of wind turbines or the extension of the power grid. In terms of policy area proportions these findings partly contradict the finding of Schroeder, Weßels, Neusser, et al. (2017) who only report a deviation of the AfD for migration but not for law \& order and other policy areas. Taking into consideration that the results of this thesis are based on data that covers a longer period of time and includes more states, it is justifiable to assume that the findings of this thesis might prevail. Comparison of a range of model specifications showed that the findings are robust against changes to model parameters. But these findings are not without limitations either. The existence of unrecognizable words after the conversion from PDF to plain text does obstruct the STM to a certain extent and makes the utilization 
of the resulting STMs more difficult. Another limitation is that a meaning could not be found for all discovered topics. One cause for this are enumerations with the same items. Future research on the state's appellations should be able to find a strategy to avoid these phenomena without losing content. We further estimated the party effect by using a simple linear regression for each state and made general deductions from the regression results for all states. Deductions across models are difficult, which one might possibly make unnecessary with a mixed-effects model that includes the policy area proportions in the model. Such an approach however would demand an in-depth contemplation about the research design; especially it would have to be considered if the expected policy area proportions for appellations resulting from different STMs could simply be used together or if this would require a different model for the discovery of the topics as well.

\subsection{Parliamentary speeches and polarization}

The second part of the results suggests that the AfD's move into a state parliament leads to a higher polarization in this parliament. It is unexpected that the classifier is able to distinguish between speeches from the AfD and the other parties with such a high precision. Specifically given the fact that we only applied a linear classifier instead of a non-linear classifier. In terms of accuracy Peterson and Spirling (2018) show that other classifiers do not necessarily lead to a higher accuracy. Nonetheless, the linguistic distinctiveness determined by our classifiers is a bit plain. A classification algorithm that is more capable of capturing linguistic nuances would eventually enrich the distinctiveness with more interesting terms, but such non-linear classifiers do not provide a feature importance whose dimensions can be directly filled with meaning.

The search for an adequate measurement of polarization in the state parliaments contained the assessment of a model classifying each pair of parties in a single parliament. The idea is to treat AfD's move into the parliaments as an exogenous shock that eventually changes the distinctness of two parties from the legislative period without the AfD to the legislative period with the party belonging to the 
parliament. The accuracy scores however do not change considerable between the legislative periods, if the AfD's move into the parliaments is the only considerable change. They do change significantly if and only if the state experiences a change in the constellation of parties in power. If a pair of parties had formed a coalition in the previous legislative period, but do not continue this coalition in the successive legislative period the classifier's accuracy to distinguish between the two increases significant. Generally, pairs of parties that govern together are more difficult to distinguish than pairs where one party belongs to the government and the other to the opposition. This observation supports the finding of this thesis that MPs are more likely to acknowledge another MP with applause if they both belong to the government or the opposition side of the parliament. Both findings suggest that the government-opposition cleavage is very strong in parliaments, but does not hold for the AfD as opposition party. An opportunity to enhance this part of the analysis could be to examine how the demonstration of agreement and disagreement with a speech potentially changes according to the item on the agenda. Such a research question would require a processing of the plenary protocols that records to which item the speaker speaks. This seems trivial to achieve at first, but in practice to create such a scraper is complex and challenging.

Besides enlarging the features gained through the processing of the plenary protocols, the analysis would probably benefit from a data set that covers a longer time span, i.e. including more previous legislative periods. Such an extension of the time period for example would allow to analyze the move to the state parliament by Bündnis 90/Die Grünen in the eighties. Presumably the party's move also had an effect on the topic prevalence and polarization in the German state parliaments. A comparison of both political events would likely produce results that show similarities and differences and subsequently improves the political theory regarding the effect of new parties on the German state parliaments. Pappi, Kurella, and Bräuninger (2019) did such a comparison for the early electoral success of both parties showing that this approach is well-founded. The following concluding remarks complete this thesis. 


\section{Conclusion}

This thesis addressed the research question of how the politicians and parliamentary groups of the AfD effect the sixteen state parliaments in Germany. The focal points were: Which political issues parties emphasize and how polarized the state parliaments are.

Minor appellations served as text-as-data for the topic prevalence part as MPs can freely choose the issue of their inquiry. As a result, of all political instruments of the state parliaments, the minor appellations should report best a diverging emphasis of parties. Parliamentary speeches were the text-as-data to measure polarization from three different angles. The results obtained from the STM provide strong evidence for

hypothesis 1 that the AfD puts their primary focus on different policy areas in the appellations than their fellow MPs from the other parties. AfD's MPs in particular but not exclusively, favor the policy areas extremism, migration, and law \& order. Depending on the circumstances in the state, they also focus on other policy areas like environment \& energy, if the policy area possesses populist potential. Concerning the methodology, the STM produced reliable results.

Equally, the second part of the results supports hypothesis two that the entrance of the AfD into a state parliament leads to a higher degree of polarization. The pattern of applause indicates that the AfD and non-AfD parliamentary blocks unite in their mutual aversion. It is remarkable how well the polarization scores map the parties on the traditional left-right dimension, despite the scores' simplicity. It would be also enriching to examine, if specific political issues attract more reactions than others.

A second proof that the AfD is not only another opposition party shows the share of AfD MPs who receive many interjections on average during their speeches. Provocation 
appears to be more a general strategy for many AfD parliamentary groups than an exception. Differences between the party's regional associations possibly indicate a different attittude towards the other parties too, strengthening the argument in the literature of bipolar strategy between fundamental opposition and the willingness to engage in parliamentary work (Schroeder, Weßels, Neusser, et al. 2017). Taking the speeches' distinctiveness as a measure, the polarization in the state parliaments is also high. Along a different language use, that explicitly surfaces in the form of address, gender-sensitive language, and specific terms, the SVM classifier can distinguish impressively between AfD and non-AfD speeches.

Far fewer studies focus on the state parliaments than on the German Bundestag. Concerning the division of law-making power between the state and federal levels, the research question often determines the legislative body of interest. However, with the appearance and success of the AfD throughout Germany, scholars started to pay more attention to the state parliaments. Only in 2018 did the AfD move into the last two state parliaments of Bavaria and Hesse, explaining the lack of literature on the party's political issues in the state parliaments and perception by the other parties. This thesis is the first in this regard beginning to close the research gap. By the end of 2019, the AfD's parliamentary groups in Brandenburg, Bremen, Saxony, and Thuringia begin their second terms in parliaments mostly with huge gains, a sign that the party is not a short term political phenomenon. In a few years, the data availability will allow estimating the AfD's effect on the state parliaments more precisely, and maybe regional differences become more visible.

In the meantime, researchers can focus on comparing the AfD and Die Grünen, distilling the similarities and differences between their moves into the state parliaments. A cross-level analysis between the party's effect on the Bundestag and the state parliaments is also worth considering. Another possible branch of research is if the AfD has an effect on which particular policies the state governments pursue. Similar to the first wins of parliamentary seats by the AfD, the first participation in a German government most likely would occur on the state level. Quantitative text analysis would undoubtedly be a promising opportunity to examine the consequences of such 
a disruptive political event. 
A Tables 
Table A.1:

\begin{tabular}{|c|c|c|c|c|c|c|c|c|c|c|c|c|c|c|}
\hline & & BB & $\mathrm{BE}$ & $\mathrm{BW}$ & BY & $\mathbf{H E}$ & $\mathbf{H H}$ & NI & NW & $\mathbf{R P}$ & SH & SN & $\mathrm{ST}$ & TH \\
\hline \multirow{12}{*}{ 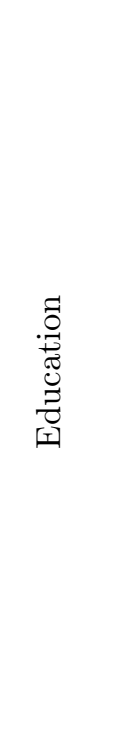 } & $\mathrm{AfD}$ & $0.026^{* * *}$ & $0.075^{* * *}$ & $0.028^{* *}$ & & & $0.066^{* * *}$ & $0.054^{* * *}$ & $0.086^{* * *}$ & $0.152^{* * *}$ & $0.080^{* *}$ & $0.073^{* * *}$ & $0.082^{* * *}$ & $0.073^{* * *}$ \\
\hline & & $(0.005)$ & $(0.005)$ & $(0.01)$ & & & $(0.006)$ & $(0.016)$ & $(0.012)$ & $(0.018)$ & $(0.027)$ & $(0.003)$ & $(0.008)$ & $(0.007)$ \\
\hline & $\mathrm{CDU}$ & $0.017^{* *}$ & $-0.026^{* * *}$ & 0.027 & & 0.074 & 0.012 & 0.088 & & 0.031 & 0.026 & -0.011 & 0.004 & $0.070^{* * *}$ \\
\hline & & $(0.004)$ & $(0.004)$ & $(0.017)$ & & $(0.036)$ & $(0.003)$ & $(0.048)$ & & $(0.012)$ & $(0.125)$ & $(0.014)$ & $(0.025)$ & $(0.007)$ \\
\hline & Die Grünen & $-0.004^{* * *}$ & $-0.017^{*}$ & $0.083^{* *}$ & $0.090^{* * *}$ & $0.058^{* *}$ & -0.028 & 0.009 & 0.006 & -0.074 & 0.029 & -0.005 & 0.001 & -0.012 \\
\hline & & $(0.007)$ & $(0.006)$ & $(0.03)$ & $(0.006)$ & $(0.045)$ & $(0.018)$ & $(0.012)$ & $(0.011)$ & $(0.04)$ & $(0.079)$ & $(0.003)$ & $(0.021)$ & $(0.022)$ \\
\hline & Die Linke & 0.004 & $-0.031^{* * *}$ & & & 0.029 & $0.020^{*}$ & & & & & $-0.030^{* * *}$ & $0.060^{* * *}$ & -0.020 \\
\hline & & $(0.006)$ & $(0.005)$ & & & $(0.017)$ & $(0.004)$ & & & & & $(0.002)$ & $(0.009)$ & $(0.009)$ \\
\hline & FDP & & $-0.031^{* * *}$ & $0.059^{* * *}$ & & 0.050 & -0.002 & $0.057^{* *}$ & & $0.173^{* *}$ & 0.159 & & & \\
\hline & & & $(0.004)$ & $(0.013)$ & & $(0.012)$ & $(0.004)$ & $(0.012)$ & & $(0.061)$ & $(0.145)$ & & & \\
\hline & SPD & 0.015 & $0.021^{* * *}$ & $0.121^{* * *}$ & $0.058^{* * *}$ & 0.092 & $0.038^{*}$ & -0.010 & $0.060^{* * *}$ & $0.129^{*}$ & $0.102^{* *}$ & 0.050 & $0.061^{* *}$ & $0.116^{* * *}$ \\
\hline & & $(0.009)$ & $(0.006)$ & $(0.018)$ & $(0.005)$ & $(0.008)$ & $(0.018)$ & $(0.048)$ & $(0.008)$ & $(0.05)$ & $(0.02)$ & $(0.028)$ & $(0.018)$ & $(0.028)$ \\
\hline \multirow{7}{*}{ 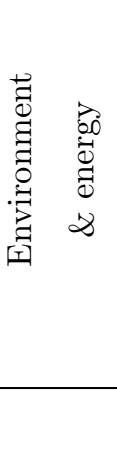 } & AfD & $0.041^{* * *}$ & & $0.051^{* * *}$ & & & & $0.109^{* * *}$ & $0.098^{* * *}$ & $0.073^{* * *}$ & $0.138^{* * *}$ & $0.003^{* * *}$ & $0.173^{* * *}$ & $0.042^{* * *}$ \\
\hline & & $(0.007)$ & & $(0.009)$ & & & & $(0.018)$ & $(0.011)$ & $(0.012)$ & $(0.028)$ & $(0.001)$ & $(0.009)$ & $(0.005)$ \\
\hline & $\mathrm{CDU}$ & $0.043^{* * *}$ & & 0.005 & & 0.082 & & $0.282^{* * *}$ & & -0.023 & -0.045 & 0.001 & 0.054 & 0.005 \\
\hline & & $(0.006)$ & & $(0.015)$ & & $(0.022)$ & & $(0.064)$ & & $(0.008)$ & $(0.121)$ & $(0.003)$ & $(0.028)$ & $(0.004)$ \\
\hline & Die Grünen & $0.248^{* * *}$ & & 0.035 & $0.070^{* * *}$ & $0.008^{* * *}$ & & $0.057^{*}$ & $0.091^{* * *}$ & $0.194^{* * *}$ & -0.136 & $0.004^{* * *}$ & -0.047 & $0.057^{* * *}$ \\
\hline & & $(0.013)$ & & $(0.028)$ & $(0.004)$ & $(0.028)$ & & $(0.016)$ & $(0.01)$ & $(0.028)$ & $(0.074)$ & $(0.001)$ & $(0.022)$ & $(0.017)$ \\
\hline & & Note: & see the fo & lowing e & lanation & interp & etation $\mathrm{i}$ & tructions & & & & \multicolumn{3}{|c|}{${ }^{*} \mathrm{p}<0.05 ;{ }^{* *} \mathrm{p}<0.01 ;{ }^{* * *} \mathrm{p}<0.00$} \\
\hline
\end{tabular}




\begin{tabular}{|c|c|c|c|c|c|c|c|c|c|c|c|c|c|c|}
\hline & & BB & $\mathrm{BE}$ & BW & BY & $\mathrm{HE}$ & $\mathbf{H H}$ & NI & NW & $\mathbf{R P}$ & SH & $\mathrm{SN}$ & $\mathrm{ST}$ & TH \\
\hline & \multirow[t]{2}{*}{ Die Linke } & $0.059^{* * *}$ & & & & -0.019 & & & & & & 0.0002 & $-0.113^{* * *}$ & 0.006 \\
\hline & & $(0.01)$ & & & & $(0.011)$ & & & & & & $(0)$ & (0.009) & $(0.006)$ \\
\hline & \multirow[t]{2}{*}{ FDP } & & & $0.066^{* * *}$ & & 0.007 & & -0.005 & & 0.094 & -0.124 & & & \\
\hline & & & & $(0.012)$ & & $(0.007)$ & & $(0.014)$ & & $(0.049)$ & $(0.128)$ & & & \\
\hline & \multirow[t]{2}{*}{ SPD } & $0.041^{* * *}$ & & -0.030 & $-0.025^{* * *}$ & $-0.052^{*}$ & & 0.008 & $-0.034^{* *}$ & 0.072 & 0.013 & 0.005 & $-0.051^{* *}$ & $0.079^{* * *}$ \\
\hline & & $(0.012)$ & & $(0.014)$ & $(0.003)$ & $(0.005)$ & & $(0.057)$ & $(0.007)$ & $(0.036)$ & $(0.02)$ & $(0.006)$ & $(0.018)$ & $(0.022)$ \\
\hline \multirow{9}{*}{ 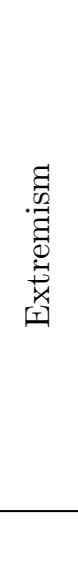 } & \multirow[t]{2}{*}{ AfD } & $0.087^{* * *}$ & $0.011^{* * *}$ & $0.109^{* * *}$ & & & $0.161^{* * *}$ & $0.056^{* * *}$ & $0.288^{* * *}$ & & $0.158^{* * *}$ & $0.110^{* * *}$ & $0.054^{* * *}$ & $0.034^{* * *}$ \\
\hline & & $(0.007)$ & $(0.002)$ & $(0.011)$ & & & $(0.005)$ & $(0.013)$ & $(0.013)$ & & $(0.024)$ & $(0.004)$ & $(0.008)$ & $(0.005)$ \\
\hline & \multirow[t]{2}{*}{$\mathrm{CDU}$} & $-0.074^{* * *}$ & -0.004 & $-0.098^{* * *}$ & & 0.072 & $-0.152^{* * *}$ & -0.053 & & & -0.153 & $-0.059^{* *}$ & -0.041 & $-0.018^{* *}$ \\
\hline & & $(0.005)$ & $(0.002)$ & $(0.013)$ & & $(0.024)$ & $(0.001)$ & $(0.035)$ & & & $(0.09)$ & $(0.019)$ & $(0.022)$ & $(0.005)$ \\
\hline & \multirow[t]{2}{*}{ Die Grünen } & $-0.074^{* * *}$ & 0.003 & $-0.057^{* * *}$ & $0.114^{* * *}$ & $-0.019^{*}$ & $-0.150^{* * *}$ & 0.020 & $-0.190^{* * *}$ & & $0.201^{*}$ & $-0.014^{*}$ & $0.078^{* * *}$ & $0.087^{* * *}$ \\
\hline & & $(0.009)$ & $(0.003)$ & $(0.024)$ & $(0.006)$ & $(0.025)$ & $(0.01)$ & $(0.011)$ & $(0.009)$ & & $(0.089)$ & $(0.004)$ & $(0.02)$ & $(0.02)$ \\
\hline & \multirow[t]{2}{*}{ Die Linke } & $0.101^{* * *}$ & $0.011^{* *}$ & & & 0.003 & $-0.138^{* * *}$ & & & & & $0.019^{* * *}$ & $0.087^{* * *}$ & $0.097^{* * *}$ \\
\hline & & $(0.009)$ & $(0.003)$ & & & $(0.011)$ & $(0.002)$ & & & & & $(0.003)$ & $(0.009)$ & $(0.008)$ \\
\hline & & Note: & see the fo & lowing exp & lanation $\mathrm{fo}$ & or interpr & tation inst & tructions & & & & $\mathrm{p}<0.05$ & $\mathrm{p}<0.01$ & ${ }^{*} \mathrm{p}<0.001$ \\
\hline
\end{tabular}




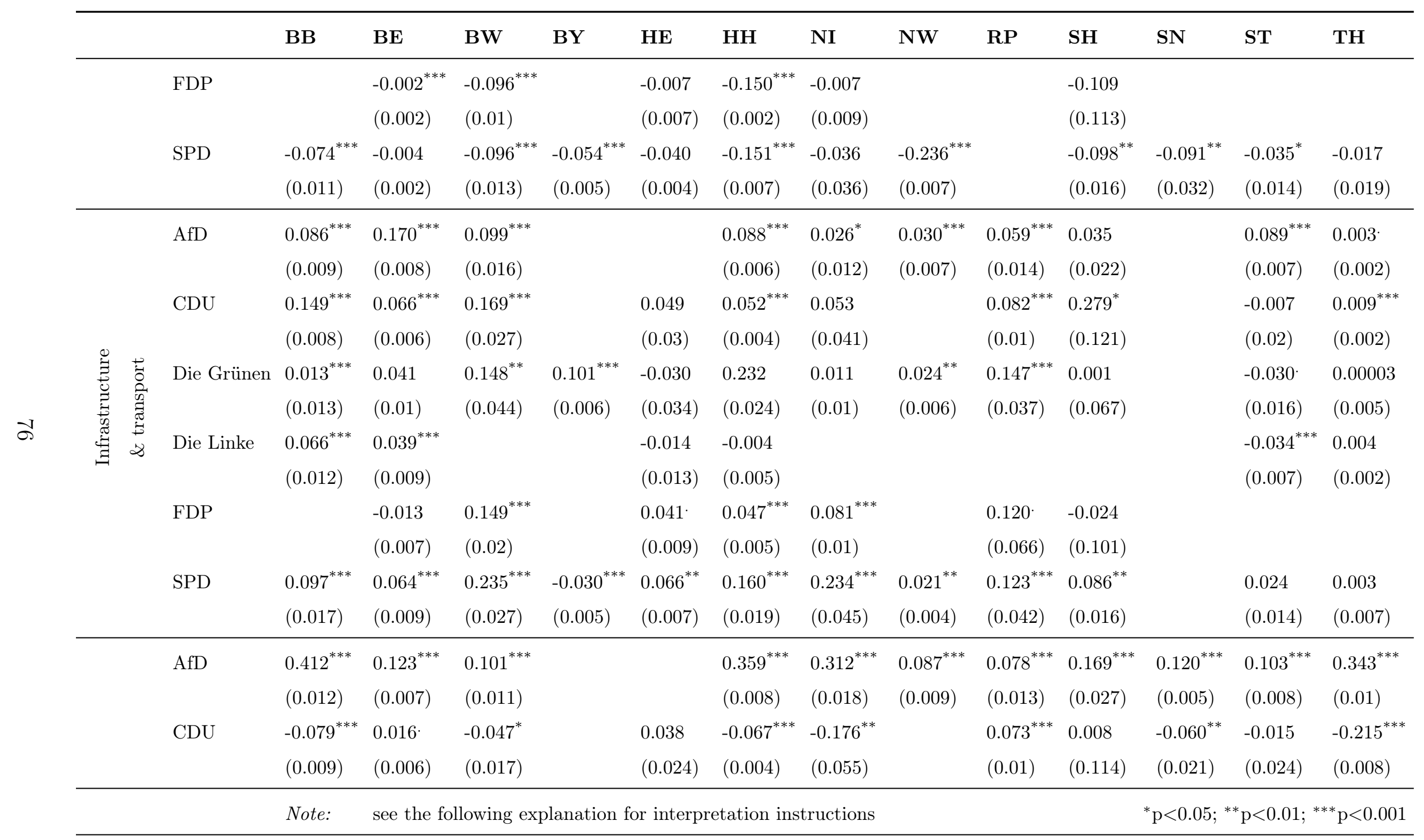




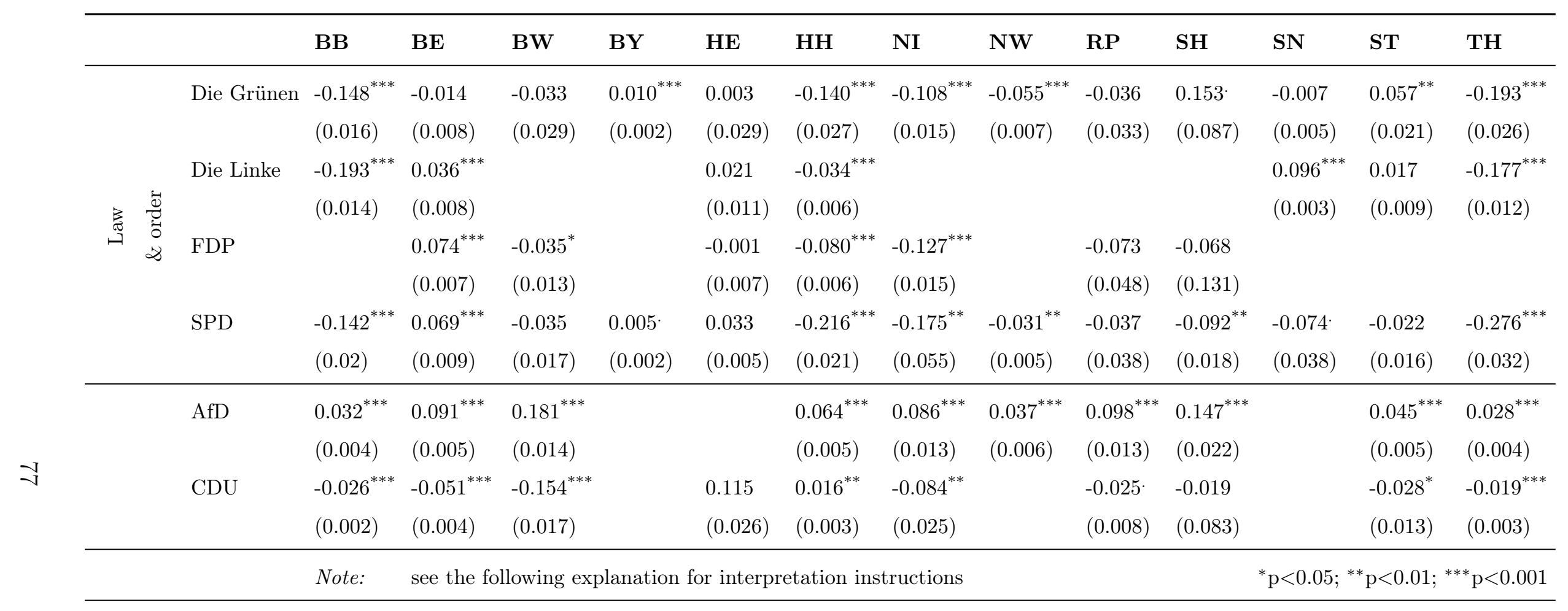




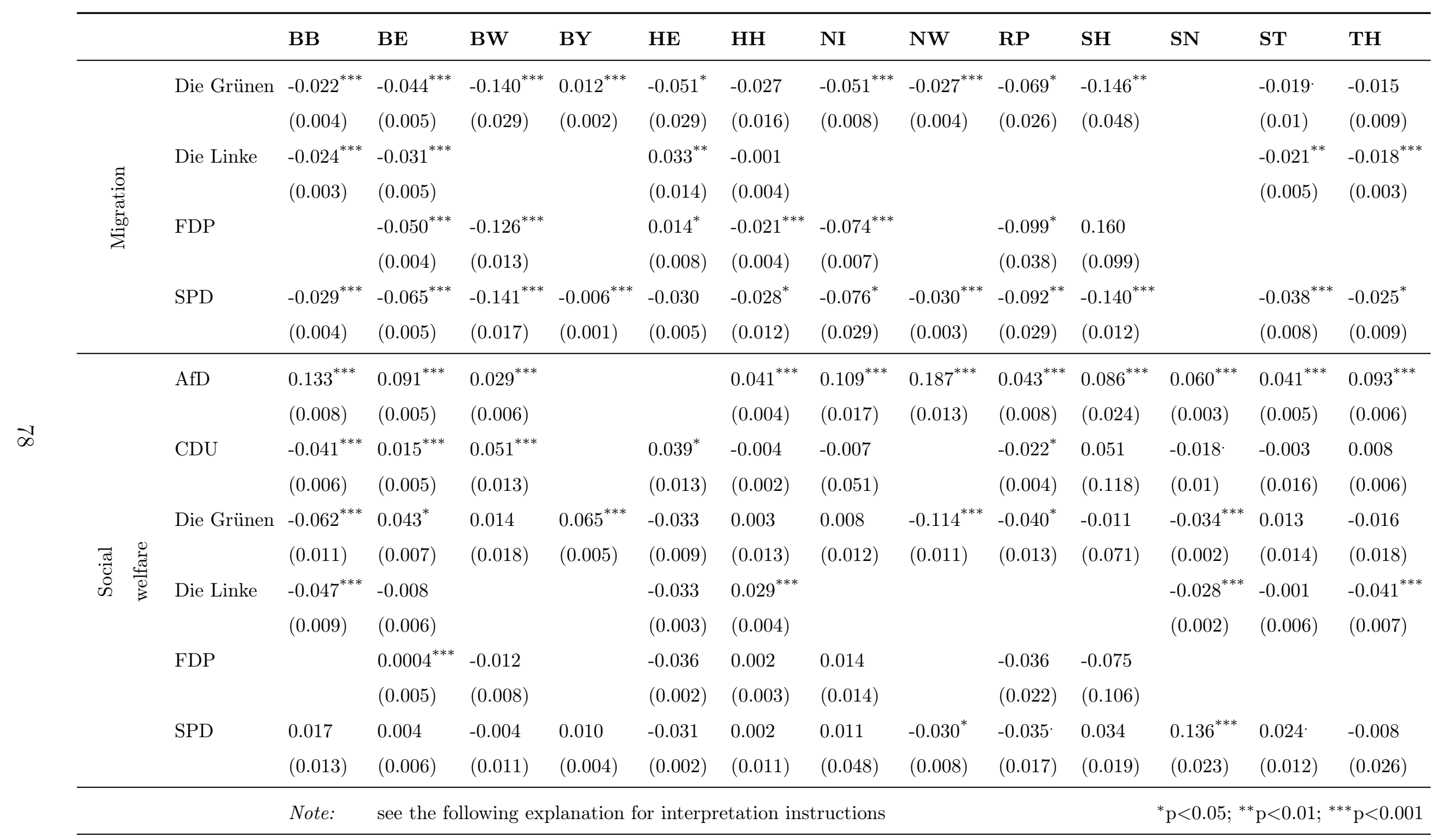




\section{Explanation to table A.1}

The first number (bold) is always the intercept and we interpret the following numbers like a regular regression interpretation. For example, if we look at the policy area education and find the column for RP, we see the intercept is 0.152 which indicates the expected proportion of education for an unseen appellation that originates from the AfD. For the SPD we would expect a proportion 0.129 higher compared to the AfD. A different case is BYfor the same policy area where the number 0.090 for Die Grünen is the intercept and where we would expect again a higher proportion by 0.058 for SPD.

Table A.2: Most representative words for each topic in the state parliament of Brandenburg

\begin{aligned} & \hline topic words \\ & \hline 1 Highest Prob frage, landesregierung, potsdam, anfrage, drucksache, brandenburg, antwort \\ & FREX ev, fbb, landeshauptstadt, strecke, ber, db, planungen \\ & Lift fahrgäste, linienführung, ortsumfahrung, ortsumgehung, regionalverkehr, ev, fahrplan \\ & Score ev, fbb, mio, infrastruktur, ministerin, landeshauptstadt, landesplanung \\ & FREX ges, aq, waffg, ingebrauchnahme, unbefugte, ao, erf \\ & Lighest Prob anzahl, diebstahl, aq, insg, einschl, ges, tv \\ & Score $\quad$ waffg, diebstahl, aq, ingebrauchnahme, unbefugte, kiosken, warenhäusern \\ & Highest Prob potsdam, cottbus, frankfurt, brandenburg, frage, gu, spree-neiße \\ & FREX gu, stpo, cottbus, einstellung, königs, spree-neiße, eberswalde \\ & Lift gu, flüchtlingsunterbringung, erledigung, waßmannsdorf, finanzämtern, strafbefehl, \\ & Score gu, stpo, einstellung, sta, anklage, versg, landkreis \end{aligned}

4 Highest Prob betriebe, anzahl, verstoß, kontrollen, kontrolle, gülle, verstöße

FREX gülle, mw, kontrollen, besonderem, betriebe, kontrolle, mg

Lift mw, gülle, tierhalter, ställen, ställe, stall, veterinär

Score mw, gülle, rinder, sauen, bimschg, mg, tiere

$5 \quad$ Highest Prob frage, landesregierung, brandenburg, drucksache, anfrage, antwort, landtag

FREX afd-fraktion, verfassungsschutz, erkenntnisse, hamburg, minister, gefährder, jung 
Table A.2: Most representative words for each topic in the state parliament of Brandenburg

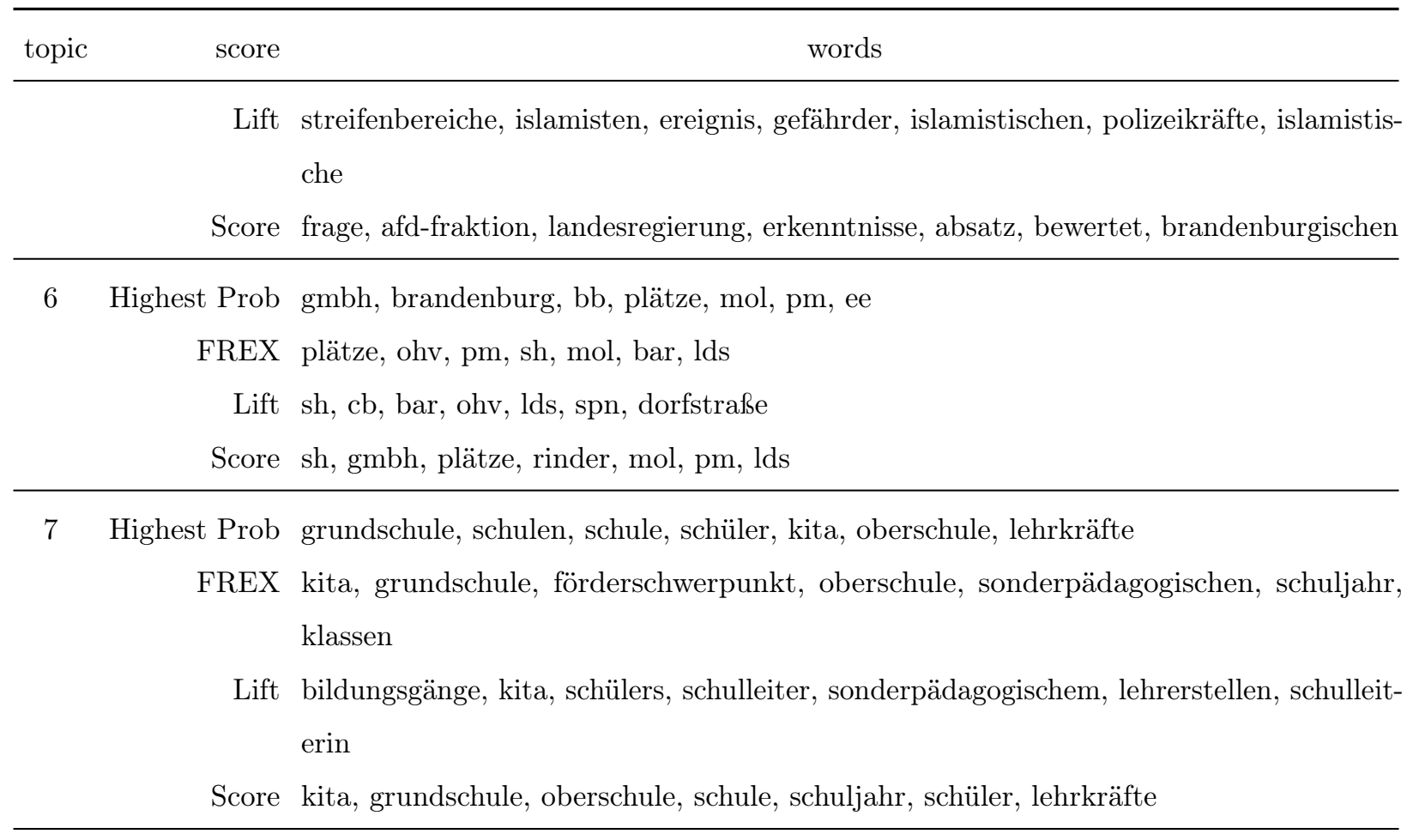

8 Highest Prob polizeirevier, polizeiinspektion, revierdienst, polizeidirektion, brandenburg, anlage, bad

FREX polizeirevier, revierdienst, polizeiinspektion, polizeidirektion, flughafen, schönefeld, belzig

Lift personenschaden, revierdienst, a.d, polizeidirektion, flughafen, schönefeld, aufgeklärt

Score polizeirevier, revierdienst, polizeiinspektion, personenschaden, polizeidirektion, insg, diebstahl

9 Highest Prob staatsangehörigkeit, tatverdächtige, seite, opfer, auszug, polizeilichen, weiblich

FREX staatsangehörigkeit, tatverdächtige, weiblich, auszug, aufgliederung, polizeilichen, opfer

Lift weiblich, aufgliederung, häuslichen, auszug, staatsangehörigkeit, tatverdächtige, polizeilichen

Score weiblich, tatverdächtige, staatsangehörigkeit, opfer, auszug, polizeilichen, korea

10 Highest Prob stgb, körperverletzung, anzahl, dauern, ermittlungen, straftaten, npd

FREX dauern, npd, kundgebung, demonstration, sene, erwach, versammlung

Lift dauern, mahnwachen, neonazistischen, unterstützerinnen, abgeordnetenbüros, asylkritische, infostände 
Table A.2: Most representative words for each topic in the state parliament of Brandenburg

\begin{tabular}{|c|c|c|}
\hline topic & score & words \\
\hline & Score & dauern, stgb, npd, kundgebung, körperverletzung, ermittlungen, straftaten \\
\hline \multirow[t]{4}{*}{11} & Highest Prob & fälle, eds, gesamt, frage, aufgeklärte, anzahl, revierbereich \\
\hline & FREX & $\begin{array}{l}\text { häufigkeitskennzahlen, strukturveränderungen, polizeireform, deliktsfelder, aufgeklärte, } \\
\text { polizeiwache, revierbereich }\end{array}$ \\
\hline & Lift & $\begin{array}{l}\text { geschäftsdienst, polizeiinternen, aufgabenbelastung, gewässergrenzen, allgemein- } \\
\text { polizeiliche, dienstpostenverteilung, direktionsstabs }\end{array}$ \\
\hline & Score & eds, revierbereich, häufigkeitskennzahlen, unerl, deliktsfelder, aufgeklärte, unbaren \\
\hline \multirow[t]{5}{*}{12} & Highest Prob & gesamt, frage, landkreis, de, page, stadt, verkehrsunfälle \\
\hline & FREX & funk, verkehrsunfälle, feuerwehr, feuerwehren, verletzte, brand, freiwilligen \\
\hline & Lift & katastrophenschutzgesetz, funk, rettungsdienstes, feuerwehren, katastrophenschutzes, \\
\hline & & bbgbkg, feuerwehr \\
\hline & Score & funk, verkehrsunfälle, feuerwehr, feuerwehren, verletzte, landkreis, freiwilligen \\
\hline \multirow[t]{4}{*}{13} & Highest Prob & stellen, prev, dienst, frage, dav, pi, gesamt \\
\hline & FREX & prev, dav, verfahrensdauer, gerichtsbarkeit, eingänge, altersabgänge, richterinnen \\
\hline & Lift & $\begin{array}{l}\text { gerichtsbarkeiten, sozialgerichtsbarkeit, arbeitsgerichte, gerichtsbarkeit, prev, verwal- } \\
\text { tungsgerichtsbarkeit, dav }\end{array}$ \\
\hline & Score & prev, dav, richter, pi, planstellen, verfahrensdauer, eingänge \\
\hline
\end{tabular}

14 Highest Prob stadt, amt, gemeinde, ortsteil, landkreis, brandenburg, gemeinden

FREX ortsteil, gemeinde, amt, mark, einwohner, ruhland, schaden

Lift ortsteil, ortsteile, rietz-neuendorf, waldsieversdorf, seelow-land, gartz, döbern-land

Score ortsteil, gemeinde, stadt, mark, landkreis, eur, amt

15 Highest Prob frage, brandenburg, jeweils, hochschulen, bitte, gefangenen, jva

FREX rbb, gefangenen, gefangene, jva, justizvollzugsanstalten, anstalt, hochschulen

Lift beamter, luckau-duben, studiengänge, hochschulgesetzes, akademischen, studiengängen, akademische

Score hochschulen, gefangenen, jva, gefangene, justizvollzugsanstalten, rbb, anstalt

16 Highest Prob nr, abs, frage, polizei, brandenburg, fälle, straftaten

FREX jagdwilderei, staatsanwaltschaft, beschuldigten, ermittlungsverfahren, verurteilungen, gespeicherten, waffen 
Table A.2: Most representative words for each topic in the state parliament of Brandenburg

\begin{aligned} \hline topic & score \\ \hline Lift & jagdwilderei, strafverfolgungsbehörden, gespeicherten, beschuldigte, verfahrensregister, \\ & verurteilungen, dunkelziffer \\ Score & jagdwilderei, straftaten, stpo, staatsanwaltschaft, person, ermittlungsverfahren, ver- \\ & fahren \end{aligned}

17 Highest Prob diebstahl, insgesamt, insg, st, stgb, sonstiger, straftaten

FREX tatverdächtiger, is, nichtdeutscher, bbgpolg, ie, computerbetrug, berichtsjahr

Lift bbgpolg, is, ie, ti, berichtsjahr, häuslicher, ra

Score bbgpolg, diebstahl, insg, bsd, unerl, eds, stgb

18 Highest Prob lk, ot, gmbh, lb, la, teltow, ruppin

FREX lk, lb, ruppin, ostprignitz, ot, la, oderland

Lift lb, mittelmark, lk, ruppin, ostprignitz, oderland, entgelt

Score $\mathrm{lb}$, lk, ot, gmbh, lws, gbr, wasser

19 Highest Prob frage, landesregierung, brandenburg, drucksache, umwelt, bzw, maßnahmen

FREX flächen, windkraftanlagen, hektar, abfälle, gewässer, wea, wka

Lift deponien, naturschutzgebieten, pflanzenarten, ackerflächen, bergrechtlichen, ffh-gebiet, ffh-gebiete

Score landwirtschaft, flächen, ländliche, türen, hektar, lfu, genehmigung

20 Highest Prob personen, aufenthg, abs, person, frage, anfrage, anlage

FREX aufenthg, ausreisepflichtige, gründe, islamische, ehemals, person, vii

Lift ausländerzentralregister, ausreisepflichtige, aufenthaltsgestattung, ausreise, herkunftsländer, ausreisepflichtig, islamische

Score aufenthg, aufenthaltsgestattung, ausreisepflichtige, person, republik, serbien, asylanträge

21 Highest Prob straftaten, frage, politisch, stgb, rechts, landesregierung, anzahl

FREX fremdenfeindlich, gegner, phänomenbereich, extremistisch, taten, gewalttaten, politisch

Lift meldeschluss, extremistisch, gewaltstraftat, linksmotivierter, linkszu, asylthematik, einzeltäter

Score straftaten, fremdenfeindlich, einzeltäter, pmk-rechts, phänomenbereich, gegner, motivierte 
Table A.2: Most representative words for each topic in the state parliament of Brandenburg

\begin{tabular}{lll}
\hline topic score & words \\
\hline
\end{tabular}

22 Highest Prob diebstahl, insg, sonstiger, st, seite, schlüsselzahl, bsd

FREX schlüsselzahl, sonstiger, computerbetrug, 25t, erlangter, 50t, rechtswidrig

Lift infaus, schlüsselzahl, geschlechtsstruktur, internetkriminalität, zugänglichmachen, jugdl, erwachs

Score diebstahl, schlüsselzahl, bsd, insg, eds, umst, erschw

23 Highest Prob eds, diebstahl, insg, unerl, bsd, sonstiger, gemäß

FREX revierpolizei, aufgekl, methamphet, kapselform, ecstasy, amphet, revier

Lift auswert, bahngruppen, bandenm.handeln, debitkarten, deliktsfel, einsät, erschütt

Score eds, unerl, bsd, revierpolizei, diebstahl, erschw, unbaren

24 Highest Prob titel, kapitel, euro, eur, anlage, nr, ausgaben

FREX titel, deckung, ansatz, mittelabfluss, kapitel, epl, zweckbestimmung

Lift zit-bb, ansatzes, bezügestelle, zweckbestimmung, mittelabfluss, abgeflossen, titelgruppe

Score kapitel, titel, deckung, eur, mittelabfluss, ansatz, epl

25 Highest Prob e.v, brandenburg, stiftung, förderung, potsdam, bildung, kultur

FREX jugendarbeit, stiftung, kulturelle, tolerantes, verein, e.v, lottomitteln

Lift sächliche, tolerantes, beratungsnetzwerk, kultureller, lottomitteln, künstlerinnen, künstler

Score e.v, stiftung, jugendarbeit, sächliche, kultur, verein, rechtsextremismus

26 Highest Prob km, landesstraßen, brandenburg, frage, bitte, ca, maßnahmen

FREX landesstraßen, bundesfernstraßen, ou, bundesstraßen, km, ortsdurchfahrten, wahlkreis

Lift bundesfern, bw, zeb, abgestuft, aktualisierenden, aufstockte, ausgelassen

Score landesstraßen, bw, km, wahlkreis, ou, ortsdurchfahrten, bundesstraßen

27 Highest Prob frage, brandenburg, landesregierung, land, kinder, kreisfreien, frauen

FREX versorgung, sgb, erstaufnahmeeinrichtung, minderjährigen, patienten, ärzte, ambulanten

Lift gesundheitsämtern, wohneinheiten, asylbewerberleistungsgesetzes, erstattungsverordnung, gesundheitsämter, inobhutnahme, jugendämter

Score sgb, frauen, wohneinheiten, versorgung, flüchtlinge, soziales, familie

28 Highest Prob gründung, erbringung, verwaltung, handel, fischerei, wasserversorgung, neu 
Table A.2: Most representative words for each topic in the state parliament of Brandenburg

\begin{aligned} \hline topic & words \\ \hline FREX & wasserversorgung, erbringung, fischerei, gründung, gastgewerbe, gesundheits, gewerbe \\ Lift & energieversorgung, fr, abwasserentsorgung, wasserversorgung, gastronomie, gast- \\ & gewerbe, fischerei \\ Score & fr, fischerei, wasserversorgung, gründung, erbringung, gastgewerbe, energieversorgung \\ \hline 29 Highest Prob & brandenburg, frage, landesregierung, land, entwicklung, förderung, unternehmen \\ FREX & ländlichen, programm, regionen, produkte, europäischen, förderprogramm, förderperi- \\ & ode \\ Lift & förderanträgen, rennwett, westdeutschland, eu-förderperiode, innovationsstrategie, \\ & arbeitslose, handlungsfelder \\ Score & unternehmen, wirtschaft, gefördert, projekte, prozent, mio, entwickelt \\ \hline Highest Prob & projektförderung, gebiete, kulap, gmbh, e.v, gbr, umstellung \\ FREX & projektförderung, kulap, gebiete, naturnahe, landbau, umstellung, ökologischer \\ Lift & kulap, förderverein, projektförderung, naturnahe, forstwirtschaftliche, ökologischer, \\ landbau & projektförderung, kulap, förderverein, gmbh, gebiete, naturnahe, gbr \\ Score & \end{aligned}




\section{B Figures}


Model diagnostics by number of topics for BB and $n=3923$

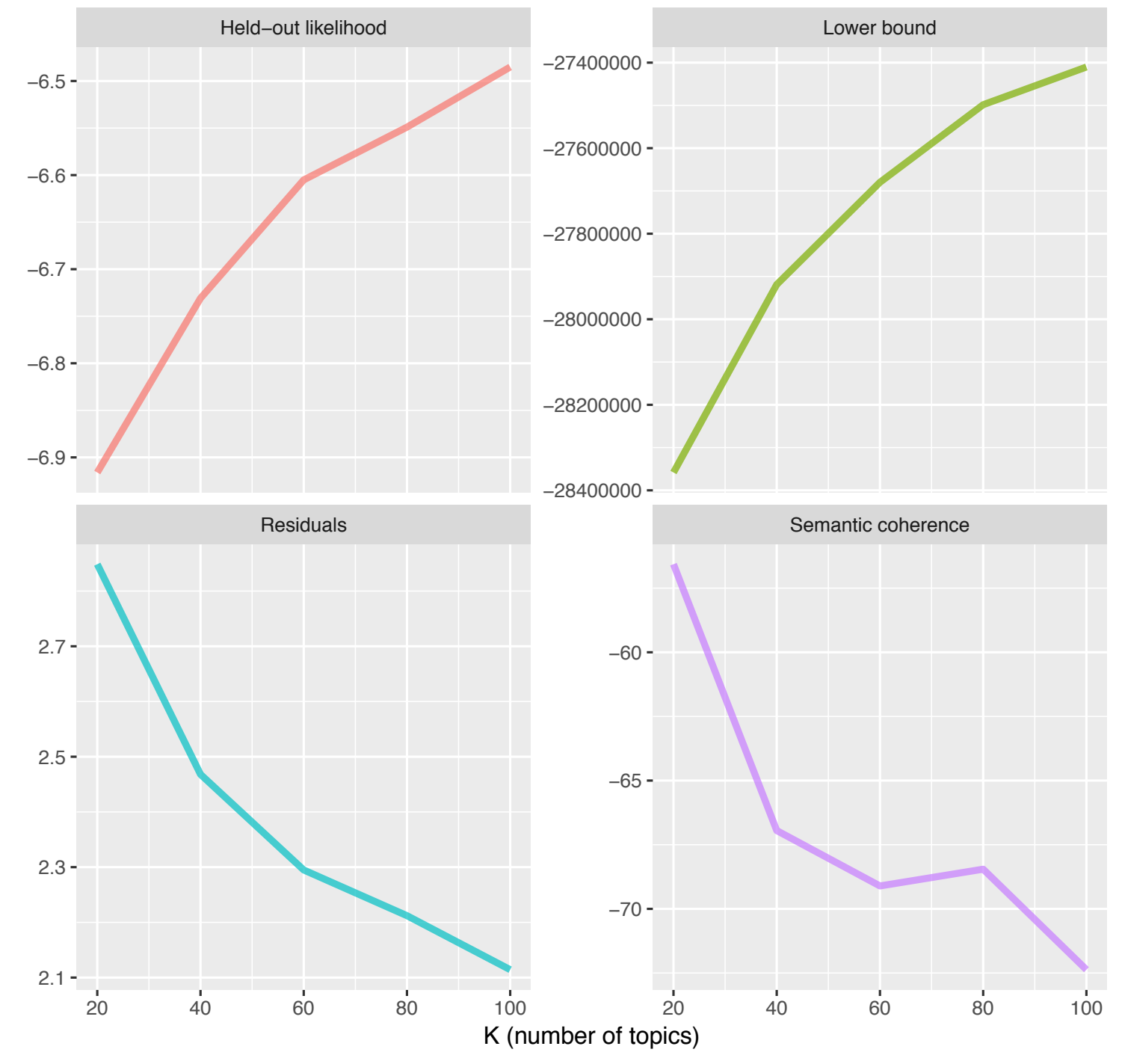

Figure B-1: Held-out likelihood, lower bound, residuals and semantic coherence for a span of number of topics 


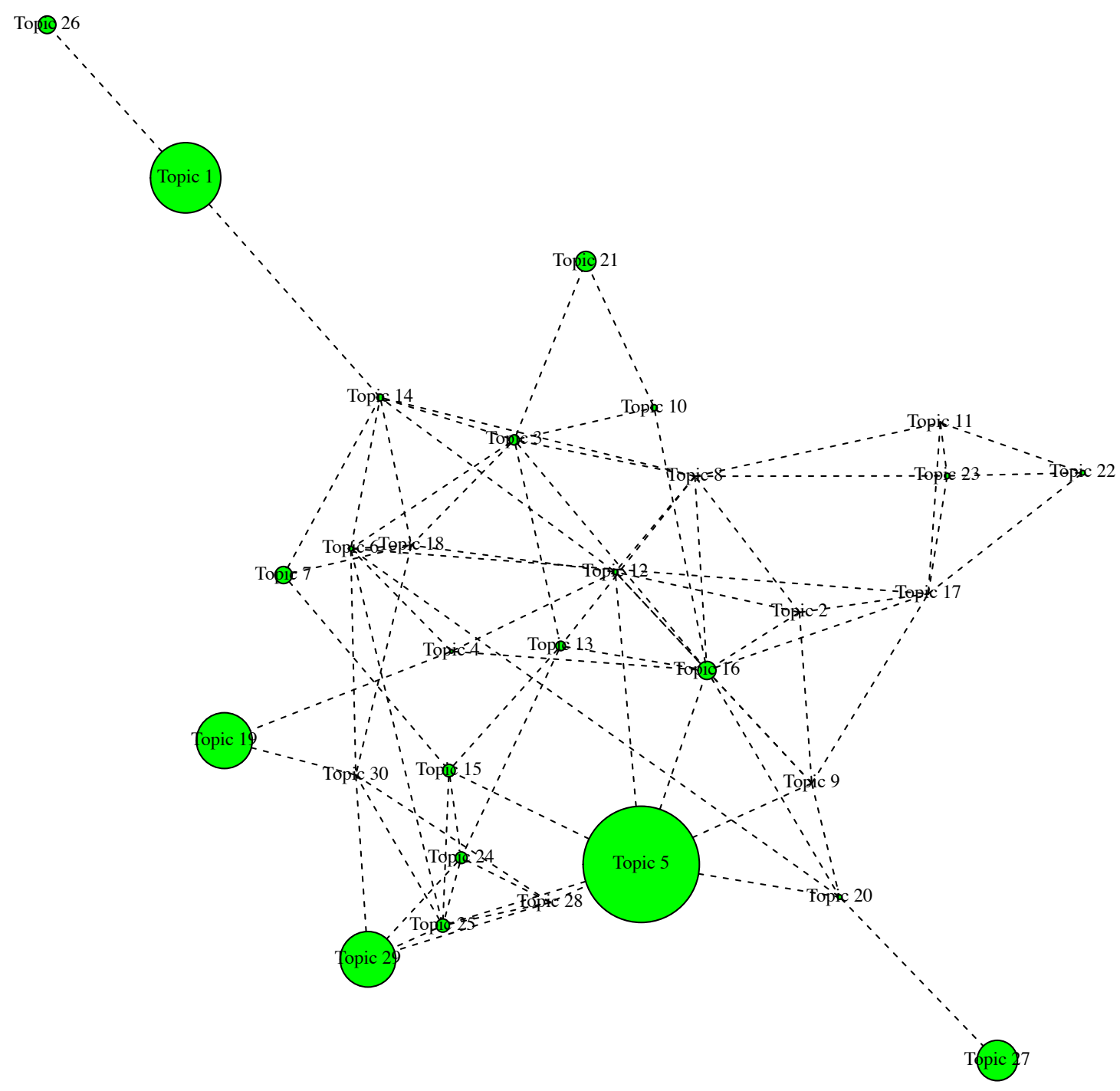

Figure B-2: Correlation graph for the appellation topics in the state parliament of Brandenburg. Vertex size is proportional to topic proportion. 


\section{Bibliography}

Abercrombie, Gavin and Riza Batista-Navarro (2018). "Aye' or 'No'? Speech-level Sentiment Analysis of Hansard UK Parliamentary Debate Transcripts". In: Proceedings of the 11th Language Resources and Evaluation Conference. Miyazaki, Japan: European Language Resource Association. URL: https : //www . aclweb . org/anthology/L18-1659 (visited on 05/29/2019).

Albertazzi, Daniele and Duncan McDonnell, eds. (2008). Twenty-first century populism: the spectre of western European democracy. Houndmills, Basingstoke, Hampshire [England] ; New York: Palgrave Macmillan. ISBN: 978-0-230-01349-0.

Bäck, Hanna, Marc Debus, and Jochen Müller (2014). "Who Takes the Parliamentary Floor? The Role of Gender in Speech-making in the Swedish Riksdag". en. In: Political Research Quarterly 67.3, pp. 504-518. ISSN: 1065-9129, 1938-274X. DOI: 10 . 1177 / 1065912914525861. URL: http: / / journals . sagepub . com/doi / 10 . $1177 / 1065912914525861$ (visited on 06/11/2019).

Baumann, Markus, Marc Debus, and Jochen Müller (2013). "Das legislative Verhalten von Bundestagsabgeordneten zwischen persönlichen Charakteristika, Wahlkreisinteressen und Parteilinie: Eine Untersuchung am Beispiel der Auseinandersetzung um die Präimplantationsdiagnostik". German. In: Zeitschrift für Politikwissenschaft : ZPol 23.2, pp. 177-211. URL: http://madoc.bib.uni-mannheim.de/35319/.

Bebnowski, David (2015). Die Alternative für Deutschland: Aufstieg und gesellschaftliche Repräsentanz einer rechten populistischen Partei. Essentials. OCLC: ocn900306449. Wiesbaden: Springer VS. ISBN: 978-3-658-08285-7.

Benoit, Kenneth and Alexander Herzog (2017). "Text analysis: Estimating policy preferences from written and spoken words". In: Analytics, Policy and Governance. Ed. by Jennifer Bachner, Kathryn Wagner Hill, and Benjamin Ginsberg. Yale University Press, pp. 137-159.

Blumenau, Jack (2019). "The effects of female leadership on women's voice in political debate". In: British Journal of Political Science. status: Advance online publication.

Chang, Jonathan et al. (2009). "Reading Tea Leaves: How Humans Interpret Topic Models". In: Advances in Neural Information Processing Systems 22. Ed. by Y. Bengio et al. Curran Associates, Inc., pp. 288-296. URL: http://papers.nips . cc/paper/3700-reading-tea-leaves-how-humans-interpret-topic-models . pdf.

Curini, Luigi, Airo Hino, and Atsushi Osaka (2018). "The Intensity of Government-Opposition Divide as Measured through Legislative Speeches and What We Can Learn from It: Analyses of Japanese Parliamentary Debates, 1953-2013". en. In: 
Government and Opposition, pp. 1-18. ISSN: 0017-257X, 1477-7053. DOI: 10.1017/ gov. 2018.15. URL: https://www .cambridge.org/core/product/identifier/ S0017257X18000155/type/journal_article (visited on 03/11/2019).

Debus, Marc and Hanna Bäck (2014). "Der Einfluss von Mandatstyp und Wahlkreiseigenschaften auf die inhaltlichen Positionen in Parlamentsreden: Eine Untersuchung anhand der parlamentarischen Debatten im Deutschen Bundestag von 1998 bis 2002". en. In: Swiss Political Science Review 20.2, pp. 330-353. ISSN: 14247755. DOI: 10.1111/spsr.12094. URL: http://doi.wiley.com/10.1111/spsr.12094 (visited on $06 / 12 / 2019$ ).

Denny, Matthew J. and Arthur Spirling (2018). "Text Preprocessing For Unsupervised Learning: Why It Matters, When It Misleads, And What To Do About It". en. In: Political Analysis 26.02, pp. 168-189. ISSN: 1047-1987, 1476-4989. DOI: 10.1017/ pan. 2017.44. URL: https://www . cambridge.org/core/product/identifier/ S1047198717000444/type/journal_article (visited on 03/14/2019).

Diermeier, Daniel et al. (2012). "Language and Ideology in Congress". In: British Journal of Political Science 42.1, pp. 31-55. ISSN: 0007-1234. URL: https://www. jstor.org/stable/41485863 (visited on 03/09/2019).

Egami, Naoki et al. (2018). "How to make causal inferences using texts". In: arXiv preprint arXiv:1802.02163.

Gentzkow, Matthew, Jesse Shapiro, and Matt Taddy (2016). Measuring Group Differences in High-Dimensional Choices: Method and Application to Congressional Speech. en. Tech. rep. w22423. Cambridge, MA: National Bureau of Economic Research. DOI: 10.3386/w22423. URL: http://www.nber.org/papers/w22423.pdf (visited on $03 / 21 / 2019$ ).

Gilardi, Fabrizio and Fabio Wasserfallen (2019). "The politics of policy diffusion: THE POLITICS OF POLICY DIFFUSION". en. In: European Journal of Political Research. ISSN: 03044130. DOI: 10.1111/1475-6765.12326. URL: http://doi . wiley.com/10.1111/1475-6765.12326 (visited on 06/11/2019).

Gilardi, Fabrizio and Bruno Wüest (2017). Newspaper coverage of female candidates during election cam paigns: evidence from a structural topic model. DOI: 10.5167/ uzh-143863. URL: http://www.zora.uzh.ch/143863 (visited on 06/11/2019).

Goet, Niels D. (2019). "Measuring Polarization with Text Analysis: Evidence from the UK House of Commons, 1811-2015". en. In: Political Analysis, pp. 1-22. ISSN: 1047-1987, 1476-4989. DOI: 10.1017/pan.2019.2. URL: https://www. cambridge. org/core/product/identifier/S1047198719000020/type/journal_article (visited on 06/11/2019).

Gölz, Sebastian and Oliver Wedderhoff (2018). "Explaining regional acceptance of the German energy transition by including trust in stakeholders and perception of fairness as socio-institutional factors". en. In: Energy Research 83 Social Science 43, pp. 96-108. ISSN: 22146296. DOI: 10.1016/j .erss .2018.05.026. URL: https : //linkinghub . elsevier. com/retrieve/pii/S2214629618305218 (visited on 10/06/2019).

Grajzl, Peter and Peter Murrell (2019). "Toward understanding 17th century English culture: A structural topic model of Francis Bacon's ideas". en. In: Journal of Comparative Economics 47.1, pp. 111-135. ISSN: 01475967. DOI: $10.1016 / \mathrm{j}$. 
jce.2018.10.004. URL: https://linkinghub.elsevier.com/retrieve/pii/ S0147596718304426 (visited on 06/12/2019).

Greene, Derek and James P. Cross (2017). "Exploring the Political Agenda of the European Parliament Using a Dynamic Topic Modeling Approach". In: Political Analysis 25.1, pp. 77-94. DOI: 10.1017/pan.2016.7.

Hess, David J. and Madison Renner (2019). "Conservative political parties and energy transitions in Europe: Opposition to climate mitigation policies". en. In: Renewable and Sustainable Energy Reviews 104, pp. 419-428. ISSN: 13640321. DOI: 10.1016/ j.rser . 2019.01.019. URL: https : / / linkinghub . elsevier . com/retrieve/ pii/S1364032119300292 (visited on 10/06/2019).

Høyland, Bjørn and Martin G. Søyland (2019). "Electoral Reform and Parliamentary Debates: Electoral Reform and Parliamentary Debates". en. In: Legislative Studies Quarterly. ISSN: 03629805. DOI: 10.1111/lsq.12237. URL: http://doi . wiley . com/10.1111/lsq. 12237 (visited on 05/24/2019).

Jankowski, Michael, Sebastian Schneider, and Markus Tepe (2017). "Ideological alternative? Analyzing Alternative für Deutschland candidates' ideal points via black box scaling". en. In: Party Politics 23.6, pp. 704-716. ISSN: 1354-0688. DOI: 10. 1177/1354068815625230. URL: https : //doi .org/10 .1177/1354068815625230 (visited on 09/29/2019).

Jung, Christopher, Dirk Schindler, and Leonie Grau (2018). "Achieving Germany's wind energy expansion target with an improved wind turbine siting approach". en. In: Energy Conversion and Management 173, pp. 383-398. ISSN: 01968904. DOI: 10.1016/j . enconman.2018.07.090. URL: https://linkinghub.elsevier.com/ retrieve/pii/S0196890418308318 (visited on 10/06/2019).

Jungherr, Andreas and Yannis Theocharis (2017). "The empiricist's challenge: Asking meaningful questions in political science in the age of big data". en. In: Journal of Information Technology \& Politics 14.2, pp. 97-109. ISSN: 1933-1681, 1933-169X. DOI: $10.1080 / 19331681.2017 .1312187$. URL: https: / www . tandfonline.com/ $\mathrm{doi} / \mathrm{full} / 10.1080 / 19331681.2017 .1312187$ (visited on 06/12/2019).

Kim, Sung Eun (2018). "Media Bias against Foreign Firms as a Veiled Trade Barrier: Evidence from Chinese Newspapers". en. In: American Political Science Review 112.4, pp. 954-970. ISSN: 0003-0554, 1537-5943. DOI: 10.1017/S0003055418000242. URL: https://www . cambridge.org/core/product/identifier/S0003055418000242/ type/journal_article (visited on 06/12/2019).

Larsen, Vegard H. (2017). Components of Uncertainty. en. Tech. rep. 5/2017. Norges Bank. URL: https://www.ssrn. com/abstract=2955655 (visited on 06/11/2019). Lauderdale, Benjamin E. and Alexander Herzog (2016). "Measuring Political Positions from Legislative Speech". en. In: Political Analysis 24.03, pp. 374-394. ISSN: 10471987, 1476-4989. DOI: 10 . 1093/pan/mpw017. URL: https : / / www . cambridge . org/core/product/identifier/S1047198700014091/type/journal_article (visited on $11 / 27 / 2018$ ).

Laver, Michael, Kenneth Benoit, and John Garry (2003). "Extracting Policy Positions from Political Texts Using Words as Data". en. In: American Political Science Review 97.02. ISSN: 0003-0554, 1537-5943. DOI: 10 . 1017 / S0003055403000698. 
URL: http : / / www . journals . cambridge . org / abstract_S0003055403000698 (visited on 06/11/2019).

Laver, Michael and John Garry (2000). "Estimating Policy Positions from Political Texts". In: American Journal of Political Science 44.3, p. 619. ISSN: 00925853. DOI: 10. $2307 / 2669268$. URL: https : //www . jstor. org/stable/2669268? origin= crossref (visited on 06/11/2019).

Lees, Charles (2018). “The 'Alternative for Germany': The rise of right-wing populism at the heart of Europe". en. In: Politics 38.3, pp. 295-310. ISSN: 0263-3957. DOI: 10. 1177/0263395718777718. URL: https : //doi .org/10 .1177/0263395718777718 (visited on $09 / 29 / 2019$ ).

Lengfeld, Holger (2017). "Die „Alternative für Deutschland": eine Partei für Modernisierungsverlierer?" de. In: KZfSS Kölner Zeitschrift für Soziologie und Sozialpsychologie 69.2, pp. 209-232. ISSN: 1861-891X. DOI: 10.1007/s11577-017-0446-1. URL: https://doi .org/10.1007/s11577-017-0446-1 (visited on 09/29/2019).

Lewicki, Pawel (2013). Windenergie. de. Text. URL: https://www . umweltbundesamt . de/themen/klima-energie/erneuerbare-energien/windenergie (visited on $10 / 06 / 2019)$.

Linder, Fridolin et al. (2018). "Text as Policy: Measuring Policy Similarity through Bill Text Reuse". en. In: Policy Studies Journal. ISSN: 0190292X. DOI: 10.1111/ psj . 12257. URL: http :// doi . wiley . com/10.1111/ps j. 12257 (visited on 06/12/2019).

Markus Frohnmaier (2015). Es spricht Markus Frohnmaier. URL: https : / / www . youtube $. \mathrm{com} /$ wat $\mathrm{ch} ? \mathrm{v}=6 \mathrm{znCu} 1 \mathrm{VMr} 5 \mathrm{Q} \&$ feature $=$ youtu. be\&t $=4 \mathrm{~m} 26 \mathrm{~s}$ (visited on $09 / 27 / 2019)$.

Meguid, Bonnie M. (2005). "Competition Between Unequals: The Role of Mainstream Party Strategy in Niche Party Success". en. In: American Political Science Review 99.3, pp. 347-359. ISSN: 0003-0554, 1537-5943. DOI: 10 . 1017 / S0003055405051701. URL: https : / / www . cambridge . org / core / product / identifier/S0003055405051701/type/journal_article (visited on 06/26/2019).

Mielke, Siegfried and Werner Reutter (2004). "Länderparlamentarismus in Deutschland - Eine Bestandsaufnahme". In: Länder-parlamentarismus in Deutschland: Geschichte - Struktur - Funktionen. Ed. by Siegfried Mielke and Werner Reutter. Wiesbaden: VS Verlag für Sozialwissenschaften, pp. 19-51. ISBN: 978-3-322-80942-1. DOI: 10.1007/978-3-322-80942-1_1. URL: https ://doi .org/10 .1007/978-3322-80942-1_1.

Mudde, Cas (2004). "The Populist Zeitgeist". en. In: Government and Opposition 39.4, pp. 541-563. ISSN: 1477-7053. DOI: $10.1111 / \mathrm{j} .1477-7053.2004 .00135$.x. URL: https : / / onlinelibrary. wiley . com/doi/abs/10.1111/j.1477-7053. 2004. 00135.x (visited on 06/19/2019).

Niedermayer, Oskar (2015). "Eine neue Konkurrentin im Parteiensystem? Die Alternative für Deutschland". de. In: Die Parteien nach der Bundestagswahl 2013. Ed. by Oskar Niedermayer. Wiesbaden: Springer Fachmedien Wiesbaden, pp. 175207. ISBN: 978-3-658-02852-7. DOI: 10 . $1007 / 978-3-658-02852-7$ _ 8. URL: https ://doi.org/10.1007/978-3-658-02852-7_8 (visited on 09/29/2019). 
O'Grady, Tom (2019). "Careerists Versus Coal-Miners: Welfare Reforms and the Substantive Representation of Social Groups in the British Labour Party". en. In: Comparative Political Studies 52.4, pp. 544-578. ISSN: 0010-4140, 1552-3829. DOI: 10 .1177/0010414018784065. URL: http://journals . sagepub.com/doi / 10.1177/0010414018784065 (visited on 03/19/2019).

Pappi, Franz Urban, Anna-Sophie Kurella, and Thomas Bräuninger (2019). "Die Etablierung neuer Parlamentsparteien. Wählerpräferenzen als Erfolgsfaktor für die Alternative für Deutschland 2017 und die Grünen 1986". de. In: Politische Vierteljahresschrift 60.2 , pp. 273-298. ISSN: 1862-2860. DOI: 10.1007 /s11615019-00150-4. URL: https://doi.org/10.1007/s11615-019-00150-4 (visited on $09 / 29 / 2019)$.

Peterson, Andrew and Arthur Spirling (2018). "Classification Accuracy as a Substantive Quantity of Interest: Measuring Polarization in Westminster Systems". en. In: Political Analysis 26.01, pp. 120-128. ISSN: 1047-1987, 1476-4989. DOI: 10.1017/ pan.2017.39. URL: https ://www . cambridge.org/core/product/identifier/ S1047198717000390/type/journal_article (visited on 03/09/2019).

Pietsch, Andra-Selina and Stefan Lessmann (2019). "Topic modeling for analyzing open-ended survey responses". In: Journal of Business Analytics 1.2, pp. 93-116. DOI: $10.1080 / 2573234 x .2019 .1590131$. URL: https: / www . tandf online.com/ doi/full/10.1080/2573234X.2019.1590131 (visited on 06/12/2019).

Proksch, Sven-Oliver, Will Lowe, et al. (2018). "Multilingual Sentiment Analysis: A New Approach to Measuring Conflict in Legislative Speeches". en. In: Legislative Studies Quarterly. ISSN: 03629805. DOI: 10.1111/lsq.12218. URL: http://doi. wiley.com/10.1111/lsq. 12218 (visited on 11/27/2018).

Proksch, Sven-Oliver and Jonathan B. Slapin (2010). "Position Taking in European Parliament Speeches". en. In: British Journal of Political Science 40.3, pp. 587611. ISSN: 0007-1234, 1469-2112. DOI: 10.1017/S0007123409990299. URL: https: //www . cambridge .org/core/product/identifier/S0007123409990299/type/ journal_article (visited on 06/11/2019).

- (2012). "Institutional Foundations of Legislative Speech: LEGISLATIVE SPEECH". en. In: American Journal of Political Science 56.3, pp. 520-537. ISSN: 00925853. DOI: $10.1111 / j .1540-5907.2011 .00565$.x. URL: http://doi . wiley.com/10 . $1111 / j .1540-5907.2011 .00565 . x$ (visited on 06/12/2019).

Rauh, Christian (2018). "Validating a sentiment dictionary for German political language - a workbench note". en. In: Journal of Information Technology \& Politics 15.4, pp. 319-343. ISSN: 1933-1681, 1933-169X. DOI: 10 .1080/19331681 . 2018. 1485608. URL: https: //www . tandfonline.com/doi/full/10.1080/19331681. 2018. 1485608 (visited on 09/21/2019).

Rheault, Ludovic, Kaspar Beelen, et al. (2016). "Measuring Emotion in Parliamentary Debates with Automated Textual Analysis". en. In: PLOS ONE 11.12. Ed. by Joseph Najbauer, e0168843. ISSN: 1932-6203. DOI: $10.1371 /$ journal pone . 0168843. URL: https://dx.plos.org/10.1371/journal.pone.0168843 (visited on $03 / 19 / 2019$ ).

Rheault, Ludovic and Christopher Cochrane (2019). "Word Embeddings for the Analysis of Ideological Placement in Parliamentary Corpora". en. In: Political Analysis, 
pp. 1-22. ISSN: 1047-1987, 1476-4989. DOI: 10.1017/pan.2019.26. URL: https: //www . cambridge.org/core/product/identifier/S1047198719000263/type/ journal_article (visited on 07/30/2019).

Roberts, Margaret E., Brandon M. Stewart, and Edoardo M. Airoldi (2016). "A Model of Text for Experimentation in the Social Sciences". en. In: Journal of the American Statistical Association 111.515, pp. 988-1003. ISSN: 0162-1459, 1537-274X. DOI: 10.1080/01621459.2016.1141684. URL: https://www.tandfonline.com/doi/ full/10.1080/01621459.2016.1141684 (visited on 06/11/2019).

Roberts, Margaret E., Brandon M. Stewart, Dustin Tingley, et al. (2014). "Structural Topic Models for Open-Ended Survey Responses". In: American Journal of Political Science 58.4, pp. 1064-1082. ISSN: 00925853, 15405907. URL: http://www. jstor . org/stable/24363543.

Rütters, Peter (2017). "„Parlamentsfähig“? - Die Abgeordneten der AfD in den Landtagen und Bürgerschaften". In: Zeitschrift für Parlamentsfragen 48.1, pp. 3-24. ISSN: 0340-1758. DOI: 10.5771/0340-1758-2017-1-3. URL: https://www . nomoselibrary . de / index . php? doi $=10.5771 / 0340-1758-2017-1-3$ (visited on 06/11/2019).

Schmitt-Beck, Rüdiger, Jan W. van Deth, and Alexander Staudt (2017). "Die AfD nach der rechtspopulistischen Wende: Wählerunterstützung am Beispiel BadenWürttembergs". de. In: Zeitschrift für Politikwissenschaft 27.3, pp. 273-303. ISSN: 1430-6387, 2366-2638. DOI: 10.1007/s41358-017-0104-1. URL: http://link . springer.com/10.1007/s41358-017-0104-1 (visited on 06/12/2019).

Schofield, Alexandra and David Mimno (2016). "Comparing Apples to Apple: The Effects of Stemmers on Topic Models". en. In: Transactions of the Association for Computational Linguistics 4, pp. 287-300. ISSN: 2307-387X. DOI: 10.1162/tacl_ a_00099. URL: https://www.mitpressjournals.org/doi/abs/10.1162/tacl_ a_00099 (visited on 10/01/2019).

Schroeder, Wolfgang, Bernhard Weßels, and Alexander Berzel (2018). "Die AfD in den Landtagen: Bipolarität als Struktur und Strategie - zwischen Parlamentsund „Bewegungs“-Orientierung”. In: Zeitschrift für Parlamentsfragen 49.1, pp. 91110. ISSN: 0340-1758. DOI: $10.5771 / 0340-1758-2018-1-91$. URL: https : //www . nomos - elibrary . de/index . php?doi=10 . 5771/0340-1758-2018-1-91 (visited on 06/11/2019).

Schroeder, Wolfgang, Bernhard Weßels, Christian Neusser, et al. (2017). Parlamentarische Praxis der AfD in deutschen Landesparlamenten. ger. WZB Discussion Paper SP V 2017-102. Berlin: Wissenschaftszentrum Berlin für Sozialforschung (WZB). URL: http://hdl.handle.net/10419/162844.

Schwarz, Daniel, Denise Traber, and Kenneth Benoit (2017). "Estimating Intra-Party Preferences: Comparing Speeches to Votes". en. In: Political Science Research and Methods 5.02, pp. 379-396. ISSN: 2049-8470, 2049-8489. DOI: 10.1017/psrm. 2015 . 77. URL: https : / / www . cambridge . org / core/product/identifier / S2049847015000771/type/journal_article (visited on 11/27/2018).

Senninger, Roman and Daniel Bischof (2018). "Working in unison: Political parties and policy issue transfer in the multilevel space". en. In: European Union Politics 19.1, pp. 140-162. ISSN: 1465-1165, 1741-2757. DOI: $10.1177 / 1465116517733819$. 
URL: http://journals. sagepub.com/doi/10.1177/1465116517733819 (visited on $06 / 11 / 2019)$.

Slapin, Jonathan B. and Sven-Oliver Proksch (2008). "A Scaling Model for Estimating Time-Series Party Positions from Texts". en. In: American Journal of Political Science 52.3, pp. 705-722. ISSN: 00925853, 15405907. DOI: $10.1111 / \mathrm{j} .1540-$ 5907 . 2008.00338 .x. URL: http: //doi .wiley . com/10.1111/j . 1540-5907. 2008.00338.x (visited on 06/12/2019).

Spirling, Arthur, Leslie Huang, and Perry Patrick (2018). "Boring in a New Way: Estimation and Inference for Political Style at Westminster, 1935-2018". en. In: SSRN Electronic Journal. ISSN: 1556-5068. DOI: 10.2139/ssrn.3235506. URL: https: //www.ssrn. com/abstract=3235506 (visited on 03/14/2019).

Spirling, Arthur and Pedro L Rodriguez (2019). What works, what doesn't, and how to tell the difference for applied research. en. Working Paper. New York University, p. 51. URL: https://www. nyu .edu/projects/spirling/documents/embed.pdf. Taylor Young, Daniel (2013). "How Do You Measure a Constitutional Moment? Using Algorithmic Topic Modeling To Evaluate Bruce Ackerman's Theory of Constitutional Change". In: Yale Law Journal 122, pp. 1990-2054.

Tzelgov, Eitan and Petrus Olander (2018). "Economic Decline and Extreme-Right Electoral Threat: How District-Level Factors Shape the Legislative Debate on Immigration". en. In: Legislative Studies Quarterly 43.4, pp. 649-679. ISSN: 19399162. DOI: 10.1111/lsq.12215. URL: https://www.onlinelibrary.wiley.com/ doi/abs/10.1111/lsq.12215 (visited on 03/19/2019).

Wilkerson, John and Andreu Casas (2017). "Large-Scale Computerized Text Analysis in Political Science: Opportunities and Challenges". In: Annual Review of Political Science 20.1, pp. 529-544. DOI: 10.1146/annurev-polisci-052615-025542. URL: https://doi .org/10.1146/annurev-polisci-052615-025542.

Wilkerson, John, David Smith, and Nicholas Stramp (2015). "Tracing the Flow of Policy Ideas in Legislatures: A Text Reuse Approach: TRACING POLICY IDEAS". en. In: American Journal of Political Science 59.4, pp. 943-956. ISSN: 00925853. DOI: 10.1111/ajps.12175. URL: http://doi.wiley.com/10.1111/ajps.12175 (visited on $06 / 10 / 2019$ ).

Willis, Rebecca (2017). "Taming the Climate? Corpus analysis of politicians' speech on climate change". In: Environmental Politics 26.2, pp. 212-231. ISSN: 0964-4016. DOI: $10.1080 / 09644016.2016 .1274504$. URL: https://rsa.tandf online.com/ doi/full/10.1080/09644016.2016.1274504 (visited on 05/29/2019).

Zafari, Babak and Tahir Ekin (2018). "Topic modelling for medical prescription fraud and abuse detection". en. In: Journal of the Royal Statistical Society: Series C (Applied Statistics). ISSN: 0035-9254, 1467-9876. DOI: 10.1111/rssc.12332. URL: https://onlinelibrary.wiley.com/doi/abs/10.1111/rssc.12332 (visited on 06/12/2019). 